\title{
Changing Course:
}

\section{Commercializing Canadian Airport, Port and Rail Governance - 1975 to 2000}

By Mark Douglas Davis,

B.Sc. (Hons.), M.A.

A thesis submitted to the Faculty of Graduate and Postdoctoral Affairs

in partial fulfillment of the requirements for the degree of

Doctor of Philosophy in Public Policy

\author{
Carleton University \\ Ottawa, Ontario
}

(C) 2016

Mark Douglas Davis 


\begin{abstract}
This thesis examines the historical public policy circumstances surrounding the Government of Canada's decision to commercialize Canadian National (CN) Railways, as well as federal airports and ports over the period 1975 to 2000. Its focus is on testing one specific empirical hypothesis:

That the commercialization of federal airport and port assets between 1975 and 2000 occurred primarily due to: (i) federal government concerns over the growing size of the national debt and deficit; and (ii) the emergence of the neoliberal ideology in Canada and its growing influence throughout federal policy making, as witnessed by the swift 1995 privatization of CN Railways.

In particular, this thesis considers the role and influence of various policy factors, such as efficiencies, governance challenges, organizational cultures, stakeholder behaviours, ideological pressures, and political realities encountered by senior federal transportation bureaucrats and the political leadership during this period. The selection of CN Railways, airports, and ports also provides a window into Transport Canada's repeated attempts at developing an integrated and multi-modal national transportation policy.

This thesis conducts a rigorous, forward-looking deductive analysis using a meso institutional framework to examine the interactions of the major micro and macro circumstances surrounding federal transportation commercialization. The three modal case studies apply the meso framework to each unique case with special consideration of the context and causality of each major reform.

The principal findings suggest that the federal government's desire for debt and deficit reduction was a major impetus for reform across all three modal cases and across all three decades. From a public relations perspective, governments of both Liberal and Progressive Conservative stripes strove to portray debt and deficit control as evidence of sound economic and fiscal management. Contrary to the national debt and deficit, however, neoliberalism did not, in the author's opinion, exert as substantial an impact upon commercialization reforms as originally hypothesized. This result occurred due to the paltry neoliberal theoretical framework from which to analyse complex governance reforms such as transportation commercialization, as well as the mere passive acceptance of neoliberal tenets by both Liberal and Progressive Conservative governments. Rather, strong leadership and the determination of senior political and bureaucratic managers at Transport Canada, combined with the need for fiscal restraint, created the ideal policy conditions for swift and comprehensive reforms to federal transportation governance.
\end{abstract}




\section{Table of Contents}

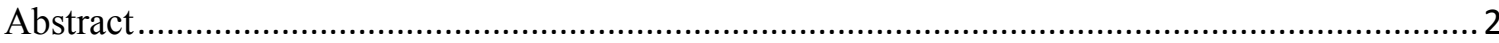

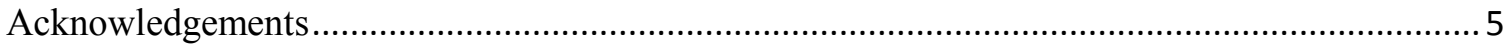

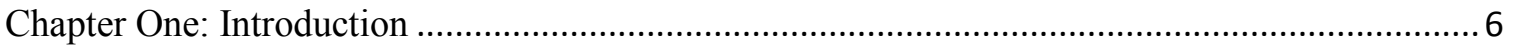

Chapter Two: Theoretical and Empirical Foundations .................................................................. 20

Chapter Three: The Privatization of Canadian National Railways ................................................95

Chapter Four: Federal Airport Reforms in Canada ............................................................ 139

Chapter Five: Federal Port Reforms in Canada ................................................................ 197

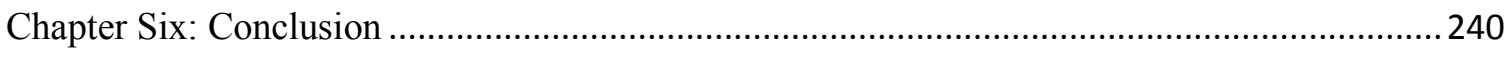

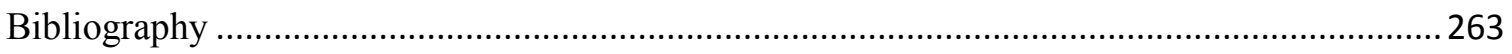




\section{List of Figures}

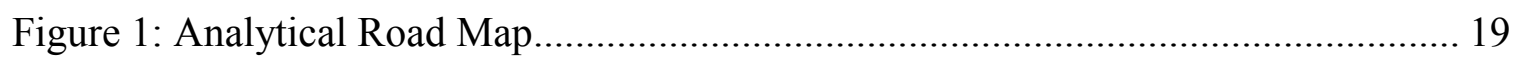

Figure 2: I-M-O Model in Different Contexts ............................................................. 25

Figure 3: Hierarchy of Cultures Influencing Public Policy in Canada ........................... 33

\section{List of Tables}

Table 1: Summary Table of Theoretical Framework...................................................... 22

Table 2: Relevant Causal Mechanisms in the Literature ............................................. 24 


\section{Acknowledgements}

I wish to gratefully acknowledge the efforts of my thesis supervisor, Dr. Christopher Stoney, and my advisory committee members, Dr. Robert Shepherd and Dr. Michael Ircha, for their continued patience, advice and support throughout the development of my thesis. They challenged me to delve deeper and question the status quo, which has helped me to become a stronger policy analyst and researcher. I would also like to thank Dr. Barry Prentice and Dr. Paul Wilson for agreeing to serve on my thesis examining board and providing constructive feedback that has contributed to a well rounded analysis.

I completed the $\mathrm{PhD}$ in Public Policy program in its entirety on a part-time basis while working full-time, and I therefore wish to thank my government colleagues for their words of encouragement throughout my journey. In particular, special thanks to Mr. Iain Tyrrell for referring me to two interview contacts and to Mr. John Linn for proof reading an earlier draft of this thesis.

I would also like to thank the many individuals who took time out of their busy schedules and graciously agreed to sit for an interview of an hour (or sometimes longer) to recount their professional experiences during this policy rich period. In particular, I wish to acknowledge the ongoing support and words of encouragement from the Honourable Doug Young and Mr. Nick Mulder during the writing of this thesis.

Most importantly, I wish to thank my family for their love and unwavering support during my educational journey. To my parents, Leonard and Wilma, for encouraging my sister and I to "rise above it all" through life's challenges and to take the positive out of every situation. Also, special thanks to my sister, Dr. Karelyn, brother-inlaw, Shawn, and little niece, Allivea, for their humour, encouragement and advice throughout the ups and downs of thesis writing.

Lastly, the opinions and analyses expressed in this thesis are solely my own, and I accept full responsibility for any errors and/or omissions contained herein. 


\section{Chapter One: Introduction}

Transportation is still an instrument of national policy, but there has in recent years been more emphasis on using the instrument judiciously, and with due regard for economic forces. The prevailing attitude, on the whole well-justified, is that the country now has a relatively good transportation system, and there just isn't the same need for huge Federal investments. ${ }^{1}$

This comment offered by Arthur Kroeger in 1980, in his role as Deputy Minister of Transport Canada, remains relevant to this day. For decades, bureaucrats, politicians and major stakeholders have sought to solve the key policy question: What is the role of the federal government in the national transportation system? Section 92(10) of the British North America Act (now the Constitution Act, 1867) assigned policy related jurisdiction over most intraprovincial transportation matters of roads, shipping and railways to the provinces, while interprovincial matters "for the general Advantage of Canada or for the Advantage of Two or more of the Provinces" resided with the federal government (CanLII, 2015). In 1936, the federal government further consolidated its role over national transportation policy with the merging of the Department of Marine and Fisheries, the Department of Railways and Canals, and the Civil Aviation Branch from the Department of National Defence to form the new Department of Transport (Library and Archives Canada, 2010). Known informally today as Transport Canada, the department extended its jurisdictional influence through the World War II and post-war periods, reaching its summit of influence in the 1960s with the advent of containerization

\footnotetext{
${ }^{1}$ Arthur Kroeger, Deputy Minister of Transport, 1979-1983. Quoted in Kroeger, 1980, p. 13.
} 
in the ports sector and the development of the jet engine in the commercial aviation industry (Ibid; McCoomb, 2014).

Traditionally, policy reform has been an evolutionary process taking place over many years involving many stakeholders. Commercialization ${ }^{2}$ and other market-oriented approaches to transportation policy reform first arose as a policy alternative in Canada during the MacPherson Royal Commission of 1967 and slowly gained prominence throughout the 1970s. By the early 1980s, the rise of neoliberal thinking brought a new approach based on the supremacy of market-based principles and a minimal role for government. As budgetary deficits escalated, governments sought ways to devolve public services to the private sector and adopt marketplace principles into public sector decision making under the umbrella of the "new" public management (NPM) framework. Government-provided transportation services, with significant capital costs and ongoing operating expenditures, were no exception to this trend. Air, rail and marine modes all experienced significant reforms as the federal government sought to deregulate and decentralize its involvement in the national transportation system.

Toward the end of the 1980s, Canada first embraced commercialization reforms with the establishment of Local Airport Authorities (LAAs) between 1987 and 1993, followed by the privatization of Air Canada in 1988. However, both processes involved lengthy consultation processes and generated significant controversy. Despite continued policy planning and advocacy of commercialization principles within the Transport

\footnotetext{
${ }^{2}$ The term commercialization is defined in this thesis as the general application of market based principles to the governance of publicly owned assets. As explained in Chapter Three, this term was frequently used by the Chretien Liberals to distinguish themselves from the transportation privatization agenda promoted by their Progressive Conservative predecessors.
} 
Canada bureaucracy, progress toward reforms remained slow into the early 1990s. Upon taking office in late 1993, the federal Liberals inherited a national deficit from their Progressive Conservative predecessors of $\$ 42$ billion and a debt level of almost $\$ 550$ billion (Janigan, 1995; Manley, 2005). Further compounding the fiscal situation were significant declines in international capital valuations in 1994, which resulted in sharp devaluations of the Canadian dollar and steady increases in interest rates on federal debt payments (Kroeger, 1996; Manley, 2005). The Government of Canada's financial position may have reached its lowest point in early 1995 when The Wall Street Journal dubbed Canada as "an honorary member of the Third World in the unmanageability of its debt problem" (WSJ, 1995). As a result of these dire fiscal circumstances, the federal government, public servants and even the majority of the general public were in agreement that difficult decisions needed to be made to control the deficit (Janigan, 1995; Manley, 2005).

In an effort to reform the Canadian financial situation and eventually eliminate the deficit, the 1994 federal budget announced a comprehensive examination of federal program expenditures over three fiscal years, known as Program Review (Kroeger, 1996; Paquet and Shepherd, 1996; Manley 2005). Senior managers at Transport Canada, however, had already recognized the urgent need for transportation sector reform in the early 1990s and had prepared recommended options for transition documents in the leadup to the 1993 federal election. The pace of commercialization accelerated dramatically in the mid-1990s, first with the privatization of CN Rail (widely believed to be impossible by industry experts at the time) following the appointment of career public service executive, Paul Tellier, as CEO of CN in 1993. Other major reforms quickly 
followed with the divestiture of airports and ports to local, non-profit transportation authorities in 1995 and 1996, respectively.

The subsequent privatization of CN Rail and the divestitures of airports and ports have been largely considered a success. During this time, the federal government engaged in privatization ${ }^{3}$ and devolution ${ }^{4}$ of many transportation agencies and modernized the role of its major transportation ministry, Transport Canada, from an operator of the national transportation system to policy maker and safety/security monitor (Transport Canada, 2010a). In addition, $\mathrm{CN}$ executives lauded the benefits of government privatization efforts in the transportation sector, while previously divested airports and ports have lobbied for greater financial and operational independence from the federal government.

\subsection{Methodology}

\subsubsection{Motivation}

Many present-day transportation stakeholders are unaware of the evolution of the federal role in national transportation policy. Furthermore, there is limited practical knowledge among analysts and senior managers at Transport Canada of the historical policy circumstances surrounding the devolution of major federal transportation assets to the non-profit and private sectors from the mid-1970s to the late 1990 s. $^{5}$ Given the

\footnotetext{
${ }^{3}$ The term privatization is defined as "The transfer of a business, industry, service, etc., from public to private ownership and control" (OED Online, 2015).

${ }^{4}$ The term devolution is defined as "The passing of the power or authority of one person or body to another" (OED Online, 2015).

${ }^{5}$ The author has worked as a Policy Analyst within the federal public service for the past 10 years, the last seven of which have been spent at Transport Canada.
} 
significant and persistent policy debate surrounding the federal role in transportation, a detailed analysis of three of the most prominent transportation reforms in Canadian history offers a valuable resource for present day policy analysis. Motivation for this analysis is supported by the fact that recent federal commercialization reforms have continued to devolve ownership responsibilities to non-federal stakeholders, with Transport Canada often acknowledging its commitment to the original principles established during the mid-1990s. In addition, many former senior transportation leaders who have remained in the transportation community have highlighted the importance of this period to present day successes in the Canadian transportation sector. Moreover, many of these former leaders have claimed responsibility as some of the chief architects of reforms, raising the question of which individuals possessed the greatest control and influence during this period.

Major transportation policy reform issues have been under-researched in the academic literature in two key areas. First, research has yet to consider Canadian transportation policy reforms as part of an evolving policy process. Second, research has yet to analyse the application of neoliberal principles to transportation policy in Canada. Consequently, this thesis will examine commercialization reforms at Transport Canada as part of the department's bureaucratic culture using a meso-organizational framework to describe the devolution of transportation related cases in Canada.

In sum, this thesis will examine the historical policy factors surrounding the commercialization of federal ports, airports and CN Rail between 1975 and 2000. It will analyse the role and influence of various policy factors, such as program efficiencies, governance challenges, organizational culture, stakeholder behaviour, ideological 
pressures, and political realities. In addition, the selection of ports, airports and CN Rail provides a window into Transport Canada's repeated attempts at developing an integrated and multi-modal national transportation policy.

\subsubsection{Hypothesis}

This thesis will demonstrate that the emergence of neoliberalism in the 1980s and 1990s was overshadowed by the quest to reduce the national debt and deficit, which when combined with strong bureaucratic and political leadership, as well as a public willingness to cut services, created the ideal conditions for the swift privatization of $\mathrm{CN}$ Rail and the dramatic devolution of ports and airports to non-profit authorities. In Canada, the majority of airport and port operations were centrally administered by Transport Canada, which permitted advanced devolution planning and quick execution of airport and port reforms, albeit to a lesser commercial extent than Transport Canada originally intended. In light of these events, the Canadian experience brought unique and sustainable changes to transportation governance frameworks in the port and airport sectors.

In light of these arguments, the principal argument or hypothesis under consideration in this thesis is the following:

That the commercialization of federal airport and port assets between 1975 and 2000 occurred primarily due to: (i) federal government concerns over the growing size of the national debt and deficit; and (ii) the emergence of the neoliberal ideology in Canada and its growing influence throughout federal policy making, as witnessed by the swift 1995 privatization of CN Railways.

This thesis is a comparative case study of the federal devolution of airports and ports to non-profit transportation authorities in Canada between 1975 and 2000, 
culminating with a particular focus on the commercialization reforms of the mid-1990s. Using the 1995 privatization of CN Rail as a benchmark, the thesis examines the rationale behind the federal government's decision to divest airports and ports to nonprofit authorities, as opposed to other commercialization models. The research demonstrates that the $\mathrm{CN}$ privatization experience displayed significant and rapid reform in what this thesis terms a "policy miracle" due to several policy factors, notably strong executive leadership, a political desire to tackle the national debt and deficit, a willingness for change in the federal transportation bureaucracy, a politically opportune time for reform and a lack of public opposition to privatization. A significant policy question worth considering is therefore why Transport Canada chose to establish airport and port authorities as public, non-profit entities as opposed to following the highly successful commercialization method observed in the divestiture of CN Railways?

Further investigation into the divestiture process reveals divergent outcomes in the evolution of airport and port governance regimes. Although airports were established as autonomous, arm's-length entities, many port stakeholders argued against a similar governance framework, insisting that the status quo close relationship between port authorities and the federal government was the most beneficial option (Ircha, 1996). As a result, port authorities instead successfully lobbied for an arm's-length regime with continued and direct federal involvement in areas such as the appointment of port boards of directors. It necessarily follows that the next question to consider is why the devolution process for airports and ports diverged and whether the resulting outcomes were the result of factors internal and/or external to the federal government. 
In a policy area as broad and diverse as transportation policy, certain limitations must be placed on the scope and content of the research. For example, one factor considered is the choice of 1975 to 2000 as the period of analysis. As will be demonstrated in the following chapters, the seeds of transportation reform were planted with the Auditor General's warning in 1975 that federal expenditures and debt borrowing were spiralling out of control. This action set in motion a multi-modal analysis of federal roles and responsibilities within the national transportation system that culminated with the major commercialization reforms of the mid-1990s.

Given that the abovementioned motivation for this thesis was to examine circumstances surrounding past reforms that could assist with current policy analysis, a logical question is why the research does not continue until the present day. Expressed in its simplest terms, the September 11, 2001 terrorist attacks resulted in a major paradigm shift of federal transportation policy away from controlling debts and deficits to expanding the role and influence of the federal government in safety and security issues. Instead of devolving assets, new agencies in areas such as passenger screening and border security were created, along with new bureaucracies and an increased federal role in national affairs. Such a shift in transportation governance is beyond the limited scope and space constraints of this thesis, but is nevertheless presented in Chapter Six as a potential area of future research.

In light of the emphasis placed on the potential role of neoliberalism in this hypothesis, another potential extension of the research would be to consider the influence of neoliberalism upon transportation governance reforms in other developed countries, such as the United Kingdom, Australia, New Zealand and the United States. However, as 
will be demonstrated below, this thesis adopts a primarily micro organizational focus on transportation policy reforms within the Canadian federal transportation bureaucracy. Potential external (macro) factors, such as neoliberalism, are considered in the scope and context of this thesis in terms of their impact upon the micro aspects of the machinery of government, as opposed to the contribution of Canadian neoliberalism to the global political phenomenon (and vice versa) during this period. More detailed macro extensions to this research, such as this example, will be considered in Chapter Six as potential areas for future research.

\subsubsection{The Case Study Approach}

The primary research technique employed in this thesis is the explanatory case study analysis involving first-hand collection of qualitative data through interviews and research of relevant government and academic documents. As Orum, Feagin, and Sjoberg (1991) outlined, there are four core benefits to case study analysis in the social sciences (pp. 6-7):

1. It permits the grounding of observations and concepts about social action and social structures in natural settings studied at close hand.

2. It provides information from a number of sources and over a period of time, thus permitting a more holistic study of complex social networks and of complexes of social action and social meanings

3. It can furnish the dimensions of time and history to the study of social life, thereby enabling the investigator to examine continuity and change in lifeworld patterns.

4. It encourages and facilitates, in practice, theoretical innovation and generalization. 
Although the case study approach may reveal useful information for historical policy analysis, there are also several potential limitations to its use. First, the case study method may be subject to the selection biases of its researcher and may therefore not be as effective as quantitative, scientific evidence (Orum, Feagin, and Sjoberg, 1991; George and Bennett, 2005). Consequently, research efforts must ensure that case study observations are generated in an objective manner that permit comparable observations across cases. One method to reduce the likelihood of biases is to conduct multiple case studies over the same time period, which allows the reader to observe patterns in historical observations and identify any potential outliers (Orum, et al., 1991). Another method to avoid biases is to include multiple sources of research to verify data, such as interviews, legislative publications and political correspondence, as well as news media reports, which Orum, et al. (1991) termed "the triangulation of resources."

A second potential concern of the case study approach is the claim that a small number of case studies is insufficient as a primary method of evidence (Rueschemeyer, 2003; George and Bennett, 2005). Critics have argued that the causation surrounding historical events is too complex for a small number of cases to effectively portray, and is only effective in determining a research hypothesis. Moreover, although case studies may provide information on the relationships between the impacts of causal mechanism on historical events, they are ineffective at determining the weight that a particular variable contributed to the historical outcome (George and Bennett, 2005).

An effective solution to the "small-N issue" is the use of the path dependence technique of historical institutionalism. Path dependence is regarded as powerful method to promote what Rueschemeyer (2003) called the "dialogue between theory and 
evidence" that is able to validate or reject a research hypothesis. Referred to as "process tracing" by George and Bennett (2005), the path dependence model must succinctly describe the sequence of events leading to an outcome in order to generate sound conclusions from the case study. If the research reveals that a sequential step is inconsistent with the theory's original predictions, then the theory must be revised or another explanation offered for the disparity. Although it may be difficult to establish the causal weight of relationships using a small number of cases, George and Bennett argued that process tracing is an effective method to determine relevance of causal mechanisms when the historical circumstances are analysed in multiple cases.

The third critique of the case study is its vulnerability to a "degrees of freedom problem," whereby it is difficult to defend the contribution of one set of circumstances from another competing argument (George and Bennett, 2005). Moreover, the failure to identify correlation (or lack thereof) between all cases under study may result in false conclusions, which is further compounded by the fact that most causal mechanisms have many attributes. Despite these issues, George and Bennett claimed that as long as process tracing reveals multiple evidence to support the hypothesis (or the hypothesis is revised to reflect new research discoveries), it is possible to achieve a defendable argument to explain an historical action. They therefore reiterated that process tracing should be able to uncover correlation between cases if performed in a manner that reveals the sequences and critical junctures under consideration.

First hand interviews with key stakeholders involved in the commercialization of federal transportation assets from the 1980s and 1990s were the dominant source of primary information used to evaluate the three commercialization cases in this thesis. 
This format was chosen due to its reliability and candid descriptions of major policy events from key players. A list of questions was established for each interviewee that focussed on his/her involvement with a specific reform period, as well as his/her thoughts on whether the reform(s) achieved the desired outcome, and also if further reforms were required.

In light of the abovementioned potential for bias in first hand interviews, other primary sources of data included federal commercialization publications from Transport Canada, the House of Commons Standing Committee on Transport, Infrastructure and Communities (SCOT) ${ }^{6}$, the Senate Standing Committee on Transport and Communications, as well as declassified ministerial correspondence and internal departmental documents obtained from Library and Archives Canada. These documents provided contextual information (especially for earlier periods such as the late 1970s), and also formed the basis of events from which the interview questions were formed. The documents also served as an objective comparison to the information received from the interviewees, as it is possible that an individual's recollection of past events may differ from recorded information due to political, personal, or time-lag factors.

Another major source of information was academic literature in several areas. Examples included: the policy reform process in federal states in the context of neoliberalism, with particular emphasis on Canada; commercialization reforms in the transportation sector; and decentralization impacts on subnational governments, including

\footnotetext{
${ }^{6}$ The current acronym to denote the name of this House Committee is "TRAN," which took effect at the beginning of the first session of the forty-first Parliament in June 2011. In previous Parliamentary sessions the Committee's acronym was denoted by "SCOTIC" and "SCOT." To avoid confusion, this thesis refers to the Committee by its most familiar acronym (SCOT) for all periods studied.
} 
accountability and fiscal sustainability. This information was applied throughout the thesis to enrich the contextual layers that described the major reforms and contributed to a more detailed explanation of the critical junctures of reform within each case study.

\subsubsection{Analytical Road Map}

The final methodological step is to provide a brief overview of the main contents

of the thesis. The principal theoretical component is the meso-organizational framework developed in Chapter Two, which is composed primarily of micro, macro and meso characteristics that are applied to analyse the commercialization of CN Rail, airport and ports over the period studied. Chapters 3, 4 and 5 subsequently apply the framework to each modal case study with special consideration of the context and causality of each major reform. The final results are presented in Chapter Six, which includes an analysis of the strengths and weaknesses of the theoretical framework, an examination of the many divergences in governance models within and among each case study, as well as opportunities for future research. A graphical representation of this analytical approach is presented below in Figure 1: 
Figure 1: Analytical Road Map

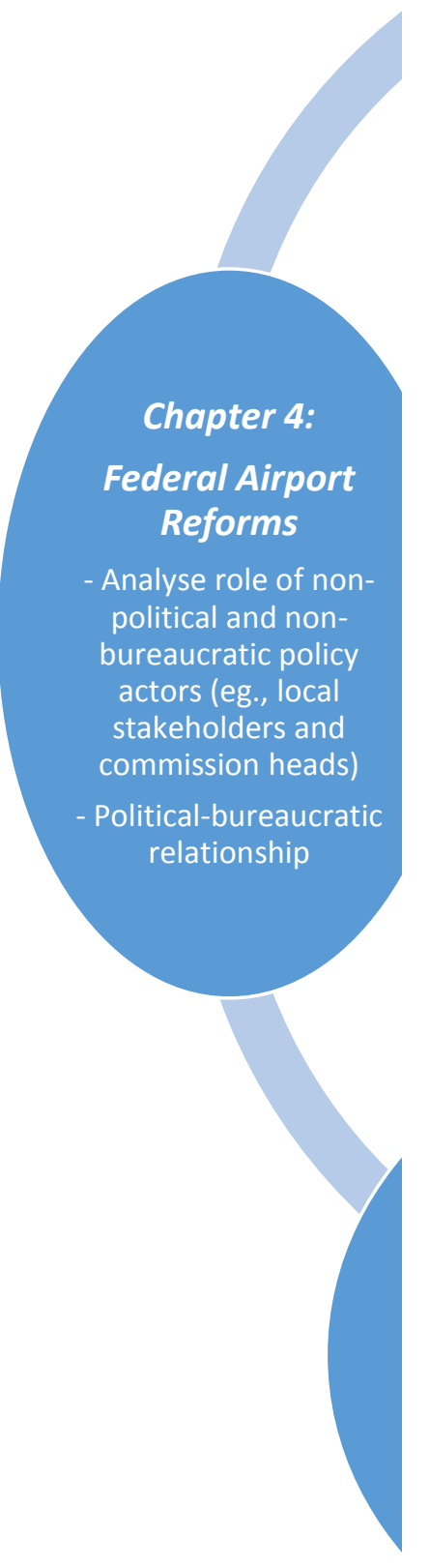




\section{Chapter Two: Theoretical and Empirical Foundations}

\subsection{Transportation Commercialization: Decision Making Models and Theories}

A thorough analysis of the commercialization of CN Railways, ports and airports by the federal government requires a strong theoretical framework. Such a framework must consider the interaction of the various organizational, political and environmental factors that shaped transportation policy from 1975 to 2000. This thesis departs from traditional methods of examining policy changes through a single lens of focus on a small number of variables in isolation of other potentially significant factors. Instead, it conducts a rigorous, forward-looking deductive analysis using a meso institutional framework to examine the interactions of the major micro and macro circumstances surrounding federal transportation commercialization.

A summary chart of the theoretical framework employed in this thesis is

presented in Table 1. Following a discussion of the relationship between causality and context, the micro, macro and meso components of the framework are presented. The micro perspective provides the framework to examine the context and conditions within Transport Canada, such as: the behaviour/actions of senior management team; superiorsubordinate relationships; organizational learning and problem solving skills; as well as organizational culture and the contribution to change. The major macro factors of relevance include broad measures impacting the federal government and international policy environment, such as: environmental influences (e.g., debt and deficit issues, neoliberalism, maturing transportation sector and reconsideration of federal role in transportation, a politically opportune time for reform at certain junctures, a general lack 
of public opposition to commercialization); and organization form (e.g., power distributions within the federal government, such as Cabinet and ministerial influence over bureaucratic decision making).

The factors affecting the interaction of micro and macro factors is then considered to yield a meso framework of commercialization to answer questions such as: did macro forces dominate micro forces during airport and port reform process; did political (cabinet/ministerial) actions (e.g., leadership decisions) lead to a new framework that encouraged Transport Canada employees to shift gears in favour of reforms; did reforms originate at the employee level; did neoliberalism lead to a dramatic change in Transport Canada's mandate; and did national debt and deficit concerns that began in the mid1970s create a strong solidarity amongst Transport Canada employees in favour of reform?

Finally, this chapter considers two major theories of policy decision making, rationalism and Marxism, and argues why they are not prime candidates to model the commercialization reforms under study. Although noble in its ability to use logical reason to describe public policy changes, rationalism underestimates the impact of political influence and decision making on the policy process, rendering any analysis of politically sensitive issues like the national debt and deficit ineffectual. Marxism, on the other hand, is primarily suited to class conflicts within society and has been proven to inaccurately describe the transfer or resources from governments to non-profit agencies such as port and airport authorities. 


\section{Table 1: Summary Table of Theoretical Framework}

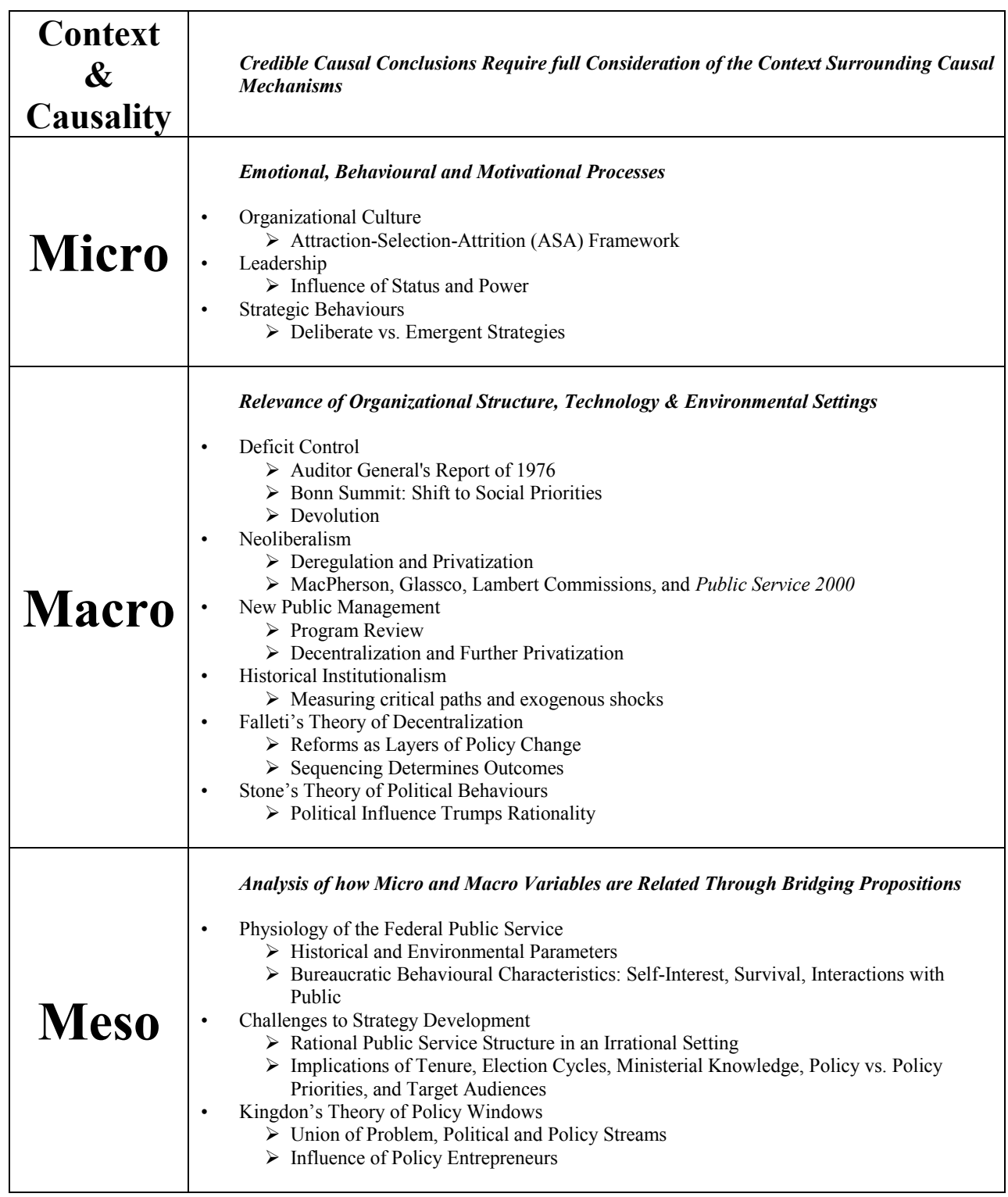

\subsubsection{Principles of Context and Causality in Public Policy Change}

An examination of the meso-institutional processes and determinants of policy change over three decades and across three transportation modes is a daunting task. A major step in analysing change is to examine the causal relationships (how?) as well as the context (why?) for reform. Yet, according to Falleti and Lynch (2009), the 
relationship between causal mechanisms and context remains poorly understood in the social sciences. In their view, credible causal conclusions will only result when the context surrounding causal mechanisms are fully considered. Given that the context of the initial policy state will differ from the reform state, the causal mechanisms in each context must be "portable," or possess similar characteristics among each context.

In order to fully explore the causal relationships among each period of policy reform, Falleti and Lynch's definition of causal mechanisms is next examined. The authors define causal mechanisms as "relational concepts... [that] describe the relationships or the actions among the units of analysis or in the cases of study" (2009, p. 1147). It is important to note that causal mechanisms are distinct from variables in a given case study. Variables, by contrast, are defined as "observable attributes of the units of analysis - with values (nominal, ordinal, or numerical) and with sample and population distributions" (2009, p. 1147).

There are currently many types of causal mechanisms identified in the literature that contribute to political and policy change. Of the 14 mechanisms outlined by Falleti and Lynch, five possibilities for this thesis are presented below in Table 2. The mechanisms are listed from individual to collective processes with those in parentheses referring to sub-units of a more general process. The most useful of the five possibilities for this thesis will be the layering effects of policy change. It will be shown below that decomposing the layers of commercialization reforms is a major component of determining the interaction of micro and macro forces through meso analysis. 


\begin{tabular}{|c|c|c|c|}
\hline Causal Mechanism & Brief Definition & $\begin{array}{l}\text { Causal } \\
\text { Agent }\end{array}$ & $\begin{array}{c}\text { Exemplary } \\
\text { Citations }\end{array}$ \\
\hline Coordination & $\begin{array}{l}\text { Benefits from a particular activity } \\
\text { increase as others adopt it, } \\
\text { encouraging further adoption. }\end{array}$ & $\begin{array}{l}\text { Individual or } \\
\text { collective }\end{array}$ & $\begin{array}{l}\text { Pierson } \\
\text { (2000b, pp. 76-77) }\end{array}$ \\
\hline $\begin{array}{l}\text { Positive feedback } \\
\text { (organizational inertia; } \\
\text { policy ratchet effect) }\end{array}$ & $\begin{array}{l}\text { Policies endure by creating their } \\
\text { own constituencies, shifting center } \\
\text { of gravity of the policy agenda. }\end{array}$ & Collective & $\begin{array}{l}\text { Huber and } \\
\text { Stephens } \\
(2001, \text { p. 22) }\end{array}$ \\
\hline Layering & $\begin{array}{l}\text { Progressive amendments, revisions, } \\
\text { and additions slowly change } \\
\text { existing institutions. }\end{array}$ & Collective & $\begin{array}{l}\text { Streeck and Thelen } \\
\text { (2005, pp. 22-23) }\end{array}$ \\
\hline Conversion & $\begin{array}{l}\text { New goals, functions, and purposes } \\
\text { redirect existing institutions. }\end{array}$ & Collective & $\begin{array}{l}\text { Streeck and Thelen } \\
(2005, \text { p. } 26)\end{array}$ \\
\hline Policy drift & $\begin{array}{l}\text { Outcomes of policies change when } \\
\text { policies are not adapted to new } \\
\text { circumstances. }\end{array}$ & $\begin{array}{l}\text { Collective or } \\
\text { social system }\end{array}$ & $\begin{array}{l}\text { Streeck and Thelen } \\
(2005, \text { pp. 24-26) }\end{array}$ \\
\hline
\end{tabular}

Source: Falleti and Lynch (2009, p. 1150).

Although causal mechanisms provide useful insights into policy changes, the analysis of commercialization reforms would be incomplete without considering the different contexts in which reforms occur. Falleti and Lynch defined context as "the relevant aspects of a setting (analytical, temporal, spatial or institutional) in which a set of 
initial conditions leads (probabilistically) to an outcome of a defined scope and meaning via a specified causal mechanism or set of causal mechanisms" (2009, p. 1152). As described in Figure 2 below, contexts A and B can lead to different outcomes, even in the presence of identical initial characteristics and causal mechanisms.

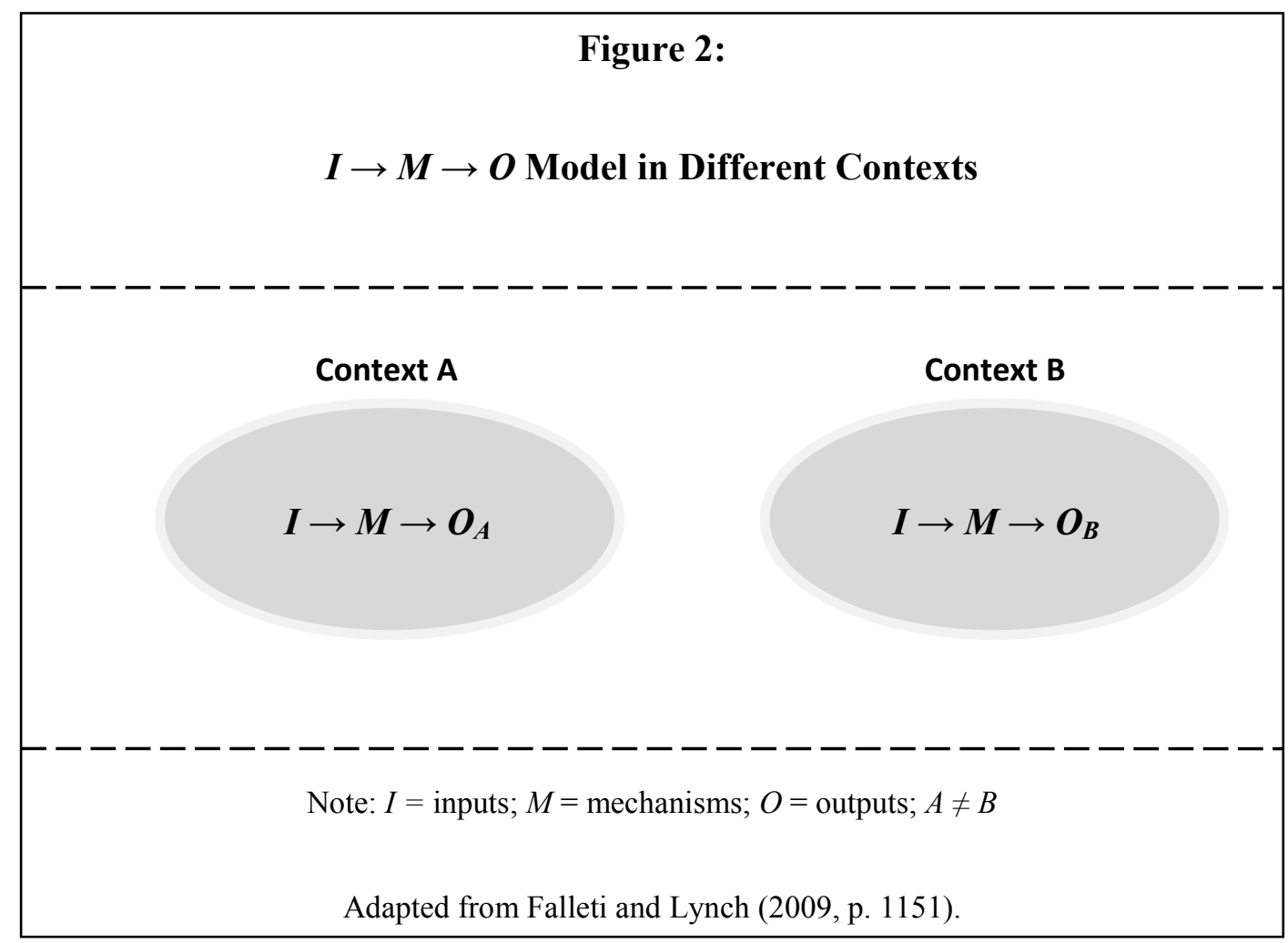

One of the most traditional methods of analysing policy change has been to consider the historical circumstances surrounding policy decisions. Falleti and Lynch highlighted the key techniques of sequencing, tempo and duration to analyze the time related aspects of a milestone event. Sequencing refers to determining the order in which change occurred in relation to a significant policy event, such as the adoption of a social welfare program. Tempo and duration refer to the implementation time observed for a policy change to take effect, which varies depending upon the interaction of causal mechanisms. 


\subsubsection{Meso Analysis of Organizational and Policy Change}

The study of the circumstances surrounding commercialization of $\mathrm{CN}$ railways, airports and ports requires consideration into the behaviours and interactions of major stakeholders at both the individual and organizational levels. According to House, Rousseau and Thomas-Hunt (1995), traditional organizational theory focussed exclusively on either the micro or macro determinants of change within organizations, with little emphasis devoted to the meso, or interactive effects of policy reforms. In the authors' view, the power of organizational theory is its ability to study the behaviour of organizations and the individuals within it in a set context. They therefore recommended meso analysis as a valuable tool to study the relationships among units of analysis within organizations.

Formally stated", "meso theory and research concerns the simultaneous study of at least two levels of analysis wherein (a) one or more levels concern individual or group behavioral processes or variables, (b) one or more levels concern organizational processes or variables, and (c) the processes by which the levels of analysis are related and articulated in the form of bridging, or linking, propositions" (House, Rousseau \& Thomas-Hunt, 1995, p. 73).

According to House (1991), organizations are assumed to take one of two major forms when analysed from a meso perspective. The first type is mechanistic and involves a high concentration of power and authority at the top of an organization. Most

\footnotetext{
${ }^{7}$ House (1991, p. 53) offered an informal definition of meso organizational analysis as one where "the distribution of power in organizations is largely a function of environment, organizational form, and individual personality characteristics."
} 
commonly used to describe public organizations, operations are assumed to proceed efficiently and predictably in a mechanistic fashion, with full cooperation and agreement from line employees. The second type, organic organizations, display both horizontal and vertical power distributions that are designed to react to changing external environments. Most commonly situated in the private sector, these organizations are constantly changing to adapt to new ideas and markets, similar to how an organic organism adapts to its natural environment. The mechanistic components and contextual circumstances will be applied to analyse commercialization reforms at Transport Canada through the interaction of micro and macro variables, which are explained below.

At the level of individuals or small groups, House, Rousseau and Thomas-Hunt described micro variables through the role of emotional, motivational and behavioural processes within organizations. The main area of research for micro organization theorists concerns how the behaviour within organizations influences the overall performance of an organization. Key factors that will be examined in this thesis include emotional, motivational and behavioural processes, which are considered in terms of executive team behaviour, superior-subordinate relationships, coordination, integration, organizational culture, as well as organizational learning and problem solving skills (House, 1991; House, Rousseau \& Thomas-Hunt).

Macro variables, on the other hand, emphasize the relevance of organizational structure, technology, and environmental settings in determining organizational change. In macro theory, the emphasis is solely on social, structural, political, economic and historical factors, while treating individual behaviours as exogenous. The macro variables most relevant for this thesis include hierarchical structures, chains of command, 
decentralization, organizational subunits, and power distributions. Despite its usefulness in explaining the impersonal characteristics of organizations, House, Rousseau and Thomas-Hunt argued that the principal flaw of macro theories is the assumption of modelling organizational performance while treating the behaviours of individuals and small groups as exogenous. Moreover, the authors claimed that macro processes ignore the potential impact of human elements upon organizational change, such as entrepreneurs, strategic decision making and organizational learning. Such micro factors are crucial to the development of the arguments in this thesis, as demonstrated by the use of Kingdon's theory of policy entrepreneurs and Mintzberg's theory of emergent strategies.

A key assumption behind meso analysis is that macro and micro variables cannot simply be analysed independently and then combined to form a sound model of organizational change. As House, Rousseau and Thomas-Hunt stated, "[i]n order to develop a meso organizational theory, micro theories and macro theories need to be integrated to articulate how organizational contextual variables and micro processes influence each other" (p. 77). In the authors' view, meso theory encourages the development of theories that are directly relevant to possible dependent variables, such as motivation, leadership and organizational change. The main component of meso analysis employed in this thesis is identifying the various layers under consideration, which enables examination of the various sequential processes and patterns behind changes in organizations. Once the main hypotheses and dependent variables are determined, the focus will move to implement broad organization variables into micro analysis and behavioural analysis into macro analysis. 
It is also noteworthy that meso analysis is not only concerned with the interaction between micro and macro variables at various levels of analysis; meso also emphasizes the qualitative (i.e., social) relationship among the variables (House, Rousseau \& Thomas-Hunt). Stated another way, "[w]hile meso theory is more complex than single level theory it offers the possibility of accumulating knowledge in a more parsimonious and coherent framework" (p. 108). In order to conduct an analysis across levels of analysis and hierarchical echelons, there must be a clear understanding of the causal mechanisms and contexts. Falleti and Lynch's (2009) abovementioned framework of context and causality is therefore crucial to examine individual behaviours, intergroup relationships and organizational constraints that may interact to create organizational cultures, which in turn impact the behaviour of these individuals and groups.

According to House, Rousseau and Thomas-Hunt, there are two principal processes that provide a framework to analyse the interaction of micro and macro variables. This first type is isomorphism, which measures the degree of similarity amongst organizational components and their relationship under the layers of study. In the authors' view, "knowledge of isomorphism provides insights about organizational functioning and helps to achieve a parsimonious understanding of how complex organizations function" (p. 95). The most common example is inclusiveness, which determines how much activities in one unit are integrated with another unit. The discussion below on organizational culture makes use of this approach. Another example is entrainment, which examines when behaviours at one level adjust to match the timing and events at other levels. Mintzberg's theory of strategic planning closely mirrors this example. The authors claimed that entrainment results in increased stability and 
resistance to external changes. Another isomorphic example is selection effects, which refers to how the selection of members shapes outcomes in groups or organizations, such as the attraction-selection-attrition framework presented below. ${ }^{8}$

It is worth noting, however, that not all organizational relationships are isomorphic. In some cases, similar variables may have different outcomes at different units of analysis. Such situations are referred to as heteromorphic, or discontinuous, and are the second type of meso processes. An example concerns discontinuity in the magnitude of variables, i.e., when the magnitude of an individual's behaviour within a group differs from the magnitude of a group's behaviour within an organization. Another example is known as variations in behaviour-outcome relationships, in that relationships may vary according to the context in which it is examined. ${ }^{9}$

The next requirement for a complete meso analysis is consideration of bridging propositions (House, Rousseau \& Thomas-Hunt). The first component of this analysis is to determine the impact of micro and macro variables upon organizational change. An example of a hypothesis involving the impact of micro and macro variables to be considered in this thesis is that large and mature organizations foster an environment where macro forces will trump micro variables. This proposition may be a potentially powerful hypothesis to explain why decentralization went so smoothly for CN Railways,

\footnotetext{
${ }^{8}$ Other examples less directly relevant to this thesis include: collective sense making analyses, which examines how groups work together in ambiguous environments to create shared cultures; and situational ambiguity, as in ambiguous organizational environments, behaviours can be influenced from many factors inside and outside the organization.

${ }^{9}$ The most common case highlighted by the authors is when employees value positive and motivational supervisors more highly during times of organizational uncertainty than during periods of organizational stability.
} 
supporting the claim of a "policy miracle." The second component of a meso analysis is to examine how the structure of organizational levels regulates the impact of major organizational decisions. One aspect of this component is the degree of coupling, which refers the amount of independence among groups within an organizational hierarchy. In the authors' opinion, the tighter the coupling between units, the greater the impact of changes at one level on the entire organization. Furthermore, when the values and beliefs of organizational units are closely aligned with the executive level, the potential for reciprocal influence is high. In other words, when organizations are "on the same page" as was the case at Transport Canada during the mid-1990s, healthy working relationships ensued and ministerial direction was quickly and effectively implemented.

\subsubsection{Micro Foundations}

\section{Organizational Culture}

Organizational culture comprises a significant micro influence within public policy and administration. According to Lemâitre (1987, p. 419), "[c]ulture is a system of representation and values shared by all the members of an enterprise" (translated in Dwivedi and Gow, 1999, p. 20). Expressed in simple terms, "cultures are often expressed as assumptions - beliefs that define "the way we do things here" (McCurdy, 1992, p. 189).

There are many different levels of culture that could be analysed in the context of commercialization reforms at Transport Canada. For example, Dwivedi and Gow (1999) presented a hierarchy of cultures to describe the behaviour of federal departments and agencies. At the top would be a Canadian culture, which represents the values, ideas and 
symbols of the country at large. Next is political culture, which includes the influence of the state (Parliament and the judiciary) as well as the current government. Administrative culture represents the public service-wide attitudes of departments, agencies and Crown corporations. This can be further subdivided into two forms of organizational culture: departmental subcultures that are formed based on mission statements, mandates and clients; and professional subcultures such as economists, engineers and lawyers. Although not directly stated by Dwivedi and Gow, one component that could be added to the hierarchy is changing global cultures that influence administrative and hence departmental cultures. A relevant example is the emergence of neoliberalism (discussed in Section 2.1.2.2) and its subsequent impact on the policy capacity of the federal public service, as witnessed at Transport Canada. This hierarchy is presented in Figure 3 below. 


\section{Figure 3: Hierarchy of Cultures Influencing Public Policy in Canada}

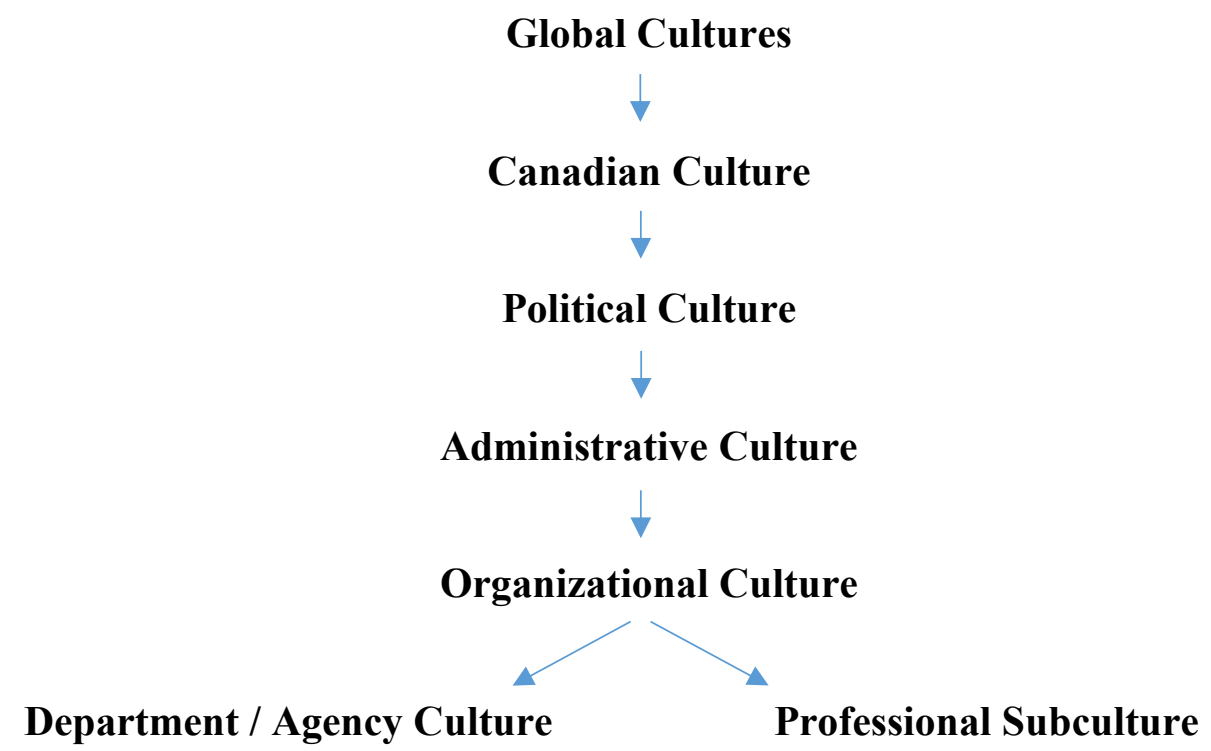

Adapted from Dwivedi and Gow (1999).

When considered in the context of this thesis, global, Canadian and administrative cultures are external to Transport Canada and are further discussed as macro variables in Section 2.1.2.2.

The framework for analysing the departmental and professional subcultures within Transport Canada is now considered. Schneider (1987) argued that academics have too often assumed that macro situations are the main determinants of organizational outcomes. Instead, he claimed that organizational actions are a result of employees demonstrating coordinated patterns of behaviour. In other words, employees determine the environment within an organization, not the other way around. As a result, the personality culture of an organization encourages like-minded individuals to apply for positions, become hired, and remain within the organization over time. Schneider termed 
this theory the attraction-selection-attrition (ASA) framework and claimed it explains why organizations differ within and across industries.

Regarding employee attraction, Schneider claimed that individuals "are differentially attracted to careers as a function of their own interests and personality" ( $p$. 441). Consequently, Schneider argued that the work environment individuals choose match the personalities of those who join them. Stated more explicitly, "similar kinds of people are likely to have similar kinds of personalities, are likely to choose to do similar kinds of things, and are likely to behave in similar kinds of ways" (ibid.). This theory may help to explain the near-unanimous support for commercialization of ports and airports at Transport Canada during the 1980s and 1990s, as well as the strong employee opposition to privatization of CN Railways over the same period.

When organizations select candidates for employment, they choose those best suited to achieve broad corporate objectives. According to Schneider, organizations not only select people based on specific competencies for a position, but also based on personal values and beliefs. Potential employees are therefore "typed" according to several characteristics that the organization believes will contribute to its long-run effectiveness. An example of this approach would be the selection of bureaucrats for senior management positions within Transport Canada during the early 1990s, most of whom had previous experience working with each other and agreed with the need to proceed with commercialization.

While the attraction and selection components place like minded individuals within an organization, the attrition aspect ensures that like-minded individuals remain 
with the organization over the long term. Schneider's main conclusion is that individuals who have been hired but do not feel part of the organizational culture will leave ${ }^{10}$, resulting in a homogeneous group of employees across many vocations. Furthermore, he argued that the attrition mechanism ensures minimal variance among employee personalities, reaffirming that major organizational decisions occur internally and are less influenced by random chance or external factors. This hypothesis may help explain the high level of union agreement with commercialization reforms within Transport Canada, resulting in zero job actions across all vocations. This outcome was in stark contrast with the many job actions at CN Railways in the early 1990s, resulting in the passage of federal back-to-work legislation in April 1995.

\section{Leadership}

Leadership is a critical component for an analysis of changes behind commercialization reforms at Transport Canada. Major reforms in public organizations since the 1980s have decreasingly occurred through the actions of one individual and have rather involved consensus decisions from a network of senior managers (Denis, Langley and Rouleau, 2007). As a result, the term "transformational leader" has come to denote someone who "provides a plausible and attractive vision of the organization's future, fosters a more reflexive approach to practices ... and is able to pay attention to individuals' specificities" (Ibid, p. 448).

\footnotetext{
${ }^{10}$ It could also be argued that those individuals who are hired by an organization but do not immediately feel comfortable may not leave but instead may grow accustomed to the culture and therefore confirm to the homogeneous identity of the group or vocation. In the author's experience, such behaviour has been dubbed "drinking the Kool-Aid."
} 
Magee and Frasier (2014) argued that the foundation of change in public organizations is the ability of an individual to influence others (i.e. subordinates and superiors) to agree with proposed reforms and assist in facilitating its implementation. Consequently, they claimed that leaders require two criteria to achieve change: status and power. Stated formally, status "is defined as the degree of respect others have for an individual ... and respect is typically accorded to individuals who are ... both competent and concerned with others' interests" (p. 308). Power, on the other hand, "is defined as asymmetric control over valued resources ... [such as] material, financial, social and knowledge-based resources" (Ibid). The authors emphasized three main components of power, namely asymmetric control of information, a high level of policy related expertise, and discretion to vary the degree of decision making within an organization.

From a practical standpoint, Magee and Frasier emphasized that status and power are dependent upon the environmental context of the circumstances under analysis. As discussed previously, Falleti and Lynch (2009) stressed that examining the context of reform is required to determine whether credible causal conclusions occur. Furthermore, Denis, Langley and Rouleau (2007) claimed that the collective process of public sector decision making occurs in the presence of many stakeholders and environmental factors, creating unpredictable outcomes that are contrary to the rational views of organizational change. On the subject of Canadian federal policy changes, Aucoin (1986, p. 26) stated:

[T] he introduction of a new leadership paradigm ... does not occur in an intellectual or political vacuum. However personal a ... paradigm may be it cannot help but be influenced by the intellectual and political environment extant when a leader assumes office. The actual organizational design that is adopted to give effect to a new paradigm will therefore reflect in some large measure the intellectual and political realities of the times. 
A relevant example that is examined in this thesis is whether the Minister of Transport received a similar level of status and power within Transport Canada as he received within Cabinet. Another application will consider whether the Deputy Minister of Transport attained the same level of status and power among his/her subordinates at Transport Canada as he/she received among colleagues, stakeholders and the Minister of Transport.

The next step in the leadership analysis is to consider Magee and Frasier's characteristics of status and power among senior public managers. Those attributed with high status enjoy a "halo effect" whereby they are held in high esteem by colleagues and subordinates. Such individuals are considered respectful during reform negotiations and are frequently solicited for advice on organizational changes. Leaders who enjoy power in organizations are typically action oriented, willing to take risks and act assertively in reform negotiations. That said, the authors claimed that the most successful characteristic of powerful individuals is an ability to think abstractly (i.e. consider the 'big picture') and examine both the "how" and "why" factors behind a potential reform option. In the case of individuals who possess both status and power in organizations, "they are typically well positioned to exercise tremendous influence" (p. 310).

In practice, the most successful leaders are those who can navigate through the tides of change within an organization and its external environment. According to Denis et al. (2007) such mangers display an "entrepreneurial view" of leadership through innovative and flexible decisions that are amenable to many political, regulatory or policy conditions. Similar to Magee and Frasier's notion of leadership power and Kingdon's version of policy entrepreneurs discussed below, an entrepreneurial leader is someone 
who recognizes current environmental trends (the 'big picture') and is ready to act when certain situations occur (i.e. a policy window opens). ${ }^{11}$

\section{Mintzberg's Theory of Emergent Strategies}

The past thirty years have witnessed a sharp increase in the use of strategic planning in the public sector. The term strategy was first employed by Western militaries to refer to sets of rules and procedures based on analysis of past events (Rose and Cray, 2010). Following World War II, the rise of multinational corporations and the resulting increased complexity of corporate governance led private firms to adopt strategic planning initiatives within their organizations (Mintzberg and Jorgensen, 1987). By the 1980s, public policy practitioners and academics began to adopt techniques of strategy formation from the private sector and apply them to large public organizations. In particular, the strategic planning discipline has promoted the use of organization theories to take into account the importance of institutional settings in the development of public policies (Mintzberg and Jorgensen).

From a public sector perspective, the terms strategy and policy are used interchangeably, which according to Mintzberg and Jorgensen, are best described as a process of "pattern in action" (1987, p. 219). The crux of their framework is that a strategy is a consistent set of actions that occur over time, regardless of whether or not those actions were planned. This concept is in contrast to the traditional rational

\footnotetext{
${ }^{11}$ In this vein, Moran (2008, p. 154) noted that the most successful institutional changes in the developed world since the 1980s occurred primarily due to leaders who were adept at "recognizing inevitability" and embracing structural change such as globalization and adapting it to their individual country.
} 
planning view discussed later in this chapter, where strategy denotes an intended plan of actions brought about from research into historical events.

Mintzberg and Jorgensen further extend their model to distinguish between two forms of strategies in modern day public organizations. The first type is deliberate strategies, which refers to policies that are intended (i.e., formally planned) and realized. According to Mintzberg (1977), focusing solely on deliberate strategies limits the quality of institutional research to normative, abstract analysis. As a result, the second type of strategies includes those that are not planned by an organization but are in fact realized, which are known as emergent strategies ${ }^{12}$. In the author's view, emergent strategies imply that "strategies can form without necessarily being formulated" [italics in original] (p. 219). These two forms of strategies were not offered as rival theories but were instead designed to occupy two polar ends of a strategy continuum.

If it is possible for strategies to emerge without formal planning, then there must be specific locations within Transport Canada's organizational hierarchy where new strategies occurred. Mintzberg and Jorgensen argued that emergent strategies arise through two main sources in public organizations. First, there may be an individual or small group of individuals within an organization who develop ideas in response to current challenges that eventually develop into a corporate strategy. This concept is also very similar to Kingdon's description of a policy entrepreneur, which is discussed below. Second, and most likely in the authors' view, organizations learn while they make policy,

\footnotetext{
${ }^{12}$ Mintzberg (1977) has also referred to emergent strategies as "retroactive" strategies.
} 
building upon current strategies that in turn enable the convergence of their actions into patterns that eventually form new strategies.

Given the potential for emergent strategies in public organizations, Mintzberg and Jorgensen's framework provides two methods for senior management to delegate authority while still maintaining overall strategic direction. The first option is an umbrella strategy, whereby senior management specifies the broad intent of a policy and assigns responsibility for its implementation to the operational cadre. ${ }^{13}$ This option is the most relevant for the analysis of commercialization reforms in this thesis. The second alternative is known as a process strategy, in which senior management seeks control of the procedure in which new policies are formed and not the specific policy outcomes. ${ }^{14}$

It must also be recognized that some strategies, be they deliberate or emergent, are formed deep within the bureaucracy of some organizations and are unknown to senior management. Mintzberg and Jorgensen classified these approaches as disconnected strategies, which usually result from the determined action of an individual or small group of employees to advance a policy or procedure for the benefit of the organization. Disconnected strategies may be either deliberate or emergent as viewed by the policy champion, but are always considered emergent from an organizational perspective. The organization must therefore be willing to learn and adapt in order to avail itself of the

\footnotetext{
${ }^{13}$ An example cited by the authors is a foreign aid agency that sets broad outlines for grants but permits its civil servants choose destination countries and funding amounts.

${ }^{14}$ An example provided for this strategy was Mintzberg and McHugh's (1985) analysis of the National Film Board of Canada, where senior management specified the process of approval for new projects but permitted free choice of topics for film and radio documentaries.
} 
new strategy. This perspective is particularly interesting when considered from the perspective of the organizational culture towards commercialization at Transport Canada and the degree of learning that was required to adjust to new policy direction that began in the late 1970s.

In light of the various forms of strategies illustrated above, the final aspect of Mintzberg's work of relevance to this thesis is to consider how strategies evolve and become adopted by large organizations. According to Mintzberg and Jorgensen, at the limit, strategies can occur in any level of any organization at any time, as long as there is a willingness to learn and sufficient resources to support the strategy's development. Strategies then become organizational when they become "collective," meaning that patterns of behaviour spread across the organization and become part of its culture. The process by which strategies permeate through an organization to become adopted may be planned, unintended, or a combination of both, especially in the case of ideas perceived as valuable to the organization. The authors further claimed that new strategies do not occur frequently, but rather that organizations experience long periods of the status quo separated by short term "strategic revolutions" or exogenous shocks that move the organization onto another path. This concept is very similar to idea of path dependence in historical institutionalism, which is discussed below. The key to successful implementation of new strategies, according to Mintzberg and Jorgensen, is for senior management to closely monitor the convergence and divergence of new ideas, recognizing those worthy of potentially succeeding current strategies and identifying the appropriate timing in order to achieve implementation success. 


\subsubsection{Macro Foundations}

\section{The Quest to Curb the National Debt and Deficit}

\section{Post-War Growth in Public Spending}

The post-World War II period witnessed substantial growth in federal public sector expenditures, employment and bureaucratic influence. As Figure 3 illustrates, federal budgetary deficits significantly increased beginning in the late 1970s and lasting until the late 1990s. In addition, the number of federal public servants fluctuated from about 216,000 in 1971 to almost 283,000 in 1978, before declining to 212,000 in 1995 (Dwivedi and Gow 1999). A governance system known as the "administrative state" thus emerged whereby the federal public sector exerted significant influence in nearly all aspects of public life via public policy making (Ibid).

Figure 3

Federal Budgetary Surpluses (-) and Deficits (+) in Canada:

1969-70 to $2000-01$

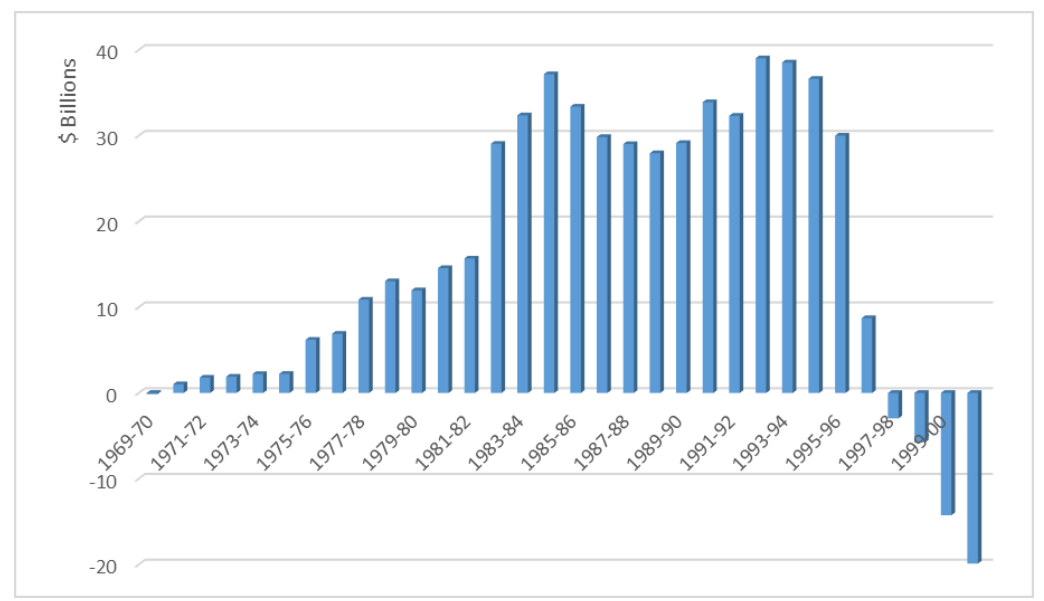

Source: Finance Canada, Archived Fiscal Reference Tables, October 2009.

Due to a break in the series following the introduction of full accrual accounting, data from 1983-84 onward are not directly comparable with earlier years. 


\section{A Wake-up Call: The Auditor General's 1976 Report}

The sharp rise in federal deficits (and the national debt) prompted the Auditor General of Canada, James J. Macdonell, to publish a scathing report on the federal government's financial management practices in 1976. Macdonell began his report by cautioning that " $[\mathrm{F}]$ inancial management and control in the Government of Canada is grossly inadequate" as "Parliament - and indeed the Government - has lost, or is close to losing, effective control of the public purse" (p. 9).

The Auditor General also criticised current and previous federal governments for insufficiently addressing the accountability concerns and management recommendations of the Glassco Commission (discussed below) nearly 15 years earlier. In particular, Macdonell claimed that bureaucrats lacked the fundamental ethos required for public service, as there was (p. 12):

An attitude ... on the part of many managers at all levels that funds are readily available and that they themselves are not personally accountable for ensuring that public funds and assets placed at their disposal are under strict control at all times and that funds are expended prudently, economically, and with the utmost concern that good value is received for money spent.

Interestingly, the Auditor General's report and the Glassco Commission both framed the federal government's financial troubles as a result of poor political supervision of the public service and a lack of concern for the public good on the part of bureaucrats. This line of reasoning was well documented before the emergence of neoliberalism or the New Public Management movement but nonetheless represented serious doubt in the ability of the public sector to effectively conduct public policy and deliver public services for Canadians. 


\section{Gathering Momentum: 1975-76}

The timing of the release of the Auditor General's report also coincided with several federal initiatives to control public spending as well as the national debt and deficit. In October 1975, the Minister of Finance, Donald S. Macdonald, announced that the federal government would take action to curb rising inflation (Savoie, 1990). The minister identified two major causes of inflation: rising government expenditures and the escalating federal deficit. As a result, the government pledged to limit growth in public expenditures to the growth in Gross National Product (GNP) and cut programs where possible. According to Savoie (1990), the largest cuts during this period focussed on non-budgetary items, such as Crown Corporations, which received \$357.4 million in cuts during the 1975-76 fiscal year, which is the equivalent of $\$ 1.49$ billion ${ }^{15}$ in 2014 dollars.

Transport Canada was not immune from the departmental reviews of spending to tackle the federal debt and deficit. In 1977, the Department summarized its major cost saving efforts as follows (Transport Canada, 1977a, pp. 1-2):

Fiscal restraint was evident in many areas, as attempts were made to make services more cost effective - to get greater benefits from the same budget. To this end, projects were scrutinized intensively and, wherever possible, existing facilities improved rather than embarking on the construction of major new infrastructures, unless these could be justified on the basis of commercial viability or of clear and overriding public requirements.

\footnotetext{
${ }^{15}$ This inflation calculation was obtained from the Bank of Canada inflation calculator on December 30, 2014 via the site: http://www.bankofcanada.ca/rates/related/inflation-calculator/
} 
The Department also began drafting legislation to consolidate 20 major port commissions under one Canadian Ports Commissioner with delegated authority to each port for day-today operations (Ibid).

Despite an ambitious agenda of cuts, inflation continued to remain high in Canada throughout the 1970s. As Savoie (1990) highlighted, the federal government began another round of cost reductions in 1977. The President of the Treasury Board, Robert Andras, instructed all ministers to review their departmental spending plans without prejudice. By early 1978, the government achieved an annual expenditure growth rate of 7.1 percent, which was lower than inflation for the first time in the Trudeau era. The Treasury Board President commented at the time that his greatest accomplishment was to end "the notion that the Treasury Board is somehow obligated to find additional funds for every worthwhile program expansion or new program and the notion that all that is needed to get these funds is to join the spending queue" (Savoie, 1990, p. 151).

\section{The Turning Point: Trudeau's Trip to Bonn}

The initial round of expenditure cuts and any potential momentum from the release of the Lambert report failed to lower Canada's inflation rate. In the summer of 1978, Prime Minister Trudeau attended a meeting of heads of government of the Organization of Economic Cooperation and Development (OECD) in Bonn, Germany to discuss possible solutions to reducing inflation in the developed world (Savoie, 1990; Dwivedi \& Gow, 1999). Following discussions with his close friend and conference host, West German Chancellor Helmut Schmidt, Trudeau became convinced that excessive government spending was the principal cause of inflation. In the words of 
Dwivedi and Gow, “[s]ince Pierre Trudeau's attendance at the Bonn summit in 1978, the dominant discourse of Canadian political leaders on budgetary questions has been one of cost control" (1999, p. 103).

Armed with a determination to control government spending and lower inflation, Trudeau bypassed any preliminary cabinet discussion and instructed his ministers to cut $\$ 2.5$ billion dollars in current expenditures. The Prime Minister even took to the airwaves to address the nation, claiming that "we must have a major re-ordering of government priorities. We must reduce the size of Government" (Savoie, 1990, p. 152). The Minister of Finance and President of the Treasury Board informed line ministers that they were to identify and cut programs that no longer complemented the core priorities of the government, namely health care and social policy ${ }^{16}$ (Savoie, 1990).

Prime Minister Trudeau's decision to reorient federal priorities to core areas of health care and social policy served as the official start to commercialization of federal transportation assets. The mantra that the federal government would be 'all things to all people' had clearly changed, as from this point onwards the government would only be involved in areas that it believed served the national interest. Trudeau's indirect blessing of reforms meant that Transport Canada was now authorized to commence analysis into the potential for full-scale devolution of ports, airports and CN Railways in an effort to trim the national debt and deficit.

Transport Canada bureaucrats wasted no time in preparing for its revised mandate. The Department released the document, Transport Canada: Its Roles and

\footnotetext{
${ }^{16}$ Departments were also granted the option of substituting other programs for cuts in lieu of Treasury Board's recommendations, as long as the total cost savings of both options were equal (Savoie, 1990).
} 
Objectives, in 1979 that acknowledged for the first time that it "need not, and indeed should not, provide all transportation facilities and services" (Transport Canada, 1979b). The strategy outlined key objectives that committed the Department to support principles such as efficiency, safety and accessibility. It also signalled an intent to develop bureaucratic strategies to grant line managers more flexibility in decision making to ensure greater accountability of human and financial resources. Although not explicitly stated in the document, the accountability provisions were likely implemented in response to the Auditor General's call for reforms in 1975.

From a modal perspective, Transport Canada initiated plans to reform airport governance through the establishment of the Task Force on Airport Management in 1978. The Task Force was mandated to develop possible alternatives to airport reform that would encompass local control and influence while remaining financially stable and accountable to tax payers (Transport Canada, 1979a; Valo, 2001: Dion, 2002). The Committee's findings were published in July 1979 with the recommendation that local airport authorities be developed with boards of directors nominated by all three levels of government, which would be accountable to the Minister of Transport through a newly created Canadian Airports Authority.

The Joe Clark Era: 1979

By the time the airports' Task Force released its report, the Trudeau Liberals had been replaced by a Progressive Conservative minority government led by Prime Minister Joe Clark in June 1979. The new Minister of Transport, Don Mazankowski, fully accepted the Task Force recommendations and instructed the 
Department to proceed with reform. During this time, however, the government's budget bill was defeated in the House of Commons December in 1979 and a new election was called. Ironically, one of the cornerstones of the government's budget was to take further steps to reduce and subsequently eliminate the national debt and deficit, but was defeated over proposed increases in taxes (Savoie, 1990).

\section{Trudeau's Return: 1980-1984}

Upon winning a majority government in 1980, Prime Minister Trudeau outlined three main priorities: patriating the constitution, addressing high energy prices, and enhancing the role of the federal government in society (Savoie, 1990). The Minister of Finance announced in his first budget that the government would focus on maintaining government expenditures in line with GNP growth and controlling the national debt and deficit. A global recession in late 1981, however, influenced the government to commit to greater spending on social programs to tackle unemployment. Expenditure restraint continued in most departments, however the goal of cuts had now shifted to finding funds to spend on social programs and not across-the-board spending reductions (Savoie, 1990).

Following nearly two decades of attempted reform, the early 1980s brought further attempts to reform port governance. The 1981 Liberal government White Paper on Port Reform set the stage for legislation to replace the National Harbours Board Act (Brooks, 2007a). In early 1983, Parliament passed the Canada Ports Corporation Act, which converted NHBs into Local Port Corporations (LPCs) (Ircha, 1997a; Brooks, 2007a). The Act created seven LPC ports in St. John's, Halifax, Saint John, Quebec City, 
Montreal, Vancouver and Prince Rupert (Ircha, 1996; 2001). As discussed further in Chapter Four, the Trudeau government lost interest in port reform and failed to establish a comprehensive governance structure that would help Canadian ports become more competitive and simultaneously reduce the financial burden to the federal government.

With respect to airport policy, industry deregulation had significantly increased air travel during the 1970s and 1980s and the airport authority model was believed to be the best method for individual airports to raise capital for expansions (Padova, 2007). Despite this initiative, airport governance reform faded from the Trudeau (Liberal) government's agenda and was not addressed until the first mandate of the Mulroney government (Dion, 2002).

The Mulroney Era: 1984-1993

According to Strain, the "legacy of deficit and debt left from the Trudeau era was certainly the most important challenge facing Mulroney when he assumed office in 1984" (2007, p. 45). As a result, the new Progressive Conservative government announced that controlling the deficit and reducing the national debt would be one of its top policy priorities. Less than two months after taking office, the government tabled an economic update in November 1984. The Minister of Finance, Michael Wilson, pledged a $\$ 15$ billion reduction in government spending by the end of the 1990-91 fiscal year (Savoie, 1990). He also pledged to cut overhead expenses such as political pensions, improve the management of crown corporations, and raise taxes in an effort to reduce the deficit (Canada, 1985a). The government cautioned the public that the large deficit and corresponding national debt was negatively impacting the 
competitiveness of the Canadian economy, particularly in the form of high interest payments on the national debt, which it claimed equalled nearly 80 percent of federal income tax revenues in 1984 (Canada, 1985b).

Following two rounds of expenditure reductions across the federal government, the Minister of Finance continued to encourage further spending cuts. In his view, "to waver on deficit reduction as the economy was improving would severely damage the government's credibility" (Savoie, 1990, p. 169). As discussed further in the next chapter, the Mulroney government chose to embark on an ambitious agenda of privatizing crown corporations as a way to lower expenditures. Many crown agencies, such as Canadair Ltd., deHavilland, Air Canada, and CN Hotels were privatized, and many other entities considered for divestiture (Savoie, 1990: Strain, 2007).

Regarding transportation policy, the federal Progressive Conservative party had begun planning for reforms following their election defeat in 1980. According to former Minister of Transport John C. Crosbie (2007), then party leader Joe Clark tasked MP Erik Nielsen and Senator Arthur Tremblay to conduct a comprehensive policy review of major departmental priorities and prepare a blueprint for change should the party regain power in 1984. The chair of the transportation reforms was Don Mazankowski, a popular and influential member of the Conservative caucus from Alberta who had served as Minister of Transport during the short-lived Joe Clark government of 1979. In Crosbie's view, the major success of the many transportation policy reforms of the late 1980s was primarily due to the party having approved most of the reforms approved in principle while in opposition, leaving Transport Canada bureaucrats to develop the details behind the desired changes. 
As part of bureaucratic efforts to implement reforms, an internal review process within Transport Canada resulted in the publication of the policy document, Freedom to Move: a Framework for Transportation Reform in 1985 (Transport Canada, 1985). The goal of this framework was to provide a new direction for federal transportation policy via a reduced regulatory burden and promotion of freer market conditions. Described as a "major shift in policy and practice," the framework stressed, "in the environment of the 1980s, the existing regulatory regime represents an obstacle to economic growth" (pp. iiiii). The main divestiture reference in the document called for streamlining the "administrative burden" of airport operations and the application of market based principles to ensure a more efficient and competitive environment (p. 22).

Despite significant efforts to control the deficit and mounting federal debt, the Mulroney government ultimately failed in its attempts to improve Canada's fiscal situation. In Strain's (2007) view, the primary source of this failure was high interest rates on debt payments during the 1980s. As part of the Bank of Canada's monetary policy to fight inflation, high interest rates led to record levels of personal and commercial debt for all Canadians, including the federal government. Furthermore, poor economic growth brought-in lower government revenues, which negated any intended benefits from increased taxes to fight the deficit. Taken together, these events led to record-high deficits by the time the Liberals returned to power in late 1993. 
As with many developed countries, the costs of operating publicly funded social programs via government borrowing became unsustainable for the federal government in the early 1990s. Upon taking office in late 1993, the federal Liberals inherited a national deficit from their Progressive Conservative predecessors of $\$ 42$ billion and a debt level of almost $\$ 550$ billion (Janigan, 1995; Manley, 2005). Further compounding the fiscal situation were significant declines in international capital valuations in 1994, which resulted in sharp devaluations of the Canadian dollar and steady increases in interest rates on federal debt payments (Kroeger, 1996; Manley, 2005). As a result, the federal government, public servants and even the majority of the general public were in agreement that difficult decisions needed to be made to control the national debt and deficit (Janigan, 1995; Greenspon and Wilson-Smith, 1997; Manley, 2005).

In an effort to reform the Canadian financial situation and eventually eliminate the deficit, the 1994 federal budget announced a comprehensive examination of federal program expenditures over three fiscal years, known as Program Review (Kroeger, 1996; Paquet and Shepherd, 1996; Manley 2005). A key feature incorporated under Program Review was the subsidiarity principle, wherein "the federal government should be involved only in circumstances where other sectors or governments cannot perform the activity satisfactorily" (Paquet and Shepherd, 1996, p. 45). Federal departments were 
required to review all major programs using six sequential criteria, ${ }^{17}$ namely (Manley, 2005, p. 23):

1. Is the program still in the public interest?

2. Is its delivery a legitimate and necessary role for the government?

3. Is the current federal role appropriate or should the program be realigned with the provinces?

4. Should it be delivered in partnership with the private or voluntary sector?

5. How can it be redesigned for efficiency?

6. Is it affordable, given fiscal constraints?

Once underway, Program Review formed the foundation for the 1995 federal budget, which Kroeger (1996) described as the final "bookend" to the post-war social safety net in Canada. Budget 1995 began the process of significant cutbacks to federal government spending of nearly $\$ 12$ billion over two years, with many federal line departments such as Transport Canada subjected to significant and immediate cuts of 50 percent to their operating budgets (Veldhuis, Clemens, and Palacios, 2011). Among the multitude of government cuts, roughly 45,000 full-time public service positions were eliminated through various methods, federal social transfers to the provinces were reduced and consolidated in the newly created Canada Health and Social Transfer (CHST), and extensive changes were made to the Canadian transportation system (Pal, 1998). According to Greenspon and Wilson-Smith (1997, p. 210):

\footnotetext{
${ }^{17}$ Greenspon and Wilson-Smith (1997) claimed that criteria number six, affordability, was the lone criteria used in practice to evaluate major departmental programs. They claimed that this decision was deemed necessary by the Minister of Finance, Paul Martin, who stated that immediate financial cuts were the first priority due to the deteriorating fiscal situation, to be followed at a later date by a reorganization of federal policy priorities.
} 
The prize pupil was Transport, which had zoomed well ahead of the pack in redefining its mission and shedding costs. The department's no-nonsense minister, Doug Young, had already unveiled a policy to place all the airports in the country under the control of local authorities, a truly staggering departure for a Liberal government.

When the dust settled in 1997, the federal government posted its first budgetary surplus since 1969 (Manley, 2005).

\section{Neoliberalism: Theoretical Components}

In order to gain a full understanding of the political environment over the period studied, the rise of neoliberalism throughout the developed world during the $1980 \mathrm{~s}$ and 1990s is next examined. In its simplest form, neoliberalism is most concisely defined by Harvey (2005, p. 2) as follows:

Neoliberalism...proposes that human well-being can best be advanced by liberating individual entrepreneurial freedoms and skills within an institutional framework characterized by strong private property rights, free markets, and free trade. The role of the state is to create and preserve an institutional framework appropriate to such practices....Furthermore, if markets do not exist...then they must be created, by state action if necessary. But beyond these tasks the state should not venture. State interventions in markets (once created) must be kept to a bare minimum because, according to the theory, the state cannot possibly possess enough information to second-guess market signals (prices) and because powerful interest groups will inevitably distort and bias state interventions (particularly in democracies) for their own benefit.

In practice, the emergence of neoliberal governments at the beginning of the 1980s (e.g. the Thatcher government in the United Kingdom, followed by the Reagan administration in the United States), led to the rise of market forces in government decision making and policy formulation (Heaver and Waters, 2005; Strain, 2007). During this time, the global economic recession, combined with large budgetary deficits, 
high tax rates and deteriorating public satisfaction with government-provided services created a negative attitude toward the ability of the governments in general, and the public service in particular, to deliver core services (Pal, 1998).

From a theoretical perspective, neoliberalism is a widespread political movement in Western democracies. Peck and Tindall (2002) argued that neoliberalism has become an "ideological software" practiced by governments across national, regional and local levels. In their view, the main principles have included a reduction in the role of the state, a commitment to financial austerity, and sweeping operational reforms of the public service. Larner (2000) noted the anti-Keynesian aspects of neoliberalism through its preferences for pro-market activities such as deregulation and privatization. In addition, Keil (2009) highlighted research that suggested neoliberalism has become the dominant ideology in Western social life, implying "an increased intensity of capital accumulation processes, a reinforcement of exchange-value-oriented activities, general liberalization, [and] the strengthening of the coercive power of competition " (p. 232).

Despite the popularity of neoliberalism amongst the political elite, it is identified as a complex and poorly understood social theory. Clarke (2008), for example, observed three conceptual characteristics of neoliberalism. First, he argued that neoliberalism is "promiscuous," in that it is often applied to many different political and economic phenomena. In one instance, the term neoliberalism is applied to any political ideology that strives to assist certain social classes in profiting from globalization and accumulating capital over time. A second example of neoliberalism is applied to an ideology that encourages the accumulation of capital and the "economization" of society through market principles, such as privatization and deregulation. The third neoliberal 
case refers to policies that encourage individuals to self-govern and use "economic logic" in social decisions. An example cited for this view is the UK government's decision to classify the unemployed as "job seekers" in order to boost morale and provide greater incentives to retrain and re-enter the labour force.

Clarke's second characteristic of neoliberalism is that it is omnipresent within developed Western societies and developing post-Soviet states. According to Clarke, this implies that neoliberalism exerts as great a cultural dominance as the prominent paradigms of globalization or even colonialism. Contrary to these other paradigms, however, Clarke argued that neoliberalism places a lower degree of isomorphic pressure on countries to conform to its principles. Instead, he explained that neoliberalism is mobile ideology that adapts itself to the national, regional or local context of which it is applied. Neoliberalism is therefore widespread in nature but diverse in its application around the world.

The final characteristic of neoliberalism is that it is omnipotent, or is the primary reason for many aspects of political and policy success. For example, Clarke's cursory review of the literature uncovered a multitude of processes that identified neoliberalism as its founding ideology, such as managerialism, privatization, agenda setting and governance. He cautioned, however, that a complete analysis of neoliberalism's influence should consider its degree of dominance in determining the context in which it appears. In order to determine whether neoliberalism is relevant, Clarke recommended two considerations: first, would the practice or policy have existed without neoliberalism; and second, is the researcher able to deconstruct the idea and re-articulate it in neoliberal terms. In the latter case, Clarke advised that re-articulation of historical process like 
managerialism should consider the impact of neoliberalism on the internal composition of institutions and the external relationships with other stakeholders. Such a process is akin to the previously outlined procedure that examines macro influences (e.g. neoliberalism) upon micro aspects (e.g. organizational culture) and the resulting meso outcomes on public policies.

In light of the abovementioned characteristics, Larner (2000) outlined three broad interpretations to narrow the focus of analysis of neoliberal reforms. The first, and in Larner's view the most commonly employed concept is neoliberalism as a policy framework. According to this framework, neoliberalism involved a transition from the Keynesian welfare state to a pro-market society based on the globalization of capital. Specifically, the core of this concept includes, "the individual; freedom of choice; market security; laissez faire, and minimal government" (p. 7). Politicians such as Thatcher, Regan and Mulroney, as well as senior bureaucrats from Finance and Treasury departments played a central role in advancing this neoliberal framework. Larner cautioned, however, that the policy approach is weakened from its lack of theoretical vigour and ability to explain the widespread adoption of neoliberalism in the developed world.

In response to the shortcomings of the policy concept, Larner proposed another concept of neoliberalism that incorporates the sociological aspects of reforms. She argued that effective neoliberal political leaders, such as Margaret Thatcher, were able to adjust the components of neoliberalism to appeal to voters across many social classes. ${ }^{18}$

\footnotetext{
${ }^{18}$ Regarding the Thatcher example, Larner's (2000) research claimed that Thatcher was able to balance a so-called "pure" neoliberal, pro-market framework with traditional Tory values like family and patriotism.
} 
Such an approach is possible, in her view, due to the absence of a rigid neoliberal framework. As a result, this signalled that the dominance of one individual social class or rigid ideology had passed, and "that close inspection of particular neo-liberal political projects is more likely to reveal a complex and hybrid political imaginary, rather than...a unified and coherent philosophy" (Larner, 2000 p. 12).

The third notion discussed by Larner is neoliberalism as a form of governmentality. A key feature of this concept is that neoliberalism implies less government involvement in the economy but still requires a prominent role for governance structures (e.g., pro-market governance) among political and bureaucratic leaders. As an example, Larner explained that entrepreneurial and innovative strategies are required in many public institutions and largely focus on developing individual wellbeing. Aside from the pro-market role, government remains involved in financial aspects of society, such as through budgeting and accounting practices. Larner claimed that much of neoliberalism has focussed on broad governance themes and has not ventured into many detailed neoliberal projects in Western society. This concept is interesting to consider when examining the federal government's decision to devolve direct operations of ports and airports to local authorities but maintain ownership and establish a relatively similar non-profit authority governance model for all sites.

Neoliberalism in Practice: From 'Letting the Managers Manage' to the New Public Management

In addition, Larner suggested that the rise of lifestyle values, such women's rights, healthy living, and sexuality, raised the prominence of individual identity during in the 1980 s. 


\section{The Glassco Commission: An Early Attempt at Reform}

In light of the unprecedented growth in the federal government and its public service, concerns soon emerged as to the effectiveness of such a large organization in serving Canadians. In September 1960, the Progressive Conservative government of John Diefenbaker formally established the Royal Commission on Government Organization. The goal of the commission was to address the government's concerns that the public service had grown so large as to undermine the ability of the cabinet to set policy and control spending (O’Neal, 1994; Dwivedi \& Gow, 1999). The government also instructed the commission to research and identify potential areas where private sector practices could be applied to the public sector to achieve efficiencies and cost savings.

Chaired by the private sector accountant J. Grant Glassco, the "Glassco Commission" released its final report in July 1962. The report was the first public document to present a negative view of the public sector in general, claiming that "[g]overnment in modern society is often burdensome and restrictive .... [and] will seldom be viewed as better than a necessary evil" (Canada, 1962, p. 25). It further warned that "[t]he machinery of administration must be made most responsive to the wants and needs of the Canadian people" (Ibid). In short, Glassco recommended a substantial reduction in the power of central agencies to control and influence government decision making, and also argued in favour of greater authority to departmental managers to generate efficiencies, create accountability measures, and ensure greater value to taxpayers (O’Neal, 1994). Perhaps most famously, the Glassco Commission created the term "let the managers manage" to highlight the benefits of the 
devolved transfer of administrative authority of public services to those best suited to make decisions. This framework was nearly two decades ahead of neoliberalism and provided the initial seed from which transportation commercialization occurred.

\section{The Lambert Commission: An Ambitious but Naïve Exercise}

Despite the Glassco Commission's call for greater accountability mechanisms on public spending and increased discretionary power for line managers, it resulted in few concrete improvements to federal government operations (O'Neal, 1994). In addition to its policies to tackle inflation and the rising national debt and deficit, the Trudeau government also established the Royal Commission on Financial Management and Accountability in 1976. Chaired by prominent TD bank executive Allan Lambert, the "Lambert Commission" was tasked to develop ways of implementing financial control across all areas of government and to establish new mechanisms under which deputy ministers would be held more accountable to the government and even Parliament (O-Neal, 1994). The commission summarized the present challenges and need for urgent reform (Canada, 1979, p. 7):

[T] he unsustainable rate of growth of government and its complexity and size make it increasingly obvious that there needs to be greater care in the use of the resources that have been entrusted to government. Not only is waste to be avoided, but in the context of today's fiscal situation and the pervasiveness of government activity, mangers in the public service are being challenged to rediscover a sense of frugality and a commitment to the careful husbanding of resources.

Continuing the theme of "letting the managers manage" first highlighted in the

Glassco report, the Lambert Commission stressed the importance of sound fiscal management in order to lower the national debt and deficit and restore public confidence 
in government. It also encouraged a greater devolution of authority from central agencies to line departments to increase operational efficiency and enhance reporting to Parliament. Furthermore, the Lambert report cited the government's lack of adoption of the Glassco devolution recommendations as a significant lost opportunity to strengthen operational efficiencies within the public sector.

Contrary to the Glassco report, the Lambert Commission recommended increased accountability controls on departmental activities (O’Neal, 1994). In particular, the commission suggested the creation of five year departmental fiscal plans, accompanied by economic priority statements, which would be tabled annually in Parliament and revised accordingly each year. It also called for deputy ministers to be held accountable by the House of Commons Public Accounts Committee and for Ministers to report to the Treasury Board for financial performance of their departments. O'Neal claimed that these proposals were "hopelessly naïve, if well-meaning," as they failed to account for the political environment surrounding public sector decision making. Unfortunately, the Commission's work "had little, if any, impact at all on the structure, program delivery, or management practices in government" (O’Neal, 1994).

\section{The Mulroney Era: Neoliberalism with a Twist}

In the lead-up to the 1984 federal election, Brian Mulroney portrayed himself as a conservative on a mission to reform the federal government. During a much publicized speech in Toronto, Mulroney stated that he was "appalled by the waste of time and talent" in the federal government and promised to "spend smarter" and "eliminate program duplication and overlap" (quoted in Savoie, 1990, p. 163). 
During the election campaign, Mulroney pledged to give public servants "pink slips and running shoes" as part of his plan to make government more efficient (quoted in Lindquist and Paquet, 2001, p. 80).

At first glance it appears that Mulroney embodied many neoliberal attitudes and actions during his tenure as Prime Minister. Upon assuming office, one of the government's main fears was insubordination by a public service interested in protecting bureaucratic influence and establishing conditions for the Liberal Party's return to power (Aucoin, 1986; Savoie, 1990; and Lindquist \& Paquet, 2000). Mulroney responded by implementing several organizational changes at the political and bureaucratic levels (Ibid). Major reforms included the implementation of a chief of staff at every line department to provide policy advice to ministers and challenge senior bureaucratic advice, the announcement of layoffs of 15,000 public service positions in the 1985 budget, and the creation of several task forces ${ }^{19}$ designed to review major government programs and report on avenues for potential cost savings.

With respect to the administrative function of the government, the Prime Minister released a white paper in December 1990 that challenged the public service to become more accountable and service-oriented to Canadians. Entitled Public Service 2000: The Renewal of the Public Service of Canada, the white paper instructed the Clerk of the Privy Council, Paul Tellier, to modernize the public service by "by cutting red tape,

\footnotetext{
${ }^{19}$ Perhaps the most well-known of the Mulroney-era task forces was the 1984 Nielsen Task Force on Program Review. Despite its intentions to conduct a major review of federal spending, Lindquist and Paquet (2000) claimed that "[t]he impact of the Nielsen exercise was insignificant, and few recommendations were adopted at that time" (p. 81). In addition, the Nielsen Review did not focus on possibilities for reform of transportation assets and governance. As a result, it is beyond the scope of this thesis and is omitted from further analysis.
} 
providing better training and shifting resources from administration to the delivery of programs" (Canada, 1990). The themes of greater accountability and a more clientfocused service closely mirrored the principles of the Glassco and Lambert commissions, with the exception that the new review was headed by a public servant ${ }^{20}$ and not a private sector administrator.

Contrary to the Glassco and Lambert commissions, Public Service 2000 led to an adoption, at least publicly, of neoliberal principles in the public service. In his 1992 progress report to the Prime Minister on the state of reform from the review, the Clerk stated an ambitious goal of where he saw the public service in the year 2000 (p. 3) [bold emphasis added]:

$[\mathrm{M}]$ ost important, it will be led and managed in a new way: one that is more oriented to service and to results and much more aware of the importance of individual initiative in contributing to improvements and efficiencies.

Some of the major reforms to come out of Public Service 2000 included a downsizing of the executive cadre for senior management, clearer delegations of authority between ministers and deputy ministers, and a streamlined staffing process with the introduction of the Public Service Employment Act in 1991 (Canada, 1992).

Further research into the performance of Mulroney as Prime Minister reveals that he was not as committed to neoliberalism as his counterparts in other countries. Aucoin (1986) argued that Mulroney's background as a private sector labour lawyer taught him

\footnotetext{
${ }^{20}$ It is worth noting that although the head of the Public Service 2000 review, Paul Tellier, was a public servant, he consistently displayed a preference for private sector principles in the federal public service. This will be discussed in more detailed in Chapter Three on the privatization of CN Railways.
} 
"that political leadership is about the accommodation of interests and not the interplay of ideas" (p. 17). In his view, Mulroney regularly engaged in "brokerage politics" with interest groups and even his Cabinet colleagues in order to maintain personal control of major political decisions. In Aucoin's view, Mulroney's preferences for accommodation were a clear violation of the core neoliberal principles of individualism and a minimal role of the state in society, which were regularly practiced by Thatcher and Regan during the 1980s.

Strain (2007) offered further reasons why Mulroney shunned a completely neoliberal approach to governing. In addition to his legal experience, Mulroney was not a political ideologue when compared to Thatcher or Regan. Rather, "[h]e believed that the state had an important role in society and the objective of governance was to strike the right balance, with the state and the private sector knowing their respective roles and playing them differently" (p. 44). Furthermore, Stone argued that the Progressive Conservatives were faced with a significant deficit that commanded significant attention from Mulroney and his Minister of Finance. Consequently, the government was unwilling to engage in riskier ideological reforms, such as major tax cuts, which Reagan had implemented in the United States but had proven unsuccessful.

Much to the surprise of the governing Progressive Conservatives, the federal public service was largely amenable to public policy reform during the Mulroney era. Aucoin (1988) offered several reasons for this occurrence. For example, many senior bureaucrats were eager to portray themselves as nonpartisan and welcomed the opportunity to pursue a noninterventionist approach to policy following two decades of Liberal governance. In addition, bureaucrats welcomed deregulation as an opportunity to 
streamline operations and focus on the essential priorities of their departments. This streamlining of the policy decision making process also involved the reduction or elimination of many central agency requirements, which was welcomed by most senior bureaucrats in line departments.

The Chretien Era: Rise of the New Public Management

The neoliberal movement brought dramatic changes to the ways in which the public sector conducted policy analysis and delivered programs. Throughout Western society, politicians responded to public criticism by promising that governments would adopt innovative ways of doing things, such as commercializing many government services to encourage private sector delivery, as well as reviewing other government functions to ensure efficiency and involvement from other stakeholders through partnerships (Pal, Ibid). These approaches became known as the new public management and spread to all areas of government policy making and program administration.

As was the case with the need for national debt and deficit control, the origins of the NPM movement in Canada took place well before the emergence of neoliberalism. The Glassco Commission stressed the need to "let the managers manage," while the Lambert Commission emphasized the need for greater accountability in program delivery and the devolution of authority away from central agencies to line departments. Even social progressives, such as Pierre Trudeau, recognized the need for the federal government to focus on core priorities and withdraw from policy areas not within the health and social policy spheres. 
From an academic perspective, NPM is recognized as an "eclectic approach" to public administration with no specific definition (Gow, 2009). Despite such a myriad of ideas, Dwivedi, Mau and Sheldrick highlighted five key NPM elements identified in the literature (2009, pp. xxxii-xxxiii):

(1) accent on results, both in planning and in evaluation of programs and people;

(2) service to the public, with a special concern for quality, citizen as a client;

(3) delegation of authority as close as possible to the level of action, and empowerment of employees;

(4) greater attention to cost through comprehensive auditing, contracting out, and introduction of competition; and

(5) private sector techniques for motivating employees, such as merit pay, mission statements, and quality circles.

Advocates of NPM reforms encouraged a smaller role for the state, balanced budgets, more effective administrative techniques, as well as client-focused services similar to those in the private sector (Charih and Rouillard, 1997).

The federal government was no exception to the NPM movement and adopted several measures that altered the policy landscape. Cheung (1997) noted that the Canadian government was active in decentralizing assets and services to regional and local organizations during the 1990s. However, from an administrative perspective, he argued that federal administrative reforms were limited to modifying existing rules and procedures, such as streamlining and unifying services across line departments.

Although modest when compared with NPM reforms in other countries, Dwivedi, et al. (2009) claimed that the NPM movement played a significant role in the elimination of the federal deficit and eventual return to budgetary surplus during the 1997-98 fiscal year. 
It is important to note, however, that the NPM movement has not advanced without significant criticism from academics and policy professionals. From a theoretical perspective, Maor (1999) claimed that NPM reforms aimed at devolving operations from central governments to arm's-length organizations may have the unintended consequence of creating greater political interference in operational and hiring decisions of the new agencies. According to the paradox, political executives (e.g., staffers and ministers) lose control of the steering function under NPM as it becomes the purview of new local agencies. Politicians respond by pressuring senior bureaucrats to interfere in the operations of newly devolved agencies, especially with respect to hiring decisions of senior managers. In Maor's view, such an approach undermines the independence of the new organization and jeopardizes the original intent of greater accountability from NPM reforms.

Within Canada, Savoie (1995) provided a detailed critique of the NPM movement in Canada, arguing that the abovementioned NPM themes were "basically flawed" and that the Canadian response over the 1980s and 1990s was much more tepid than in other Westminster countries. In particular, Savoie claimed that applying the philosophy of client-focused service to the public sector overlooks the important social distinction between businesses providing return for shareholders (i.e., profit) and governments providing services for the public good (i.e., social assistance, regional development). He also emphasized that the federal public service had been unfairly targeted as the source of inefficiency and waste by politicians, while the root of the problem lies in the institutional factors of ministerial responsibility, such as the increased power of the Prime Minister's Office and the federal cabinet. 


\section{Historical Institutionalism}

Another major theory employed in this thesis is the historical institutionalism approach developed in the political science literature. Traditionally, historical institutionalism approaches have been applied to describe institutional changes arising from a major policy shift that adjusts the sequencing of future events. Furthermore, a thorough analysis of significant policy changes requires careful consideration of the institutional circumstances and actions of all major stakeholders that led to a decision. Sanders (2006, p. 39) noted that "to understand the actions of all these political players, one must take cognizance of the historical development of the institution, and the original, distinct culture and problems in which it arose."

The first step in an historical institutionalism analysis is to search for "empirical puzzles" that arise from past political decisions (Thelen, 1999, p. 373). As part of this process, the timing and sequencing of events is considered using the concepts of path dependence and increasing returns. According to path dependence theory, when a government changes course with a new policy direction, the costs (e.g., political, financial) of moving to another course of action are very high and are thus unlikely to occur (Pierson, 2000a). In other words, the new policy path is essentially "locked in," forcing stakeholders to adapt to the current policy framework (Thelen, 1999, p. 385). In recent years, political scientists have borrowed the economic concept of increasing returns to further emphasize the power of path dependence models to predict future political decisions. As an example, Pierson highlighted the increasing returns concept as one where "the probability of further steps along the same path increases with each move down that path" (2000a, p. 252). In Pierson's view, these two theories together implied 
that major political decisions could have lasting consequences and remain in effect for significant periods of time. Such is the strength of the path chosen that only "exogenous shocks" to the system can alter the current path and launch a new policy direction.

Once the decision path has been identified, the next step is to investigate the key components of a policy's development. In this situation, the analyst attempts to establish the "critical junctures" in the new path that arose due to exogenous shocks to the system (Thelen, 1999). As part of this process, Thelen noted the importance of timing for a policy change and the sequencing of subsequent events. In particular, the actions of the individuals are examined to determine the impact of their behaviours upon the new policy's growth. Although the critical junctures approach explains the circumstances of time in which a new policy direction is taken, it is unable to explain the sustainability of the new path. Consequently, Thelen argued that feedback mechanisms occur within the new path to ensure the "logic" of the new approach is understood and followed. As a result, the new institutional structure indirectly serves as a set of rules that are obeyed by policy stakeholders. It is important to note, however, that Thelen emphasized how similar policy decisions adopted in different jurisdictions (e.g., provinces or countries) may lead to a variety of path dependent models and outcomes. These differences are mainly due to underlying distinctions in political and cultural traditions that lead to unique policy trajectories within each system.

Falleti and Lynch (2009) also recommended historical institutionalism as the primary system of analysis for examining historical policy change. The authors emphasized that identifying the beginning of a new policy period is crucial to determine a shift in one context to the next. The turning point where a causal mechanism begins to 
impact a process is known as a critical juncture. Falleti and Lynch argued that critical junctures receive insufficient analysis in current academic research, which leads to incomplete and/or incorrect information when causal analysis occurs at a meso or macro level.

According to Falleti and Lynch, the last 10 years have witnessed an increased attention to critical junctures in the historical institutionalism literature. They claimed that this has resulted in a higher quality of historical analysis, as researchers have provided greater focus on the context surrounding period of change (i.e., the critical juncture). Examples of new methods to examine breaks between policy contexts include considering exogenous shocks, emergence of new institutions, and the discovery of indirect, independent variables. Furthermore, there may also be many layers of context and multiple causal mechanisms influencing policy change. It is also possible for each contextual layer to interact with other layers in a behaviour known as policy drift. In theory, each contextual policy layer could develop at different rates and points in time, implying that consideration of only one context behind a policy change risks omitting key explanatory evidence.

\section{Falleti's Theory of Sequential Decentralization}

From a macro perspective, Falleti's $(2005,2010)$ framework is built upon the contribution of intergovernmental relations in explaining major economic and political reforms. According to Falleti, the literature on decentralization has been dominated by the contribution of partisan and electoral interests in major public policy reforms. Contrary to these models, Falleti's framework focused on the influence of 
territorial interests to the development of policy outcomes. She defined territorial politics "as the set of conflicting territorial interests among levels of government and geopolitical units, as represented by political and societal actors in a given conflict or bargaining process" (2010, p. 32). By establishing the territorial assumption, both horizontal and vertical analysis is possible to examine the relationship between policy stakeholders and the interaction of various levels of government.

Falleti's framework of decentralization is composed of three major elements. The first aspect concerns the identification and definition of decentralization as three types: administrative; fiscal; and political (2010, p. 17). Administrative decentralization is defined as "the set of policies that transfer the dispensation of social services (education, health, housing, etc.) to subnational governments." Fiscal decentralization are policies "designed to increase the revenues or fiscal authority of subnational governments," whereas political decentralization involves "constitutional or electoral reforms designed to devolve political authority to subnational actors and to create or activate spaces for the political representation of subnational polities" (2010, p. 17).

Several points must next be qualified with respect to the three forms of decentralization. Under administrative decentralization, Falleti claimed that downloaded services to subnational governments that are unaccompanied by financial support are referred to as unfunded decentralization reforms. On the other hand, the inclusion of finances from the centre to support the cost of operating the downloaded program is known as funded decentralization. Falleti argued, however, that funded administrative decentralization is not equivalent to fiscal decentralization, as the former assists with the expenditure side of program operations, whereas the latter refers to mechanisms to permit 
subnational governments to raise revenue through policies such as taxation ${ }^{21}$. Falleti's definition of political decentralization encompasses more than the traditional definition of providing greater legislative representation to subnational groups and includes constitutional amendments that increase the autonomy of subnational groups.

The second aspect of Falleti's model concerns the bargaining activities of territorial interests in the policy reform process. Falleti distinguished between partisan interests and territorial interests in this component. ${ }^{22}$ Partisan interests of stakeholders are identified by membership in political parties or expressed ideologies in the form of support for governing or opposition policies. In contrast, territorial interests refer to the level of government that each policy actor represents or supports, and may also be further subdivided into demographic groups and coalitions involved in the decentralization process, such as the national executive, national legislators, local mayors, state governors, regional associations, unions, and private sector associations.

The final aspect of the decentralization model concerns the preference ordering of territorial interests and the subsequent sequence of policy reforms. A central component of Falleti's framework is that decentralization occurs as multiple layers of policy change. In particular, the first layer of reform is crucial to determine the remaining steps of the reform process. Furthermore, Falleti argued that each territorial interest has a unique

\footnotetext{
${ }^{21}$ Falleti (2010) noted that lump-sum transfers from the central to subnational governments would fall under fiscal decentralization, as they are not tied to specific administrative programs.

${ }^{22}$ Falleti claimed that partisan and territorial interests are interrelated, with partisan interests favouring ruling or opposition policies at a given level of government, and territorial interests supporting the national or subnational government for a given policy issue. As a result, four types of stakeholders therefore emerge: ruling-national; ruling-subnational; opposition-national; and opposition-subnational.
} 
preference ordering for decentralization in the first layer of reform. For example, Falleti predicted that national governments generally prefer administrative decentralization to subnational governments over fiscal and political alternatives, as administrative reform divests expenditure responsibilities to subnational governments while maintaining revenue powers for the central government. Political devolution is the least preferred option among national governments due to their desire to maintain legal control over subnational units as much as possible. This scenario is valuable in potentially explaining the federal government's decision to divest day-to-day operations and financial responsibilities to local port and airport authorities while continuing to maintain ownership and accrue rents from the non-profit authorities.

The opposite preference ordering in the first layer of reform occurs when analysed from the subnational perspective. According to Falleti, subnational entities prefer political decentralization, followed by fiscal and administrative alternatives. Political decentralization in this situation would involve legal and/or constitutional legitimacy for a subnational government or agency to operate and take advantage of local authority and control. It follows from this reasoning that a subnational government that receives legal control would most likely demand fiscal decentralization as the next step in reform, given that it has absorbed a significant portion of jurisdictional responsibilities. ${ }^{23}$

Given that present day policy making is much more complex than simple national-subnational government activities, Falleti expanded her model to include six

\footnotetext{
${ }^{23}$ To use Falleti's terminology, the majority of Canada's large airports have recently argued that administrative decentralization (i.e., devolution) was in practice a de facto political decentralization and should be followed by greater fiscal decentralization (i.e., more transfers and/or lower rents). This issue is further discussed in the concluding chapter as part of the discussion on areas for future research.
} 
possible coalitions of territorial interests. The 'national-level coalition' is composed of members from ruling and opposition parties at the national level that agree on the same partisan issue. The 'subnational coalition' involves similar ruling and opposition partisan interests but takes place at the subnational level. The 'ruling coalition' includes the national and subnational ruling parties that agree on the same partisan issue, whereas the 'opposition coalition' is composed of national and subnational opposition party members who share the same partisan issue. Two mixed coalitions are also possible, the first between the national ruling party and the subnational opposition party, and the second between the national opposition party and the subnational ruling party.

Following the development of preference models for each level of government, the next step of the final aspect is to hypothesize the sequence of each decentralization reform. Falleti argued that most decentralization reforms include more than one reform (but not necessarily all three) at different points in time. The timing and context of each reform provides further information as to the sequence of possible decentralization combinations within each case study. Consequently, Falleti stressed that stakeholder preference choices in the first round of reform creates circumstances that influence the behaviour observed in the second stage, as part of an overall path dependent model. An example of path dependent behaviour is a subnational coalition with strong preferences in the first round that successfully lobbies the national government for political decentralization. The subnational group receives greater political power from the transfer of authority and demands more powers from the centre, which in turn leads to fiscal decentralization in the second stage of reform, followed by administrative decentralization in the final sequence. This type of process is known in the literature as 
the "policy ratchet effect," whereby circumstances create self-reinforcing mechanisms that advance the preferences of the dominant stakeholder(s).

Falleti claimed that the reverse process would prevail in circumstances where the national government displayed the strongest preferences in the first round of reforms. A dominant central government would implement administrative decentralization in the first round for reasons discussed above. Assuming the administrative reforms such as commercialization were unfunded, the centre would prefer fiscal decentralization over political reforms, as political control would continue to permit the national government to exercise jurisdiction over a subnational entity as desired. Similar to the policy ratchet effect, the culmination of momentum towards increasing national dominance of reforms is known as the "power reproduction mechanism," which operates "by promoting institutional changes to enhance power, and defending from encroachment by outsiders" (Stinchcombe, 1968, pp. 177-78 in Falleti, 2010, p. 57). ${ }^{24}$ It follows from the previous discussion of the federal government's preference for administrative reforms that this proposed administrative-fiscal-political process is a candidate to best describe the devolution process of airports and ports in Canada.

In situations where no dominant preferences emerge in the first round, Falleti argued that the next-best outcome of fiscal decentralization will be the likely outcome for

\footnotetext{
${ }^{24}$ It is also noteworthy that reactionary behaviours are possible in the second layer of reform that may alter the original preferences and intended sequence from the first round. For example, national governments may dislike the resulting impact generated from political decentralization to subnational interests in the first round, leading to administrative decentralization in round two, followed by fiscal decentralization. On the other hand, subnational territorial interests may react negatively to the national government's administrative decentralization in round one and create pressure that leads to political decentralization in the second round, followed by fiscal decentralization.
} 
both national and subnational entities. In cases where national preferences emerge as the dominant factor in the second round, administrative decentralization is likely to occur, followed by political reform in the final stage of reform. Similarly, if subnational interests prevail in the second round, the framework predicts political decentralization to occur, followed by administrative devolution. ${ }^{25}$

\section{Stone's Theory of Political Behaviours in Policy Making}

An important next step in the macro analysis is to consider the broad political factors involved in public policy making. According to Stone (1988), many policy decisions result in paradoxes that are not easily explained by traditional theories such as rationalism (discussed below). The main explanation for this outcome, in Stone's view, is that the policy environment is inherently political and does not follow the logical steps outlined by rationalist theory. Consequently, she proposed a new model that uses political reasoning to explain policy paradoxes and to further support her view that rationalism is insufficient in explaining policy development.

Stone introduced a model of policy making that is influenced by the political community, or polis. According to Stone (1988. p. 13), "A theory of politics must start with a model of political society, that is, a model of the simplest version of society that retains the essential elements of politics." She therefore presented 10 elements, or characteristics of the polis that are instrumental in the development and implementation of public policy and are summarized below (1988, p. 25):

\footnotetext{
${ }^{25}$ It should be noted that these sequences are based on Falleti's assessment of Latin American reform and are not offered here as a prediction of event sequencing for transportation commercialization in Canada.
} 
1. It is a community.

2. It has a public interest, if only as an idea about which people fight.

3. Most of its policy problems are commons problems.

4. Influence is pervasive, and the boundary between influence and coercion is always contested.

5. Cooperation is as important as competition.

6. Loyalty is the norm.

7. Groups and organizations are the building blocks.

8. Information is interpretive, incomplete, and strategic.

9. It is governed by the laws of passion as well as the laws of matter.

10. Power, derivative of all the above elements, coordinates individual intentions and actions into collective purposes and results.

The characteristics of community, public interest, commons problems (numbers one, two and three in the above list) are relatively straightforward concepts and are not directly relevant to this thesis. The remaining seven are now briefly summarized in turn. First, Stone argued that influence is one of the most powerful elements in the polis, and includes many aspects ranging from education and persuasion to coercion. Next, cooperation refers to the coalitions and alliances formed among interest groups that are constantly striving to seek and maintain power. Similar to cooperation, loyalty involves alliances among groups or within organizations; however, Stone argued that loyalty results in strong friendships that are not easily broken and requires significant change for 
new loyalties to be made. ${ }^{26}$ As a result of interest, cooperation and loyalty, Stone argued that collective groups are formed to become the most important building block of the polis. Prominent examples of groups to be analysed within this thesis are senior members of the bureaucracy involved who were directly in transportation commercialization, unions, and the national electorate.

The next element in Stone's policy is information, which is considered imperfect, incomplete, vulnerable to multiple interpretations, and subject to strategic manipulation. The most emotional of Stone's characteristics is passion, which refers to the increased level of satisfaction and commitment that individuals experience when they work towards a certain goal. Similar to the loyalty concept, it is difficult to break the status quo and entertain new ideas and procedures the longer a group has worked together. All of these elements culminate into Stone's final component of power, which is the quest to subvert individual self-interest to the preferences of the polis. The impact of various political behaviours upon resulting power distributions within the polis is next examined.

\subsubsection{Meso Foundations}

The Physiology of the Federal Public Service

The analysis of institutional change in transportation governance reform would be incomplete without consideration of the "physiology" of the federal public service. The term "physiology" was first used in the context of the federal bureaucracy by Hodgetts (1972) to provide a comprehensive historical analysis of the federal public service from

\footnotetext{
${ }^{26}$ Although not explicitly stated by Stone, the loyalty aspect is very similar to the "locked-in" characteristic of the path dependence concept previously discussed.
} 
1867 to 1970. Linquist (2009) noted that one of Hodgetts' key recommendations was that analysis of institutional change should focus on four factors: policy decision-making, interactions within the bureaucracy and between the public service and the general public, internal bureaucratic survival processes, and bureaucratic accountability mechanisms.

An important aspect of Hodgetts' analysis for this thesis is his emphasis upon historical and environmental parameters when investigating institutional change within the federal public service. In particular, Hodgetts hypothesized that the federal public service would evolve to alter its internal structure as a result of changing internal and external circumstances (Lindquist, 2009). In other words, the historical and behavioural characteristics of the public service play a crucial role in how bureaucrats make decisions affecting their survival and natural evolution. As a result, theories such as historical institutionalism and the sequencing of policy reforms provide a powerful lens through which to analyse federal transportation reforms.

\section{Challenges to Strategy Development}

Despite the potential power of deliberate and emergent strategies to model public sector decision making, there exist many challenges in the organizational structure and surrounding policy making environment that threaten effective strategic development. First, Mintzberg and Jorgensen (1987) argued that Canada's public sector was developed in a time when policy making was much simpler with a narrower focus than today's complex policy making environment. As a result, they explained that today's system is largely structured along a traditional, rational planning approach that favours deliberate processes and suppresses emergent strategies. They concluded that such a system 
dominated by deliberate strategies hinders innovation within the operational ranks of the bureaucracy and is reinforced through comprehensive and process oriented requirements of central agencies.

The argument that the public service naturally suppresses change is supported by theories governing the principles of merit and tenure security of the bureaucracy. Many Western bureaucracies, including Canada, have hired bureaucrats based on expertise and awarded tenured employment in exchange for nonpartisan service to the government in power (Maor, 1999). Despite the perceived benefits of tenured service, many academics have questioned the efficiency of such practices. Downs (1967), for example, claimed that the degree of risk averseness increases with the rank of senior bureaucrats. This implies that senior managers in public organizations tend to avoid changing policies, claiming that current rules were established through legislation and should not be amended (Maor, 1999). Combining this hypothesis with the Weberian view that tenure leads to bureaucratic self-interest, Downs argued that "[t]he longer an official has been in a bureau, the more he has been exposed to the difficulties and frustrations of trying to change its behavior, hence the less optimistic he is likely to be about achieving future changes" 27 (1967, p. 99).

Second, Rose and Cray (2010) claimed that the election cycle of a four to five year majority mandate implies that there is only a short window through which political masters are willing to adopt controversial or dramatic policy initiatives recommended by

\footnotetext{
${ }^{27}$ This hypothesis is contrary to the public choice theory of bureaucratic behaviour, which claimed that senior bureaucrats are motivated to adopt new policies based on maximizing their self-interest. For more information, see Simard's (2004) summary of Niskanen's view of the budget maximizing bureaucrat.
} 
the public service. Once this window closes, the governing political party tends to focus efforts solely on activities that would maximize the potential for re-election. This concept is explored further detailed below on Kingdon's theory of policy windows.

A third obstacle is that new ministers appointed to departmental portfolios tend to have little to no knowledge of the subject matter under their responsibility. Mintzberg and Jorgensen noted that many ministers also have little time to devote to decision making within their department due to responsibilities to cabinet and the governing political party. Consequently, they delegate responsibility to political staffers or "whiz kids," who are usually well versed in current legislation and procedures but often lack experience in solving policy issues. In the authors' view, these staffers “operate based on the illusion of comprehension and of being in control," which promotes deliberate strategies and discourages learning and thus emergent strategies (1987, p. 227). In addition, Rose and Cray emphasized that such a situation implies that a potential for time lags between the time that bureaucrats propose new ideas and the minister renders a decision. In some cases, the abovementioned window of opportunity to implement a new idea may have closed during the time for ministerial deliberations and the initiative has failed to be implemented. Mintzberg and Jorgensen thus lamented, "[i]t is the supreme irony of the system ... that those often best able to learn are precluded from involvement in policy-making, which is left to those who are often the most removed from the situation (p. 228).

A fourth difficulty encountered by public managers is when the priorities of the public (and presumably the public service) are not in line with those of the political leadership within the government. Consequently, Rose and Cray claimed that public 
servants must be cognizant of political realities when formulating strategies, in particular the roles and influences of political interest groups closest to the government, to ensure that proposed policies receive a high likelihood of support. Failure to identify the political considerations of proposed initiatives could result in delays in policy implementation and/or rejection of policy proposals.

Another added complexity for public managers is the difficulty in identifying the target audience, or what Rose and Cray termed the "customer," of individual policies. Potential organizations in addition to political interests that vie for attention in policy development include other federal departments and central agencies, other orders of government, the media, socio-economic lobby groups, industry associations, multinational corporations, domestic and international non-profit organizations, as well as foreign governments.

\section{Kingdon's Theory of Policy Windows}

In order to perform an in-depth examination of the meso-level implications of transportation reform, the next theoretical component includes Kingdon's theory of agenda setting. According to Kingdon (1984), government decisions are formed out of the union of problem, political, and policy streams. The problem stream involves the identification of various issues in society as worthy of government attention. Methods such as quantitative indicators of socio-economic activity, national or international crises of varying degrees, as well as feedback received from the general public on government performance all contribute to the emergence of policy matters on the government's agenda. In Kingdon's (1984) view, government decisions result not only from political factors, but also from problem and policy factors. 
The political stream includes the behaviours and interactions of politicians as they vie for support from the general public to attain and preserve political power. Kingdon argued that the "national mood" is very influential in this category, as politicians strive to enact decisions they believe will garner the greatest support. Politicians also engage in bargaining amongst themselves and with interest groups in this stream, as concessions are frequently made to acquire enhanced political collaboration.

The policy stream refers to the sets of ideas conceived by those in the decision making process, including interest groups, politicians, academics and the general public. These ideas and proposals float around in what Kingdon described as the "policy primeval soup," whereby ideas for policy problems exist in multiple combinations and frequently change over time to match political and economic realities.

The crucial aspect of Kingdon's model is that policy windows must open for an idea to become reality. According to Kingdon, policy windows occur infrequently and are of two types. The first category, problem windows, transpires when a major public policy situation occurs and a new idea has already been developed by a policy stakeholder and is ready to be implemented. An example would be a national currency crisis that surprised policy makers and led to the implementation of a currency union with a neighbouring country, as suggested by an economic policy think-tank. The second category, political windows, traditionally occurs when a new political party is elected to power and welcomes the introduction of new ideas that match their political ideology. An example is the significant privatizations of government assets in the United Kingdom during the neoliberal Thatcher era of the 1980s. 
Once a policy window opens, Kingdon emphasized that considerable effort is required for an idea to become policy. The key criteria to complete the process is what Kingdon described as a joining or "coupling" of the problem, political and policy streams by "policy entrepreneurs" [i.e., this is the true meso integration of micro and macro]. These entrepreneurs are policy specialists, usually but not always located on the inside of government, who have taken a primary interest in a policy and have prepared one or multiple possible implementation scenarios in the event of a policy window opening. They work diligently to take advantage of policy windows, such as bringing together politicians of similar policy interests, and attracting media attention to an issue. Kingdon therefore stressed that new ideas are not implemented randomly, as policy entrepreneurs greatly increase the probability of a new idea materializing upon the opening of a window.

\subsection{Overview of Competing Theories of Public Policy Change}

\subsubsection{Rationalism}

Rationalism is one of the oldest theories to attempt to model public sector decision making. According to Hayes (2007), rational decision making "evokes a vision of policy makers clearly defining objectives and making value-maximizing choices after a thorough examination of relevant alternatives" (p. 39). In other words, rationalism benefits from a form of "scientific precision" that leads efficient policy decisions (Kernaghan and Siegel, 1995). In Hayes' view, the rationalist model contains three key steps. First, policy makers unanimously and accurately identify and rank public policy problems in order of importance. Second, policy makers must agree to share the same 
priorities. Of particular reference to this thesis, Hayes cited one sub-assumption that all policy makers must agree to trade-offs when allocating limited financial resources. Third, rational policy makers are assumed to precisely determine the consequences of choosing one policy option over another.

Despite its appealing characteristics of near omniscient policy making, the rationalist model has received much criticism in the literature. From a values perspective, Kernaghan and Siegel argued that the diverse nature of policy making renders it practically impossible for a representative bureaucracy to rank values, attitudes and opinions according to predetermined priorities. Furthermore, Hayes claimed that most policy priorities are determined through pressure exerted upon the bureaucracy by political masters or strong pressure groups, leaving bureaucrats to implement outcomes regardless of their personal preferences. Similar circumstances hold for financial issues, where Hayes emphasized that financial pressures prevent universal agreements within governments, as money spent in one area results in less available resources for other priorities. A relevant example for this thesis was the abovementioned continuous quest of governments to tame the national debt and deficit from the late 1970s to the mid1990s. Consideration of the impact from the elimination of major programs, especially during Budget 1995, ranked a distant second behind the determination to reduce deficit expenditures.

The key failure of rationalism in the context of this thesis is its inability to account for political behaviour in policy making. As mentioned above, Stone (1988) claimed that policy decision making is inherently political and does not follow the logical steps required by rationalist theory. The closest Canadian example of rationalism in 
federal policy making was Aucoin's (1986) analysis of the Pierre Trudeau era. In Aucoin's view, Trudeau incorporated a largely non-ideological approach to politics based upon reason and not emotional partisanship. In addition, Aucoin claimed that Trudeau favoured organizational leadership in the form of collective decision making with his cabinet to prevent a monopolization of ideas and abuse of authority.

From the perspective of transportation policy, however, Trudeau's governance behaviour did not follow rationalist principles. Trudeau's abovementioned decision in 1978 to unilaterally cut government expenditures by $\$ 2.5$ billion and shift the focus of federal influence to the core areas of health and social policy was made without consultation of his cabinet or senior bureaucrats. This event is a clear challenge to Aucoin's rationalist assertions and demonstrates that political influence trumps the principles of rational decision making when federal expenditures, particularly national deficits, are concerned. In policy cases such as the divestiture and devolution of transportation assets, the huge burden on public expenditures resulted in responses that were highly political, emotional and partisan, which rendered rationalism powerless to explain reforms.

\subsubsection{Marxism}

Another traditional theory of public decision making employed in the social sciences is Marxism. Based on the writings of the $19^{\text {th }}$ century philosopher Karl Marx, Marxism claims that the interests of the state are directed towards satisfying the ruling or dominant classes in capitalist societies (Kernaghan and Siegel, 1995; Eisenschitz and Gough, 1998; Collyer, 2003). The government, or more specifically its administrative arm, the bureaucracy, is designed to exploit the wealthy ruling class at the expense of the 
middle and lower social classes. The eventual result is a proletarian uprising that will in turn create a classless society (Ibid).

Although Marx did not extensively consider the role and influence of public bureaucracies, modern-day proponents, termed neo-Marxists, have argued that the primary goal of bureaucrats is serving the interests of the capitalist class. For example, neo-Marxists have theorized that senior bureaucrats hold personal ties to members of the ruling wealthy class and strive to promote policies that would benefit the capitalist economy (Kernaghan and Siegel, 1995). Some "pure" neo-Marxists have taken the analysis further and argued that bureaucrats "are simply puppets whose strings are pulled by the members of the elite" (Hill, 1991, p. 279).

From the analysis presented in this thesis, however, Marxism is an insufficient theory to model the devolution of federal transportation assets. First, as part of his academic review of the discipline, Gow (2009) claimed that Marxism has yet to be employed by Canadian public administration scholars, and has instead been a tool used by political scientists and sociologists to analyse wealth formation. Second, Collyer (2003) has concluded that Marxism is a little-used and overall poor theoretical framework to model the transfer of public assets in processes such as privatization. In cases where Marxists attempted to use their framework to model privatization, he claimed that they presented the process as the secretive sales of public assets that encourage selfprovisioning and an increased domestic burden placed on women and families. This thesis presents many examples that demonstrate significant public, political and bureaucratic support for the privatization of transportation assets in Canada over the 1975 
to 2000 period, all of which cannot be explained by the Marxist assumptions of privatization.

In general terms, the majority of events surrounding the devolutions examined in this thesis do not follow the general prescriptions of Marxism. When port and airport divestitures in Chapters Four and Five are considered, it is clear that the need for infrastructure investment combined with the federal government's preference to reduce total expenditures drove commercialization reforms. In these cases, the federal government and most of its transportation stakeholders were in agreement that the assets should remain under public ownership and not be fully transferred to the private sector. Marxism fails to account for such a preference, and it is clear that the bureaucratic support for changes is contrary to Marxist assumptions of a pro-market, anti-reform prejudice.

\subsection{Conclusions}

\section{Relationship between Political Leadership and Bureaucratic Responsiveness}

An underlying theme occurring throughout this chapter and the subsequent modal analysis is the relationship between the political leadership (e.g. ministers) and the public service (e.g. senior bureaucrats) during the period studied. The political-bureaucratic dynamic is largely understudied within the academic literature and little information is known to the general public. As a result, the most useful method of research is to consult relevant writings from former ministers and senior bureaucrats in order to analyse this organizational dynamic. In its simplest terms, the relationship is best described through 
three principles by the former Clerk of the Privy Council and Senator, Michael Pitfield as follows (summarized in Robertson, 1983, pp. 11):

$[\mathrm{I}] \mathrm{t}$ is the politicians who make the final decision on policy; that the public servant provides objective advice and support; and, thirdly, that 'in order to make the two previous principles work, the public servant must remain silent,' neither disagreeing with nor partisanly supporting his Minister and government.

Robertson (1983) argued that primary bureaucratic responsibility for maintaining this dynamic rests with the Deputy Minister of each department. He summarized such a responsibility as a difficult balance between providing objective advice and avoiding politically sensitive issues (p. 12):

It is his duty to point out the traps he sees in the path he urges the government to follow, and equally to warn of any traps he perceives on a road they may want. Such advice is not always gratefully received, especially if it appears to be raising obstacles to policies to which a party or Ministers may have committed themselves in the heat of an election campaign. A new government may see such warnings as rigidity, lack of cooperation or even deliberate frustration of their mandate....The line between 'support' and 'partisanship' is fine indeed. ${ }^{28}$

As illustrated in this chapter, political-bureaucratic tensions first publicly emerged with the release of the Glassco Commission in 1962. Prime Minister John Diefenbaker struck the Commission due to his fears that the public service was becoming too large to be held accountable by Parliament and the Cabinet. One of the commission's main recommendations was that greater policy and management responsibility be devolved

\footnotetext{
${ }^{28}$ From a political management perspective, another lens from which to examine the politicalbureaucratic dynamic is to consider the role and/or duty of ministers and their political staffers in providing political stewardship and direction to senior bureaucratic management. This politically sensitive and controversial issue is further discussed in Savoie (2003).
} 
from central agencies to managers in line departments in order to provide greater efficiencies and transparencies to Parliament.

A similar process occurred as part of the Trudeau era during the 1970s. Kroeger (1996) noted that Trudeau's decision to significantly expand ministers' responsibilities at Cabinet committees required an increase in the number of senior bureaucrats to administer departmental files for time-constrained ministers. Following the Auditor General's warning of a dire need for greater accountability mechanisms to control public expenditures, the Trudeau government struck the Lambert Commission in 1976. This commission recommended more formal responsibilities for Deputy Ministers in order to render them more accountable to Parliament and the Cabinet. It also argued in favour of an increased devolution of responsibilities from central agencies to line departments, as per the Glassco Commission's advice 15 years earlier. Largely for financial reasons, Trudeau challenged the bureaucracy in 1978 to focus solely on social/health policy priorities and divest itself from leadership and ownership in virtually all other areas that were no longer considered federal priorities.

A deeper mistrust ensued following the election of the Progressive Conservatives to government in 1984. As this chapter demonstrated, the Conservatives believed that senior public servants favoured the Trudeau Liberals and were working to create the conditions for their return to power. As a prominent Cabinet minister in the Clark and Mulroney governments, Flora MacDonald (1980, p. 29), claimed that "the Minister is indeed at the mercy of bureaucratic domination." In MacDonald's view, senior public servants engaged in the following four "entrapment devices" during her time as Minister 
to manipulate control of the policy agenda in departments [emphasis added] (Ibid, pp. 3031):

(a) [U]nnecessarily numerous crisis corridor decisions...- here is the situation; (breathless pause), let us have your instructions.

(b) [U]nnecessarily long and numerous memos.

(c) [L]ate delivery to me of my submissions to cabinet, sometimes just a couple of hours (or less) before the meeting took place.

(d) [O]ne-dimensional opinions put forward in memos.

In response to these negative opinions of senior bureaucrats, the Mulroney Conservatives established the chief of staff position in September 1984 as a check on bureaucratic policy advice. According to O'Connor (1991, p. 23), the rationale behind the chief of staff system originated from the belief that "[1] oyalty to the minister, first and foremost, and to the government in general, is stressed at the ministerial staff level, in a way that is not deemed acceptable at the departmental or bureaucratic level." O'Connor further noted that "[a] key role of the chief of staff is to ensure that ministerial directives are being carried out within the department. In this way, the chief of staff assists in increasing ministerial control and accountability" (Ibid, p. 24). It was during this period that Stone's (1988) theory best applied to the political-bureaucratic relationship, as it became clear that any major public policy decision must include the essential elements of politics.

Policy making in the Chretien era featured many client-focussed, NPM-themed reforms in an atmosphere of fiscal restraint. Kroeger (1996) commented that this period featured an increased devolution of responsibilities from the Centre to departmental 
ministers, along with a shift in responsibilities from central agencies to senior departmental bureaucrats. At this juncture it is worth reiterating Maor's (1999) argument that devolving authority from central agencies to line departments creates the opportunity for politicians to closely access and influence departmental policy and administrative functions (e.g. hiring). Although it may initially appear that such reforms would clarify administrative responsibilities and streamline the policy making process, the devolution of authority to line departments could result in heightened political-bureaucratic tensions as both parties vie for a greater share of policy related responsibilities.

Despite occasional political criticisms of an alleged slow and inflexible bureaucracy, there remain many staunch defenders of the federal bureaucratic function. Former Deputy Minister, Arthur Kroeger, argued for example that "[w]hen an incumbent government is defeated at the polls, two things remain behind: the country's problems, and the officials who worry about them. Officials are, so to speak, the permanent custodians of permanent problems" (1992, p. 4). Former Deputy Minister and Liberal Cabinet Minister, Mitchell Sharp, argued that a permanent public service that provides non-partisan advice to political masters is an essential component of Canadian parliamentary government, as (1981, p. 43):

Government is, in fact, a specialized affair which cannot be run successfully by amateurs without professional advice and professional execution. With rare exceptions, in a parliamentary system politicians are amateurs in any field of government administration, at least at the beginning of their political careers.

The many checks and balances to limit the influence of senior bureaucrats that were implemented during the Mulroney era have also been criticized for their excessive and ineffective nature. Doern (1987), for example, criticized Mulroney's Prime 
Minister's Office for wasting resources on positions (such as a chief of staff) that attempt to interfere with the bureaucracy's role in policy making. In his view, "Mulroney and his PMO advisors seriously misjudged this modern fact of governing" as a "well-functioning and broadly trusted public service is an indispensable key to staying out of many kinds of political trouble" (p. 4). Robertson (1983) used similar logic to question political supervision of non-partisan bureaucrats, noting that "with clear dependence on ministerial or governmental pleasure for retention of office, a changing set of advisers is less likely to have the experience, the interest or the security that will produce clear warnings when they may be needed in the public interest" (p. 12). Interestingly, this chapter highlighted Mintzberg and Jorgensen's (1987) argument that a major consequence of busy ministerial schedules was that politicians delegated too much policy responsibility to young "whiz kids" instead of senior bureaucrats, which further strains the policy making process.

It is also noteworthy that all of the abovementioned restrictions to bureaucratic influence were implemented by both Liberal and Progressive Conservative governments. The Glassco Commission and reforms such as the chief of staff position were implicated by Conservative governments that were fearful of an alleged Liberal-tinged bureaucracy eroding the influence of the Cabinet and Prime Minister in policy decisions. In contrast, the Trudeau era Liberals recognized (mainly through the Auditor General's public warnings) that federal spending could not continue along the trend of the 1960s and 1970s and fiscal reforms had to occur. The Liberals therefore decided to shift their policy focus to the core ideas of health and social policy. In essence, both Liberal and Conservative governments were motivated by controlling spending, however each party 
took different routes by applying their distinctive political philosophies to implement bureaucratic and policy reforms.

\section{Analytical Approach}

The goal of this chapter was to build a theoretical foundation upon which to examine the commercialization of ports and airports in Canada from the late 1970s to 2000 , and analyse the outcomes from the perspective of circumstances that led to the privatization of CN Railways in 1995. Chapter Three applies the meso framework to the privatization of CN Railways, followed by an examination of port and airport devolution reforms in Chapters Four and Five, respectively.

Each modal chapter follows a similar approach: first, a short historical summary of the major policy reforms is considered; second, the meso framework is applied to each reform to examine the interactions of the major micro and macro forces behind each outcome; and third, the airport and port reforms are analysed with respect to the "policy miracle" of CN privatization to account for differences in each modal outcome. The key conclusions from the framework are then presented in the context of transportation governance reforms in particular and federal policy making in times of financial stress in general. 


\section{Chapter Three: The Privatization of Canadian National Railways}

In Canada, it seems, all modes are created equal -

but some are obviously more equal than others. ${ }^{29}$

\subsection{Historical Summary}

\subsubsection{The Emergence of Liberalisation: 1960-1975}

The post-war era proved challenging to rail companies in the face of increased competition from the trucking and water cargo sectors and the heavy burden of strict shipping rate regulations (Gratwick, 2001; Intervistas Consulting Inc., 2003; Heaver and Waters, 2005). In response to these conditions, the federal government struck the MacPherson Royal Commission on Transportation in 1959. Although initially mandated to investigate rising railway rates, the Commission expanded its mandate to include recommendations aimed towards the implementation of market principles and reduced regulation as part of a new national transportation policy. With regards to railway competition, the MacPherson Commission encouraged the federal government to recognize the need for $\mathrm{CN}$ to compete independently with the Canadian Pacific Railway (CP) to ensure that Canada has "two great (railway) systems, both with substantially similar management, operating alongside each other in healthy rivalry from coast to coast" (quoted in Morin, 1985, pp. 130-131). The Commission released its three volume

\footnotetext{
${ }^{29}$ W.H. Morin, Senior Vice President (Marketing), Canadian National Railways. Remarks given in 1985 during an address to the Montreal Board of Trade.
} 
findings in 1961 and is widely credited as launching a new era of limited government intervention in national transportation policy.

The work of the MacPherson Commission subsequently served as the primary input for the National Transportation Act of 1967. For the first time, federal transportation legislation emphasized multimodal competition over a previously near exclusive focus on rail. The most significant change in approach occurred with the Act's national statement on transportation policy (quoted in Heaver and Waters, 2005, p. 782):

It is hereby declared that an economic, efficient and adequate transportation system, making the best use of all available modes of transportation at the lowest total cost is essential to protect the interests of the users of transportation and to maintain the economic well-being and growth of Canada, and that these objectives are most likely to be met when all modes of transport are able to compete.

The passage of the Act in 1967 also brought more commercial freedom to the rail industry and provided a regulatory complaints process through the newly created Canada Transport Commission.

\subsubsection{Initial Governance Reforms: $1975-1980$}

Despite market liberalisations in the Canadian rail industry, $\mathrm{CN}$ continued to experience significant financial problems in the 1960s and early 1970s. Political interference in the operations and decisions of CN Rail resulted in line overcapacity, inefficient equipment, uncompetitive schedule making, and ultimately high debt, while CN's board of directors was comprised of political appointees based on their allegiance to the governing party of the day (MacKay, 1992; Bruce, 1997). 
By the mid-1970s, however, $\mathrm{CN}$ had no choice but to adopt aggressive financial measures to control its expenses. In 1974, Dr. Robert Bandeen became the youngest President and Chief Executive Officer (CEO) in CN's history at the age of 43. Bandeen's first attempt at reform was a comprehensive reorganization of the entire $\mathrm{CN}$ governance structure into six subsidiary companies based on primary functions. Examples included CN Rail (passenger and freight), CN Trucking and Express, CN Telecommunications, and CN Marine (MacKay, 1992).

Bandeen's reorganization resulted in short-term improvements to CN's financial situation. In 1976, the corporation turned its first profit in 20 years (MacKay, 1992). Despite new optimism within its executive ranks, $\mathrm{CN}$ was faced with a huge accumulated debt and associated interest payments. In $1978 \mathrm{CN}$ requested and was granted financial assistance from the federal government in the form of an $\$ 800$ million debt conversion of common stocks in exchange for $\mathrm{CN}$ paying the government a 20 percent dividend on all stocks moving forward. The federal debt conversion reduced CN's annual interest on its debt by $\$ 65$ million, which was granted on the condition that $\mathrm{CN}$ become financially selfsufficient (MacKay, 1992; Bruce, 1997).

Now on healthier financial ground, $\mathrm{CN}$ next sought to address its systemic losses from passenger transportation. In 1977, Bandeen devolved all of CN's passenger business into a new subsidiary, VIA Rail Canada. ${ }^{30}$ According to MacKay (1992), this decision was made contrary to the wishes of the Transport Canada bureaucracy, who instead preferred a joint 50-50 passenger rail ownership arrangement between $\mathrm{CN}$ and its

\footnotetext{
${ }^{30}$ Mackay (1992) explained that the name "VIA Rail" originated as part of CN's marketing efforts in 1977 to promote the new subsidiary as running "VIA CN".
} 
private sector rival, CP. Unhappy with the present state of passenger rail in Canada, the federal government responded in 1978 with an offer to purchase the passenger rail components of both $\mathrm{CN}$ and $\mathrm{CP}$ and operate them as an independent Crown Corporation. The railways agreed and the Via Rail Canada Act was passed in 1978, creating a new publicly funded passenger railway system based on the governance arrangement of its American counterpart, Amtrak, which was founded eight years earlier (Transport Canada, 1977a; MacKay, 1992; Bruce, 1997; Heavers and Waters, 2005).

\subsubsection{Follow the American Leaders: 1980-1984}

Canada was by no means the only country engaged in deregulation and liberalization of its rail lines and networks during the early 1980s. One of the most significant reforms to impact the North American rail industry occurred with the passage of the Staggers Rail Act by the United States government in 1980 (Madar, 2002;

Thompson, 2003). In Roper's (1992, p. 4) view, “[t]he Staggers Act...was a response to a concern that excessive governmental regulation both at the federal and state level had contributed to the financial difficulties of major railroads." For the first time, shippers and rail companies were permitted to negotiate confidential contracts, and many of the regulations governing rail line abandonment were eliminated or greatly relaxed. In many cases rate setting requirements were eliminated, which in turn permitted rail companies to tailor the quality of shipments (and hence prices) to the level the seller was willing to pay. When observed on the whole, the Staggers Act represented a significant withdrawal 
of federal involvement in United States rail governance and an increase in market liberalisation. $^{31}$

Given that Canada's two national rail lines, $\mathrm{CN}$ and $\mathrm{CP}$, operate service throughout the United States, the Staggers Act had an impact on rail operations north of the border. The influence on the Canadian rail policy environment during this time is best illustrated as follows (Intervistas Consulting Inc., 2003, p. 24):

The success of the 1967 Canadian rail policy was the model used for the new U.S. policy, but by incorporating the ability to shed low utilisation track and other reforms, the U.S. policy went beyond that in Canada - the U.S. not only caught up to Canada in terms of rail policy, it leapfrogged Canada.

According to Gratwick (2001), the Canadian government considered implementing a separate set of rail reforms in the early 1980s in line with the Staggers Act that would have been applicable only to rail services bound for the United States. Upon further consideration, the federal government decided against this option due to the significant bureaucratic burden such regulations would impose, and instead opted to begin work on a revised multi-modal transportation policy.

In addition to facing competitive pressures from a highly deregulated American market, $\mathrm{CN}$ was forced to upgrade its Western rail infrastructure to keep pace with rising demands for natural resources and increasing trade flows to and from Asia. MacKay (1992) noted that CN invested heavily in rolling stock and formed a new subsidiary, CN

\footnotetext{
${ }^{31}$ Roper (1992, p. 4) cautioned, however, that "it is not correct to say that the industry has been deregulated. Rather, regulation has been significantly relaxed in some areas and has been eliminated in other areas." Despite the many reforms, the United States federal government continued to hold the regulatory power to force rail companies to share their tracks with competitors, which remains a controversial issue known as "open access."
} 
Exploration, to exploit oil, gas and mineral rights inherited from its predecessors, Canadian Northern Railways. Bandeen continued his attempt to transform CN into what he called a "transportation conglomerate" and focussed on core railroading initiatives that would boost CN's revenues (Ibid, p. 289). Examples included the purchase of several smaller railroads in the United States, and the announcement of CN's intent to end rail service in Newfoundland through the elimination of its subsidiary, Terra Transport.

\subsubsection{The Progressive Conservatives and Freedom to Move: 1985-1992}

In 1985, the newly elected Progressive Conservative (PC) government embarked on a new approach to developing a national transportation policy. According to Bruce (1997), the arrival of the PC government was not viewed favourably by senior CN managers. In particular, he noted that the Conservatives disliked what they considered to be Liberal government-created Crown Corporations competing against private sector companies. As a result, Bruce noted that "[h]istorically, Conservatives had backed CP and abused CN" (1997, p. 16). In addition, the new Minister of Transport, Don Mazankowski, released the policy paper, Freedom to Move: A Framework for Transportation Reform, following an internal policy review at Transport Canada (Gratwick, 2001; Heavers and Waters, 2005). The new framework did not refer to $\mathrm{CN}$ in particular, but rather sought to encourage more competition and less regulatory burden throughout the transportation sector, while providing rail shippers with greater freedom and transparency to negotiate contracts.

The House of Commons Standing Committee on Transport (SCOT) undertook a cross-country tour in 1986 to solicit feedback from stakeholders and the general public on 
the new transportation legislation. Their efforts culminated in the passing of the National Transportation Act of 1987, which took effect on January 1, 1988. MacKay (1992) noted, however, that next to none of the concerns or recommendations expressed by $\mathrm{CN}$ to the government's proposals were reflected in the final legislation.

Although the 1987 Act was the first to mention the air, rail and highway sectors in one piece of federal legislation, railway issues received the most emphasis (Intervistas Consulting Inc., 2003; Heavers and Waters, 2005). From the perspective of Canadian railway companies, the Act permitted greater freedom to abandon unprofitable rail lines in a similar manner granted south of the border in the Staggers Act. However, many rail reforms were seen as benefiting shippers at the expense of rail freight operators (Ibid). For example, shippers were now authorized to engage in confidential contracts with rail companies, which was viewed in the rail industry as a method to enable shippers to exaggerate offers received from other rail operators to lower the price quoted by the negotiating rail company. In addition, the Act also permitted a greater geographic area where shippers could engage in a technique known as "interswitching," whereby a shipper may request its goods be delivered by a rival rail company to avail of its more convenient scheduling.

In light of these policy developments and economic conditions, CN Railways continued to experience difficult financial times. The federal government instructed $\mathrm{CN}$ to privatize remaining unprofitable assets in 1988 in order to reduce its public debt burden. $\mathrm{CN}$ then sold its hotel chain to Canadian Pacific, and divested all its telecommunication interests to the private sector. By $1989, \mathrm{CN}$ had lowered its debt to $\$ 1.9$ billion and reduced its debt-equity ratio from 53 to 35 percent. 
Bruce (1997) emphasized that the major financial problems experienced by $\mathrm{CN}$ during the late 1980 s were directly attributable to this legislation. As previously mentioned, the Act granted greater freedom to shippers in negotiating business contracts with railways, but failed to grant favourable financial provisions to railways and did not grant as much freedom to relinquish unprofitable track as $\mathrm{CN}$ desired. In other words, "[the Act] deregulated the price side of the railway business, but not the cost side" (Bruce, 1997, p. 19). Furthermore, the significant growth of the trucking industry in the 1980s combined with an increase in US railways hauling Canadian cross-border goods since passage of the Staggers Act meant CN was forced to compete with new rivals under old regulations. By 1992, $\mathrm{CN}$ had lost more than $\$ 1.2$ billion in revenues as a result of the Act, according to a joint $\mathrm{CN}-\mathrm{CP}$ commissioned consultant report on the rail industry. Shortly before his retirement as President and CEO of CN in June 1992, Ronald E. Lawless wrote a letter to senior management stating, "[t]he future of $\mathrm{CN}$ is at stake...[a] plan of action for survival is required" (Bruce, 1997, p. 23).

\subsubsection{The CN Privatization Process: 1993-1995}

By the early 1990s, the federal government had begun a low-key search to replace the retiring Ronald Lawless as President and CEO of CN Rail. In early 1992, Prime Minister Brian Mulroney approached the Clerk of the Privy Council, Paul Tellier, to informally inquire if Tellier was interested in becoming the next head of $\mathrm{CN}$ (Bruce, 1997). Having previously expressed his desire of entering the private sector to Mulroney, Tellier accepted the offer, but only on the condition that he be permitted to privatize $\mathrm{CN}$. Mulroney agreed and Tellier began work as the new CN boss in late September 1992. 
Known for his strong leadership skills and no-nonsense approach, Tellier pledged to lower CN's operating ratio as quickly as possible. Although open to other opinions on reform at $\mathrm{CN}$, Tellier took a hard line on the need for change with his senior managers, unions and the media. He also skilfully used his public sector experience to convince the federal Cabinet of the need to eliminate 11,000 positions at CN between 1993 and 1995 in an effort to lower CN's costs and improve its credit rating.

Following a failed merger between CP and CN Rail in early 1994, Tellier and his team of senior managers were determined to move forward with the privatization of $\mathrm{CN}$. In late 1994, the new Liberal Minister of Transport, Doug Young, assembled the "Government Task Force on the Canadian National Railway System," composed of eight Liberal Members of Parliament and one Liberal Senator. The group was headed by Robert Nault, a former employee of CP, and the terms of reference was written by David Todd, the Vice President of Government Affairs at CN (Canada, 1994). According to Bruce, Doug Young instructed the Committee to use the term "commercialization" and not "privatization" when referring to CN's future, as privatization was viewed as a conservative term strictly opposed by the Liberal party during the 1993 federal election.

Following completion of the consultation process in early 1995, only six of the nine committee members favoured privatization of CN. Bruce (1997) noted that the remaining members were hesitant to endorse full privatization due to the mixed success for the federal government from the privatization of Air Canada and parts of PetroCanada. This was troubling news for Doug Young, as he acknowledged that only unanimous committee support would convince the federal Cabinet to approve privatization. Bruce outlined how Young responded by encouraging his Liberal allies to 
attend meetings of the Committee and reassuring its members that privatization would not result in a degradation of service to their respective regions. The lobbying proved successful and the Committee recommended, "that the Minister of Transport commit to a process leading to the full commercialization of the Canadian National Railways as a coast-to-coast main-line operation" (Government Parliamentary Task Force, 1994, p. ix).

Given that the Liberal Red Book of 1993 made no reference to the privatization of $\mathrm{CN}$, the federal government was forced to convince Canadians that reform was necessary. Doug Young made public statements leading up to the 1995 federal budget that argued the federal government must sell assets in order to lower its debt and protect social programs such as Medicare. The day following the budget tabling in the House of Commons, the Minister of Finance, Paul Martin, rose to make the following announcement (Bruce, 1997, p. 70) [emphasis in original]:

If government doesn't need to run something, it shouldn't. And in the future, it won't...Today, we are announcing that the Minister of Transport will initiate steps this year to sell $\mathrm{CN}$.

The CN Commercialization Act was passed into law in July 1995, a mere four months after it was proposed in the federal budget.

The intricate details of CN's privatization were handled by the Departments of Transport and Finance. The major leaders at Transport Canada were the Deputy Minister, Nick Mulder, and the Assistant Deputy Minister, Policy, Moya Greene. Mulder was well respected within the transportation sector, and enjoyed a positive relationship with Transport Canada's unions, which greatly enabled reforms during his tenure. The federal government officially sold CN to financial underwriters in November 1995 for 
$\$ 2.2$ billion, which was the largest initial public offering (IPO) in Canadian history (Bruce, 1997).

\subsubsection{A Successful Model of Divestiture: 1996-2000}

Another major development in the rail sector that reaffirmed the critical path set forth by Paul Tellier's decision to privatize CN Rail was the release of the Canada Transportation Act in 1996. The Act granted rail companies greater freedom and a more efficient process to abandon rail lines, consistent with changes implemented in the Staggers Act of 1980 (Gratwick, 2001). As a result of this reform, CN and CP reduced their combined share of Canadian rail lines from 89 percent in the early 1990s to roughly 65 percent by the end of the decade (Intervistas Consulting Inc., 2003). Rail line abandonment subsequently led to the emergence of many short-line rail companies, who took control of former $\mathrm{CN}$ and $\mathrm{CP}$ tracks and established operations in regional areas (Heavers and Waters, 2005).

\subsection{Meso Analysis}

\subsubsection{Micro Influences}

The Trudeau and Clark Eras: 1975-1984

From an organizational perspective, Transport Canada of the late 1970s and early 1980s governed itself along three administrative components: (i) air, marine and surface functions, (ii) an administrative facet, such as the executive, personnel and finance branches, and (iii) satellite agencies (Langford, 1982). Within this third classification, Langford claimed that the department ranked agencies in terms of "inner and outer 
circles" of importance, of which $\mathrm{CN}$ was placed on the periphery due to its arm's-length status. The key implication of CN's low ranking within Transport Canada, as will be demonstrated below, is that the line bureaucracy was not involved in the day-to-day operations of $\mathrm{CN}$ but only took interest when politicians attempted to influence the affairs of the corporation for ideological and political reasons, or when $\mathrm{CN}$ took a decision that the department felt would potentially impact one of its direct modal functions or its inner agency circle.

CN's internal governance structure also contributed to slow, inefficient decisionmaking that rendered any hope of a more market-friendly focus, let alone privatization, unlikely during the Trudeau and Clark eras. The main hindrance to effective governance change during this period was the strong political influence exerted by the government and Members of Parliament (MPs). Not only did Cabinet appoint party supporters with little or no knowledge of the railroad business, but even local MPs were able to influence micro decisions such as changing the railroad's track schedules to avoid night-time travels through residential areas (MacKay, 1992). Even more disconcerting to CN's operations was the perception by senior management that the government was more content with operating losses than profits. According to CEO Robert Bandeen (Ibid, p. 286),

All the years we made money...never once did anybody in Ottawa say that was a good thing. It had become easier for Ottawa to deal with a deficit than with a profit. If there was a profit government opponents would be screaming that we were charging too high a rate or that we fired people that should have been kept on staff. 
Partly a result of such political interference, $\mathrm{CN}$ developed a strong union culture that further resisted change. Many stories of union dominance at $\mathrm{CN}$ even attracted the attention of national media outlets who reported of cases of conductors cancelling trips due to a shortage of onboard water bottles, diesel mechanics cancelling services by refusing to change locomotive headlights, outdated collective agreements that awarded two-and-a-half days' pay for travelling 250 miles in one day and allowed laid-off employees to remain at home on full salary and benefits until they received a severance payout and retirement pension (Bruce, 1997). In the words of former CN chairman David McLean, "this created a sense of entitlement that, over time, fostered an unproductive and inefficient work environment" (2014, p. 163).

Despite such an inefficient governance structure, CN featured strong, entrepreneurial leaders who consistently encouraged their employees and the government to adopt a more productive operational outlook. As mentioned above, Dr. Robert Bandeen immediately sought to change the culture at $\mathrm{CN}$ upon his appointment as President and CEO from government dependence to a more entrepreneurial and costconscious enterprise. In his words, "[w]e had people with brilliant ideas, but the old tradition persisted and I got tired of people saying $\mathrm{CN}$ was 'government', inefficient and bureaucratic" (MacKay, 1992, p. 280). The efforts of Bandeen and his new executive team were supported, albeit only in principle, by the Liberal Minister of Transport, Otto Lang, who in MacKay's view encouraged an environment where "[t]he socio-economic role was downplayed in favour of commercial self-sufficiency" (Ibid, p. 281). Unfortunately for CN, Lang's influence proved insufficient to avoid political influence and allow $\mathrm{CN}$ to develop more commercialized operations. 
Analysing these factors reveals that $\mathrm{CN}$ was a host to three separate and at times conflicting organizational cultures. They included the pro-business executive cadre, the staunchly pro-union employee ranks, and the politically appointed board of directors. Interestingly, each of the three sub-cultures demonstrated the behavioural characteristics of Schneider's attraction-selection-attrition framework, although the characteristics varied among each group. Within each group there were similarly typed individuals with comparable values who performed similar duties within the organization. Each group was essentially locked-in to their positions, and the lack of accomplished reforms during this period implied an inability of senior leaders to reach-out to each other to establish a consensus. Using Magee and Frasier's (2014) framework, each leader had attained the status within their respective career circle but were prevented from executing power by the high degree of political influence upon CN's affairs.

From a strategic perspective, CN's organizational framework in this period prevented the creation and cultivation of new ideas towards reform. The union based operational ranks were focussed on aspects such as seniority and working conditions, and usually denounced any senior management attempts at reform as a threat to job security. Union actions were usually supported by government and opposition MPs, who tried to influence executive decisions at $\mathrm{CN}$ through the politically appointed board of directors. The executive, despite significant union and political opposition, attempted numerous reforms to improve CN's fiscal situation, resulting only in short-term financial gains that failed to address systemic economic issues such as profitability and long-term debt. In the words of its CEO Bandeen, "[w] hat used to annoy the hell out of me, was that 
individual parts of the company did well but we did not seem to be able to pull the whole thing together" (MacKay, 1992, p. 280).

Analysing this outcome in terms Mintzberg and Jorgensen's (1987) framework, $\mathrm{CN}$ displayed a predominantly top-down approach to strategic planning in the Trudeau and Clark eras. The potential for emergent strategies occurred only within the executive cadre, as line employees were largely uninterested in new ideas that could take the form of disconnected strategies. From the executive perspective, senior managers were largely operating in an organizational vacuum with little interest in change from their employees, board of directors, and even Transport Canada.

The Mulroney Era: 1985-1993

For reasons that will be discussed in the macro subsection, the election of the Progressive Conservative government in September 1984 brought a more market oriented approach to the governance of transportation programs and assets. Ironically, the Conservatives engaged in more direct political interventions in CN's operations than their Liberal predecessors. In particular, the federal government instructed $\mathrm{CN}$ to privatize remaining unprofitable non-rail assets in 1988, in part to help reduce its public debt burden. $\mathrm{CN}$ then sold its hotel chain to $\mathrm{CP}$, and divested all its telecommunication interests to the private sector. By $1989, \mathrm{CN}$ had lowered its debt to $\$ 1.9$ billion and reduced its debt-equity ratio from 53 to 35 percent (MacKay, 1992). Over this period the organizational structure was simplified as the corporation shrunk to focus nearly exclusively on rail freight operations. Despite these developments and governance reforms, $\mathrm{CN}$ continued to experience difficult financial times. 
Contrary to the Trudeau and Clark terms, the Mulroney era marked the first time that strong leadership led to sustained governance reforms at $\mathrm{CN}$. The primary leaders during this period were the President and CEO, Ronald E. Lawless, and the Minister of Transport, Don Mazankowski. ${ }^{32}$ As a Cabinet minister from Alberta, Mazankowski once stated that "most people in Western Canada put little trust in the railways" (MacKay, 1992, p. 289). As a Conservative, Mazankowski was convinced that a Crown Corporation like $\mathrm{CN}$ should not be directly involved in operations that competed against privately run enterprises. As a result, he took a keen interest in the general affairs of $\mathrm{CN}$ and routinely offered direction to its president. According to Lawless (2014), "we couldn't just make the desired changes, and we would get into some pretty tough battles with them (the Minister's office)....[e]specially with Don Mazankowski as the Minister....the attitude was very much ownership on the government's part."

As was the case during Bandeen's tenure at CN, Lawless initially faced strong opposition to reform from CN's union leaders. As a life-long railroader and career $\mathrm{CN}$ employee, Lawless was well acquainted with CN's management-union relationship. According to Lawless (2014), "I had to work with 16 unions, and they resisted every change I had to make.” Under Lawless' tenure as President, employee layoffs or "downsizing" became the most common way to cut costs. Following a general strike in 1987 that resulted in Parliament legislating CN employees back to work, roughly 4,000 jobs were eliminated every year until 1991 (MacKay, 1992). Despite the frequent job cuts, a major difference, however, between Lawless' and Bandeen's time at $\mathrm{CN}$ was the

\footnotetext{
${ }^{32}$ The author spoke via telephone with the Right Honourable Don Mazankowski in June 2014. Mr. Mazankowski conveyed his regrets that he was unable to participate in a formal interview due to health reasons.
} 
identification by some union leaders of the opportunities for reform. In Lawless' view, "there were enlightened heads of some of the unions who realized that reforms had to occur or they would be on the outside looking in." A key factor responsible for convincing the unions to accept changes was Lawless' ability to transform $\mathrm{CN}$ into a multimodal container business that could compete with the trucking industry, which was the dominant threat to CN's profitability at the time.

In another contrast to Bandeen's tenure at $\mathrm{CN}$ during the Trudeau/Clark era, the late 1980s saw heightened political interest in CN's operations. As previously mentioned, Mazankowski took a great interest in the rail industry and CN's operations from a general operational perspective. In the view of his Cabinet colleague and second successor as Minister of Transport, Benoit Bouchard (2014),

[T]he policies implemented by the Minister (Mazankowski) over time convinced $\mathrm{CN}$... that it would be better to focus on the rail operations because they would have had the opportunity to abandon branch lines and focus on the main lines of the company and to devote much more aggressiveness to their operations in the rail industry.

The interest in $\mathrm{CN}$ cost-cutting also extended to the Prime Minister's Office. According to Lawless (2014), Prime Minister Brian Mulroney would occasionally receive complaints from MPs regarding cuts to $\mathrm{CN}$ services and would instruct Lawless to reverse planned service reductions. To Lawless' recollection, the first and only time Mulroney upheld a $\mathrm{CN}$ cost cutting decision was for the proposed elimination of all railway service in Newfoundland, which ironically was first service cut recommended by former President and CEO Robert Bandeen in 1979. 
Lawless and his executive team were convinced that $\mathrm{CN}$ needed to be privatized and commissioned two feasibility studies in the late 1980s. Despite the government's efforts to deregulate the railroad industry largely in favour of shippers, Mazankowski declined Lawless' recommendation to privatize CN. To Lawless' (2014) recollection, "[t]he Minister indicated that the government was going to privatize the post office and Air Canada before CN. We were at the bottom of the list." Following Air Canada's privatization, Lawless returned to Mazankowski to again seek permission for privatization, but was informed that "the government was not yet ready to privatize $\mathrm{CN}$. I didn't receive an outright rejection, but I was told the time was not yet right."

Benoit Bouchard (2014) recalled that the government had encountered strong opposition in Western Canada to its attempts at revoking the Crow Rate ${ }^{33}$ at the time, which meant little appetite for further reforms such as the privatization of $\mathrm{CN}$, as "Mulroney and Mazankowski didn’t want to provoke things." ${ }^{34}$ Following a second attempt to persuade the minister to choose privatization, however, Lawless and Mazankowski agreed that $\mathrm{CN}$ should narrow its focus of operations to rail related operations in an effort to lower its debt and increase its attractiveness to private investors.

\footnotetext{
${ }^{33}$ Known officially as the "Crow's Nest Pass Agreement," the Crow Rate was an agreement between the Canadian Pacific Railway (CPR) and the Government of Canada that granted the CPR a subsidy and territorial access to extend its rail network into British Columbia in exchange for a guaranteed reduced shipping rate for agricultural products (e.g., grain and flour). Enacted in 1897, the Crow Rate existed in various forms until the passage of the Western Grain Transportation Act in 1983, in which the government permitted shipping prices to rise in exchange for federal and CPR investment in rail infrastructure. The federal government formally ended all Crow Rate related pricing and subsidies by 1995 and implemented the Western Grain Transition Payment Program to provide a one-time subsidy for farmers to adjust to new, non-subsidized shipping prices. For more information, see Historica Canada (2015).

${ }^{34}$ Kroeger (2009) referred to the Crow Rate as "one of Canada's most politically sensitive policies."
} 
As for next steps, Lawless claimed that "we did it (the divestitures) with the understanding that once $\mathrm{CN}$ has divested everything, the government would privatize it."

From a strategic perspective, Lawless demonstrated the umbrella strategy outlined by Mintzberg and Jorgensen (1987) whereby the intent to cut costs and prepare $\mathrm{CN}$ for privatization was clearly conveyed to senior management and operational employees. Outside of the executive ranks, however, this strategy was not well received by most employees, except for a minority of union leaders who recognized that the macro context facing the North American railway industry demanded a leaner and more responsive $\mathrm{CN}$. Consequently, reforms at $\mathrm{CN}$ during this period were primarily top-down and focussed on reducing expenditures, as opposed to entrepreneurial, bottom-up changes to employee attitudes and performance.

The influence of the political sphere upon CN's governance framework during this era was clearly more interventionist and supportive of reforms than the Trudeau/Clark eras. The Minister's office strongly supported efforts that would reduce CN's burden on taxpayers and allow greater market forces into CN's decision making processes. As the Minister most interested in CN's operations during the Mulroney era, Mazankowski sought regular meetings with $\mathrm{CN}$ executives and often issued directives on major operational matters. However, Mazankowski stopped short of authorizing the full privatization of $\mathrm{CN}$ on two occasions and argued that the government was not yet ready to address such a substantial issue. For reasons that will be further explained below in the macro subsection, it is clear that Mazankowski's rail priorities concerned industry deregulation that granted greater negotiation powers to shippers and farmers and would satisfy his political constituents. Mazankowski clearly recognized and accepted Lawless' 
vision for a fully private, rail-focussed $\mathrm{CN}$, however his political pragmatism stood in the way of further reforms.

The Chretien Era: 1993-2000

Paul Tellier: From Bureaucrat to CEO

As illustrated in the previous subsection, the financial losses at $\mathrm{CN}$ continued to mount through the early 1990s. From an organizational perspective, CN continued to operate at arm's-length from the Transport Canada bureaucracy, with the exception of occasional interventions from former Minister of Transport, Don Mazankowski, who had left the Transport portfolio to serve as Deputy Prime Minister from 1986 to $1992^{35}$ (Mulder, 2014; Bouchard, 2014). However, CN's traditional status quo was soon to be disturbed by the appointment of Paul Tellier as Ronald Lawless' successor as President and CEO in September 1992.

Tellier was determined to change the organizational culture at $\mathrm{CN}$ from an inefficient business with overgenerous labour contracts to a modern and profitable international railway. In his first major speech as head of the railway, Tellier vowed, "I have no intention to run $\mathrm{CN}$ as a money-losing venture. We will not dally in making the necessary adjustments" (Bruce, 1997, p. 29). In the context of this thesis, Tellier turned CN's organizational culture (and Schneider's (1987) ASA framework) on its head, first within the executive ranks and then within the railroad's union culture. Instead of perpetuating what he considered as the railroading culture within the $\mathrm{CN}$ executive cadre

\footnotetext{
${ }^{35}$ According to Mulder (2014) and Bouchard (2014), Don Mazankowski's personal interest in federal transportation policy was the primary reason for his continued involvement in the affairs of Transport Canada during his tenure as Deputy Prime Minister.
} 
and conforming to its values, Tellier decided to instill his own organizational culture and attract like-minded executives to his team. Within his first four months on the job, Tellier had dismissed four senior vice-presidents and the chief operating officer (Bruce, 1997). In Tellier's view (Bruce, 1997, p. 31):

I discovered very quickly that certain professional railroaders were so fixed in their thinking they just could not accept the amount of change needed. They'd say, 'Now, Paul, here are seventeen reasons why we cannot do what you want.' So I decided to move them out.

Motivated primarily by establishing favourable financial conditions to privatize $\mathrm{CN}$, Tellier next set his sights on reducing CN's workforce. His plan was to lay off 11,000 line employees between 1993 and 1995 in order to achieve more favourable credit ratings on CN's massive debt (Bruce, 1997). But as the previous subsection demonstrated, any significant employee related reforms at $\mathrm{CN}$ traditionally faced the ire of MPs and the government, who routinely denied CN permission to adopt more financially favourable policies for fear of political backlash. Anticipating such an outcome from his years as a senior federal bureaucrat, Tellier decided to outmanoeuver the unions and politicians by laying a strategic trap. In early 1993, Tellier met privately with the heads of all of CN's major unions to explain his proposed cuts. As expected, the unions leaked his plans to the Globe and Mail, where it made front page headlines the next day. According to Tellier, a senior Cabinet member phoned him the next day and commented, "we don't like this, but whether we do it or not, the damage is already done. It's here in the press....so let's do it" (Bruce, 1997, p. 33).

From a management perspective, Tellier's vision and leadership signalled the end of CN's manipulation by union and political forces. In a matter of months, the 
organizational culture had changed from 'the way we've done things around here' to 'the way I am going to do things around here.' In terms of Mintzberg and Jorgensen's (1987) strategic framework, Tellier imposed a deliberate, top-down strategy that set in motion a fundamental shift towards a more entrepreneurial and market-focussed railroad. Tellier most likely recognized that he needed to act swiftly and strongly with his intended organizational changes in order to reduce the risk of opposition from senior management, unions and politicians. His timing also likely corresponded to the need for immediate financial reforms to a railroad that was headed for bankruptcy and an eventual recapitalization that the federal government could not afford.

Tellier's leadership skills also provided an example of an executive that employed his new authority as President and CEO to assert his credibility within $\mathrm{CN}$ and the larger railroad community. In the framework expressed by Magee and Rousseau (2014), Tellier used power to obtain status. He advanced his vision as a response to what he considered to be an inefficient and ineffective railroading culture at $\mathrm{CN}$. Upon further examination, however, this appears to be a paradox, as the executives that Tellier chose to dismiss were those who assembled and submitted two government privatization proposals under Lawless' leadership. That these leaders were harming CN's operational success appears doubtful; rather it appears that these dismissals were the result of Tellier's preference to hire non-rail executives with whom he had a close relationship during his public service career. His leadership was of a definite transformative nature, but he decided against the traditional strategy of building bridges among his inherited executive cadre, instead opting to craft his own like-minded organizational culture and dismissing those who disagreed with him. Although likely considered heavy-handed by his critics, Tellier 
nonetheless succeeded in implementing the desired vision for $\mathrm{CN}$ that he first discussed with Prime Minister Brian Mulroney in the summer of 1992. In the words of former CN Chairman David McLean, “[w]e had the right CEO in Paul Tellier, who worked extremely hard on cost-cutting measures that prepared the company for privatization. It was no easy task....but Paul got the job done" (2014, pp.14-15).

Similar to Lawless, Tellier had taken steps to reorient $\mathrm{CN}$ towards privatization. Unfortunately for Lawless, he argued the case for reform to the Minister of Transport but was denied permission to continue. Tellier, on the other hand, most likely leveraged his position as Clerk of the Privy Council to speak directly with the Prime Minister to convey his intent on privatizing CN. By bypassing the Minister and by extension the politically appointed CN Board of Directors, Tellier obtained the political support from the Prime Minister for privatization and never looked back. He openly expressed his own selfconfidence as (Bruce, 1997, p. 31):

Here is what I bring to this job....First, I know the shareholder of this company inside out....Second, I know this country from Newfoundland to British Columbia to the Yukon, and I know all the sensitivities that exist. And third, I have extensive experience in tough negotiations....So listen, I'm not a railroader, and I'm too old to become one....I bring these other things. This complementarity should be extremely good.

\section{Doug Young: The Clear Leader of Privatization}

Although Tellier's determination and visionary leadership played a significant role in preparing $\mathrm{CN}$ for privatization, there remained substantial legislative, political and policy related requirements to accomplish at Transport Canada before the process could be finalized. Contrary to Otto Lang, who favoured a commercialized approach to $\mathrm{CN}$ during the late 1970s but shied away from approving formal pro-market 
governance reforms, and contrary to Don Mazankowski, who supported the premise of privatization in the late 1980s but twice ruled against CN's request to initiate the process, Doug Young was the Minister CN needed who not only supported privatization but was prepared to take action to convince bureaucrats, fellow politicians and the general public of the need for reforms. As a result of his efforts, Doug Young is widely credited as the chief political architect of the $\mathrm{CN}$ privatization process.

First elected federally in 1988, Doug Young was no stranger to the political side of public policy debates. A native of Northern New Brunswick, the new Minister of Transport was a fluently bilingual, successful lawyer and businessman, and former provincial Liberal leader and cabinet minister. Referred to by the national media as "the Dirty Harry of Chretien's Cabinet," Young was a strong-willed leader who was determined to reform the Canadian transportation system, including streamlining Transport Canada and privatizing CN (Bruce, 1997, p. 58).

In terms of Denis et al.'s (2007) framework, Doug Young fit the definition of an entrepreneurial leader; that is, a visionary who recognizes "the big picture" and is ready to act when the timing for change is favourable. The first example of Doug Young's leadership occurred during the negotiations between $\mathrm{CN}$ and $\mathrm{CP}$ to merge operations east of Winnipeg ${ }^{36}$ in the winter of 1994 . After formally granting the two railways approval to engage in merger negotiations, Young instructed his Deputy Minister, Jocelyne Bourgon, to begin a thorough evaluation of CN's operations, including a valuation of

\footnotetext{
${ }^{36}$ The precise location of the proposed CN-CP merger varies in the sources consulted by the author. Bruce (1997) reported that the newly merged company would conduct operations east of Winnipeg, but it was later decided that it would operate east of Thunder Bay, Ontario. Several interviewees informed the author that other potential regions included east of Toronto and east of Montreal.
} 
assets, analysis of labour agreements, legislative requirements, and public opinion research (Young, 2014; Bourgon, 2014). As discussed early in this chapter, merger talks between CN and CP ended in July 1994. Now armed with significant knowledge of the financial, political and political considerations surrounding $\mathrm{CN}$, Young had the foresight and initiative to set the stage for privatization. In his words (2014):

That (the failed merger) then opened the door, because we had a lot of homework done, and I went to the Prime Minister and said that I'd like to take a shot at privatizing $\mathrm{CN}$, and I explained the rationale for it....If the $\mathrm{CN}$ and $\mathrm{CP}$ Atlantic merger had happened, I'd doubt very much that anything else would have transpired with respect to the Western assets, as it provided a catalyst to shift and go to privatization.

In addition to his sharp policy mind, Young was also very adept at political manoeuvers to ensure his idea for privatization would be accepted amongst his cabinet colleagues. Further to Magee and Frasier's (2014) claim that effective leaders are able to persuade others to follow a certain viewpoint, Doug Young was able to convince two major stakeholders that the privatization of $\mathrm{CN}$ was the correct choice for both the railroad and the taxpayer. The first major stakeholder was Young's Liberal cabinet colleagues. Some cabinet members, like Prime Minister Jean Chretien and Minister of Finance Paul Martin, were in favour of CN privatization due to the need to sell Crown assets to reduce the federal deficit and to ensure that $\mathrm{CN}$ received private investment to remain competitive (Bruce, 1997). Other cabinet members ${ }^{37}$ were not necessarily opposed to privatization, but were concerned that not enough consideration was devoted to alternative methods of divestiture of $\mathrm{CN}$, such as those that occurred under the Local

\footnotetext{
${ }^{37}$ According to David Collenette, the Chief of Staff to Prime Minister Chretien, Jean Pelletier, favoured the United Kingdom divestiture model for $\mathrm{CN}$ whereby the federal government would privatize $\mathrm{CN}$ but retain ownership and operation of all track infrastructure.
} 
Airport Authority model in the 1980s. Despite such concerns, Doug Young appeared to have convinced the majority of the cabinet of the need to act quickly to assist with the country's finances and help save the railroad. According to David Collenette (2014), who would later become one of Young's successors as Minister of Transport:

On the privatization of $\mathrm{CN}$, this was controversial because many of us in Cabinet had grown up as statists, if you will, i.e., that it was good that there would be a publicly owned railway. However, we recognized that there were a lot of inefficiencies, overstaffing and all the rest....There was an evaluation of the assets, and I thought we made some errors in allowing $\mathrm{CN}$ to keep certain things.... But I also recognized during the discussions, and Doug (Young) was doing the presentations, he was a pretty hard-nosed guy to push it through....that (public ownership) was not to be the order of the day.

The second stakeholder that Doug Young sought to bring onside with the privatization of $\mathrm{CN}$ was his Liberal caucus members, and by extension, the general public. On September 29, 1994 Young struck a committee of eight MPs and one Senator to travel the country to consult with Canadians on the potential commercialization of $\mathrm{CN}$. From a leadership perspective it is interesting to note that Young assembled a committee composed entirely of Liberals, which was chaired by Robert (Bob) Nault, a former railroad union executive. According to Chairman Nault (2014):

[W]e reported to Minister Young that Canadians in general, in particular the unions, had no problems with the idea of transferring $\mathrm{CN}$ as a railway into private hands. They were very much of the view, as I was, that $\mathrm{CN}$ was a bloated management structure, was costing a lot of money, (and) should be making huge profits with the kind of quality infrastructure.

The choice of Bob Nault as chair proved to be a sharp political decision by Young, not only due to Nault's union influence, but also for his ability to settle disputes among committee members that would have resulted in a less than unanimous support for 
complete commercialization of CN. In Bruce's view, "Nault knew Young wanted the task force not just to recommend the sale of $\mathrm{CN}$, holus bolus, but to recommend it unanimously" (1997, p. 63). The unanimous approval of commercialization marked another turning point for $\mathrm{CN}$, as " $[\mathrm{t}]$ hat single recommendation...the result of deliberations after hearings all across Canada, helped Young gain support for CN's privatization from the Liberal caucus, and that helped him gain its approval in cabinet" [emphasis in the original] (Bruce, pp. 64-65).

From a strategic perspective, the reforms initiated by Doug Young were of a top down nature that were implemented by the Transport Canada bureaucracy. As the next chapter on airport governance reforms will demonstrate, the department was already well in favour of the commercialization reforms advocated by Young, however just not at the pace that he advocated. In the words of the departmental liaison and bureaucrat, Gerard McDonald (2014):

He came in and he ruminated for two or three weeks on what should be done and basically gave the department their marching orders. And I think the department was a little taken aback by the aggressiveness of it, but he was very adamant that we should move aggressively. And to his credit, he got everyone to buy into his way of moving forward.

Consequently, there were no emergent strategies of the nature suggested by Mintzberg and Jorgensen (1997), except for policy related advice provided by the Deputy Minister, Nick Mulder, and the Assistant Deputy Minister of Policy, Moya Greene during the privatization process.

Despite Doug Young's portrayal in the national media as an aggressive debater who refused to accept opinions contrary to his own, he was an admired and respected 
leader amongst senior management at Transport Canada. Regarded as intelligent, organized and well-versed on the department's policy issues, Young was credited with establishing and maintaining consistent "bottom-line communications" that ensured an effective, uninterrupted flow of information between the minister's office, the department's senior management, and CN's executive cadre (Mulder, 2014). With his equally strong personality, Paul Tellier and Doug Young often disagreed and at times engaged in heated arguments over the course of action for CN's privatization (Bruce, 1997). However, both respected each other's knowledge and abilities and were united by their commitment to achieve the best financial package for Canadian taxpayers. In the words of Paul Tellier, "I have never seen a minister manage a file as effectively and rapidly as Mr. Young did....He was the champion. Without Doug Young, Canadian National would not have been privatized. This is really his personal achievement" (Bruce, p. 74).

\subsubsection{Macro Influences}

The Trudeau and Clark Eras: 1975-1984

As outlined in Chapter Two, the federal policy environment underwent a shift of priorities in the late 1970s from federal leadership of all economic portfolios to a concentration solely on social policy priorities. This shift was driven primarily by a desire to control the burgeoning national debt and deficit and follow Prime Minister Trudeau's 1978 directive to reduce the size and cost of government. Senior management at Transport Canada responded to this directive by transitioning the department from a prominent owner and operator of national transportation assets to a promoter and 
facilitator of the conditions for efficient multi-modal productivity and growth. As a Crown Corporation, $\mathrm{CN}$ was part of the outer sphere of influence at Transport Canada and was seldom included in the department's day to day decisions. Meanwhile at CN, President and CEO Robert Bandeen was struggling to implement a more business-like operational focus against strong resistance from MPs and a politically appointed board of directors.

Although this period displayed entrepreneurial and pro-market characteristics, there is little evidence to suggest that it was motivated by the approaching tide of neoliberalism. As Clarke (2008) cautioned, any examination of the impact of neoliberalism upon policy change must consider its dominance in determining the context of reforms. Clarke's first test of neoliberal presence is whether historical changes would have occurred should neoliberalism been present in policy discussions. For example, it is highly doubtful that the recapitalization of $\mathrm{CN}$ in 1978 would have occurred under a Thatcher- or Reagan-esque type of regime, as providing such a significant ( $\$ 800$ million) public subsidy for a government owned enterprise to compete against privately owned and operated companies (e.g., CP) was staunchly opposite to neoliberal principles. Furthermore, this chapter mentioned how it was more politically palatable for the federal government to deal with $\mathrm{CN}$ deficits and not profits during this era, which is in clear contrast to a government seeking a productive return on its investments for taxpayers. In addition, from a commercial perspective, a staunchly neoliberal government would have had little interest in interfering in CN's operations through the appointment process for board directors, and it would not have permitted government MPs from personally intervening in operational decisions that impacted local constituencies. 
Clarke's second test for the presence of neoliberalism in the late 1970s is the ability to deconstruct decisions and re-articulate them in neoliberal terms. From the department's perspective, the 1979 strategic policy document, Transport Canada: Its Roles and Objectives outlined the department's new approach to reorient itself towards the pursuit of greater efficiencies. The lone direct reference to $\mathrm{CN}$ in the document was the department's declaration "to support Crown corporations in their pursuit of commercial viability while maintaining their obligations to provide services in the public interest" (1979b, Appendix II, p. 6). Despite this pro-market angle, it was not based upon a neoliberal themed push for reform. Rather, the evidence presented in this chapter has argued that it was primarily a financially based decision from CN's senior management, in particular its President and CEO Robert Bandeen, that led to a greater focus at $\mathrm{CN}$ on rail specific operations and an attempt to divest other non-rail entities as subsidiaries of $\mathrm{CN}$ or independent Crown corporations.

Following the Trudeau government's return to power in March 1980, it was clear that rail transportation was losing its economic influence. As MacKay noted, "[i]n the war between rail and highway, highway had won" (1992, p. 285). The macro policy environment of the period was heavily influenced by American deregulation following the passage of the Staggers Act in 1980. In response, the federal government initially considered deregulation of the rail industry in line with American reforms, eventually opting for consultations towards a revised multi-modal transportation policy. These factors meant that the governance of $\mathrm{CN}$ clearly ranked lower in importance behind regulatory reforms on the government's rail policy agenda, with the lone political influence occurring from appointments to CN's board of directors. The political will was 
clearly not present for governance reforms at $\mathrm{CN}$, despite efforts by its senior management to reduce costs by divesting non-rail entities and laying off unionized workers.

The Mulroney Era: 1985-1993

As Chapter Two outlined, the election of a PC government in late 1984 resulted in a shift in governance based on neoliberal principles. Two of the party's early priorities were to reduce the escalating federal deficit and withdraw from public influence in areas the party felt were best suited to private enterprise. The new Minister of Transport, Don Mazankowski, embarked on an ambitious agenda of deregulation within all modes of the national transportation sector. The guiding piece for reforms was the government's flagship document, Freedom to Move: A Framework for Transportation Reform, which outlined principles for air transportation, railway freight, extraprovincial trucking, and marine transportation. According to Mazankowski (Transport Canada, 1985, p. ii):

In the environment of the $1980 \mathrm{~s}$, the existing regulatory regime represents an obstacle to economic growth, innovation and competitiveness....The government must facilitate and encourage, rather than obstruct and intervene. We must allow the system to operate under market conditions and allow business to play its proper role in fostering economic growth.

At first glance, these statements appear to conform to Clarke's (2008) characterization of neoliberalism as an omnipresent ideology. Benoit Bouchard (2014), for example, noted that "it was really in the flesh of the party to talk about deregulation" and as a Conservative, Mazankowski "was very well informed, he was very committed to that movement." The previous chapter noted how the government set-out to put its neoliberal principles into practice by enshrining the general deregulatory principles of 
Freedom to Move into legislation with the passage of the National Transportation Act in 1988, which paid special attention to railway shipping rates that would make the rail sector more competitive in a post-Staggers rail market.

Further examination into Mazankowski's reforms using Clarke's model, however, illustrates Clarke's claim that neoliberalism's lack of theoretical rigour implies that the ideology is quite promiscuous. Chapter Two emphasized how Prime Minister Mulroney was not as committed to the neoliberal cause as Thatcher or Reagan, due to his frequent use of political brinkmanship to avoid conflict and his personal beliefs that the state should play at least a minor role in ensuring a minimum standard of personal welfare. As Bourchard commented, "[w]e were actually Progressive Conservatives, I would say more centre-right than right [emphasis added]." From a government-wide policy perspective, it was also clear that the government had no interest in testing the political waters on privatizing $\mathrm{CN}$, especially considering the large political audience for CN's services, not just from the government, but also from MPs. The political environment of this time was also quite complex, with Mulroney already engaged in significant discussions with the United States and Mexico over free trade, as well as domestic discussions with the province of Quebec over the Meech Lake and Charlottetown Accords, and even High Speed Rail. ${ }^{38}$

\footnotetext{
${ }^{38}$ At the request of Premier Peterson of Ontario and Premier Bourassa of Quebec, Prime Minister Mulroney struck a tri-party panel to investigate the feasibility of High Speed Passenger Rail Service in the Quebec City-Windsor corridor in 1989. Following completion of the study in 1991, Mr. Peterson was defeated in an election and Mr. Bourassa resigned from politics due to illness. Interest in the project waned and the idea was no longer actively pursued (Labelle, 2014).
} 
It was also apparent during this period that there was little appetite for reform at $\mathrm{CN}$ within the Minister of Transport's office. Mazankowski was focussed on appealing to his Western Canadian electoral base, which demanded more rights for shippers and suppliers (e.g., farmers) against what were considered anti-competitive and unfair contractual situations with the railways. In other words, it was clear that Mazankowski's focus was on reforming the rail based supply chain and not the governance of $\mathrm{CN}$. Interviews with his successors have revealed that by the time that Mazankowski moved on to become Deputy Prime Minister, the privatization issue was no longer a priority for the government (Bouchard, 2014; Lewis, 2014).

The Chretien Era: 1993-2000

The election of the Chretien Liberals marked the first time in CN's history that privatization was simultaneously considered a legitimate policy option by $\mathrm{CN}$, the Transport Canada bureaucracy, and the federal political leadership. As previously demonstrated, the early 1990s brought huge challenges to $\mathrm{CN}$, such as rising multimodal trade with Asia, an urgent need for major infrastructure investments, as well as a number of money-losing branch lines, particularly in Eastern Canada. At the federal level, the need to address rising government debts and deficits in an era of neoliberalism meant that money-losing, capital intensive Crown assets, such as $\mathrm{CN}$, would be attractive targets for full-scale privatization. At the instruction of the Minister, Transport Canada was for the first time engaged in detailed policy discussions on the future of $\mathrm{CN}$ that would eventually set the stage for the largest initial public offering (IPO) in Canadian history. 
Historical institutionalism (HI) provides the most comprehensive and descriptive framework to describe the circumstances and decisions leading to the privatization of CN. As noted in Chapter Two, Sanders (2006) outlined that the first step in an HI analysis is to consider the personalities of the key decision makers and examine the institutional culture of the organizations under study. This chapter has previously analysed the personalities of Paul Tellier and Doug Young, which revealed two strong willed individuals with an in-depth knowledge of the federal machinery of government, who were both determined to achieve the privatization of $\mathrm{CN}$. It is also important to examine the key individuals within the Transport Canada bureaucracy who guided the privatization process through the many regulatory, legislative and political hurdles of the mid-1990s.

There were three key senior executives who shaped the policy environment at Transport Canada in favour of privatization. The first was Jocelyne Bourgon, who quickly and effectively responded to instructions from Minister Young following the failure of the proposed $\mathrm{CN}-\mathrm{CP}$ east coast merger to commence a formal evaluation of all $\mathrm{CN}$ assets, which provided the Minister with detailed evidence to support his request to the Prime Minister to initiate the privatization process. Bourgon was promoted in 1993 by Jean Chretien as Clerk of the Privy Council, where she brought her detailed knowledge of Transport Canada's files, in particular the privatization of $\mathrm{CN}$, to the most influential central agency of the public service. ${ }^{39}$

\footnotetext{
${ }^{39}$ On the appointment of Jocelyne Bourgon as Clerk, Doug Young (2014) commented, "[t]hat was a gift from God, because you had somebody who worked with me for quite some time and knew exactly what we wanted to do and went to a place where she could make things happen when there are problems."
} 
The second individual was Nick Mulder, who replaced Bourgon as Deputy Minister and brought with him nearly 30 years of experience in transportation policy, including what he described as someone "who actually knows what the skeletons are in the closet” (2014). Mulder was a well-respected Deputy Minister known for his ability to build successful relationships among his staff and the department's major stakeholders. In a policy file as complex and fast-paced as the $\mathrm{CN}$ privatization, communication and professionalism at the apex of an organization are paramount. The departmental liaison, Gerard McDonald, summed-up the importance of personal relationships in the success of $\mathrm{CN}$ as follows (2014):

Fred Drummie was Doug Young's Chief of Staff and close confidant. And you had Nick Mulder as Deputy Minister. They were all very close and had gone to the University of New Brunswick. They jokingly referred to themselves as the UNB mafia. They had that personal connection, and I think that also helped in moving these issues so quickly, in that they all knew and trusted each other from years before.

The third senior executive who played a major role in reforms was Moya Greene, the Assistant Deputy Minister of Policy. Her responsibilities included amending regulations and legislation, as well as implementing changes to collective agreements between $\mathrm{CN}$ and its unions in order to create a more efficient organization that was attractive to private investors (Greene, 2014; Mulder, 2014; McLean, 2014). Greene was also one of the lead bureaucrats that worked closely with Doug Young during the nine month negotiation process to prepare $\mathrm{CN}$ for its IPO in late 1995. In the words of $\mathrm{CN}$ Chairman, David McLean, "she had a problem-solving mindset and had done an admirable job coordinating appropriate communications between the government and our executive team" (p. 12). 
The next stage of the analysis is to consider the timing and sequencing of events leading to the privatization of CN. As argued by Thelen (1999), the circumstances required to move from one policy track to another are usually quite significant and require an exogenous shock to initiate new reforms. Given Don Mazankowski's twice refusal of CN's request to privatize, it is clear that the presence of neoliberalism alone ${ }^{40}$ in federal policy making was an insufficient condition for reform. What was needed in addition to a neoliberal climate was an environmental condition of such a serious nature as to warrant immediate political attention and to substantially reduce the political risk from taking action to the party in power.

The necessary condition that instigated the privatization of $\mathrm{CN}$ was the significant deficit situation facing the federal Liberals upon assuming power in late 1993. As mentioned in the previous chapter, the deficit of $\$ 42$ billion in 1993 received near universal condemnation and it was clear that a significant fiscal restructuring was required. Meanwhile financial losses at $\mathrm{CN}$ continued to mount, despite the company's attempts at slashing jobs and divesting its non-rail operations. According to Moya Greene (2014):

I would say that it was an incredibly policy-rich time, and there was nothing like the fiscal environment to be an impetus for dramatic changes to areas that had been considered sacred cows for a long time, where you couldn't even have a serious discussion of what was happening. Given the fiscal environment, you were able to have much more far-reaching discussion and debate, and you were able to get a lot more done in a specific period of time than any other period that I was in government.

\footnotetext{
${ }^{40}$ The author has determined that the impact of the New Public Management (NPM) was negligible in influencing the privatization of CN. As an arm's-length Crown Corporation, CN was independent and adhered to financial principles, as opposed to the public policy making principles of NPM.
} 
With the deficit crisis serving as the exogenous shock, the next step is to determine the critical junctures, or what Falleti and Lynch (2009) described as the key actions of certain individuals that helped to "lock-in" or set the new policy reforms on a sustainable path to success. The key individual who secured the privatization path was Doug Young. In his words (2014),

[T] he onus was on everyone to look at what might be achieved in the next few years trying to undo this massive deficit... To be able to get a government that was broadly based across the country and get them to agree that this kind of thing was going to take place was also very important.

He was able to set the macro policy agenda for reforms at $\mathrm{CN}$ by skillfully aligning it within the neoliberal framework and the government's urgent need to tackle the deficit. In other words, Young integrated the reforms not only within the department's framework, but also within the federal policy framework. In order to do accomplish these reforms, he needed competent, trustworthy bureaucrats within the senior ranks of the public service who worked diligently to achieve privatization, such as the three mentioned above.

The CN privatization case provides an excellent example of Falleti and Lynch's (2009) assertion that there are many layers of policy context that could be responsible for explaining dramatic changes in policy direction. The general policy climate of neoliberalism was clearly insufficient to advance privatization at $\mathrm{CN}$, as it ultimately required a strong leader and widespread calls for reform within the policy community to address a burgeoning national debt and massive federal deficit. Such a multiple layering of reforms also provides evidence to support Stone's (1988) assertion that policy making is inherently political and at times very irrational. Organizations, such as Transport 
Canada during the $\mathrm{CN}$ negotiations, form an important building block of the polis that results in powerful influence and an ability to influence change. Although these key individuals may have worked to promote self-interest (e.g. enhance opportunities for promotion and recognition), the research has demonstrated that every major player ranked the importance of solving the national deficit crisis as their prime motivation during this era. In terms of Stone's framework, the passion to perform subverted the power of self-interest in the service to the polis.

\subsubsection{Meso Influences}

Chapter Two outlined how micro and macro policy variables should not be analysed independently, but rather in various layers that examine the sequential processes and patterns behind policy changes. In its simplest form, meso analysis considers the influence of broad organizational variables on micro factors, as well as the influence of behavioural variables on macro factors. Considering the meso framework in terms of its isomorphic components (House, Rousseau, \& Thomas-Hunt, 1995), it is clear that the organizational culture among senior bureaucratic executives Jocelyne Bourgon, Nick Mulder, and Moya Greene, along with their positive working relationship with Minister Young, was one of the primary reasons for the successful privatization of CN in 1995. Minister Young, in turn, fostered a cordial relationship with CN's President and CEO, Paul Tellier, which completed a perfect triangular union between the operational, political and policy branches of the reform process. Every senior individual involved in the reforms was very interested in participating in such an active policy experience and openly cited the need to obtain a fair return to taxpayers as the their primary motivation for participating in the privatization process. 
The next step in the meso analysis is to determine the influence of the micro and macro variables upon the privatization process. Stated another way, the key question is whether macro forces trumped micro forces, as hypothesized in Chapter Two. In order to answer this question, three primary factors leading to the privatization of $\mathrm{CN}$ were discovered and considered in this chapter. Those factors were strong leadership, the presence of neoliberalism, and the urgent desire by the Chretien Liberals to make deficit reduction their number one policy priority upon assuming office. All three factors were required to bring about the governance reforms at $\mathrm{CN}$, however the research has shown that the deficit crisis of the mid-1990s was the driving force behind reforms.

As previously explained, the 1980s and 1990s featured strong leadership at the senior levels of CN, Transport Canada, and the Minister of Transport's office. Despite the presence of neoliberalism in Canada during the Mulroney era, the determination by CN's President and CEO Ron Lawless to sway the Minister of Transport in favour of privatization was insufficient in the face of a government uninterested in taking further political risks in the rail sector. By the time the Liberals assumed power, the national debt and deficit had reached unsustainable levels and the consensus among most was that dramatic and urgent cost reforms needed to occur. Although the new Minister of Transport and head of $\mathrm{CN}$ were staunch personal supporters of privatization, it is doubtful that such dramatic reforms would have occurred in a more fiscally sound environment. As the last two chapters demonstrated, the Liberals were neither immediately nor universally in favour of such dramatic cost reforms, with most MPs and cabinet members reluctantly agreeing to the measures as the only option to respond to a troubling financial situation. 
One of the most practical methods to illustrate the triumph of macro over micro variables in this case is to model the privatization of $\mathrm{CN}$ in terms of Kingdon's theory of policy windows. The problem stream in this case is the poor financial state of the publicly owned $\mathrm{CN}$ in the context of record high federal deficits, resulting in the inability of the federal government to afford a much needed railway recapitalization. The political stream is represented by the national mood of the country and politicians at the time, which was a reluctant agreement that political action was required to address federal finances through the sale of $\mathrm{CN}$ to private investors. The policy stream in this case is the valuation of assets that was initially prepared at Transport Canada under the leadership of Jocelyne Bourgon following Doug Young's instructions in late 1993. This valuation exercise essentially created what Kingdon described as the "policy primeval soup" of ideas that await implementation when the need arises.

In Kingdon's terms, the problem window opened in early 1994 when the Chretien government signalled a need to urgently address the deficit. With the political mood in favour of reforms, the policy solution was awaiting implementation. All that was required was the implementation of a policy response by a policy entrepreneur, or someone who would couple the three streams into reality. The primary entrepreneur in this situation was Doug Young, who by both personal and political desire sought and successfully led the privatization of $\mathrm{CN}$. This case demonstrated that some policy ideas, such as the privatization issue, do not occur randomly but are only implemented when all three streams are linked in a given policy space.

\subsection{Conclusion}




\section{Relationship between Political Leadership and Bureaucratic Responsiveness}

Major operational and policy decisions at CN during the 1970s and 1980s were administered within the Crown Corporation and not the senior bureaucracy at Transport Canada. In theory, this structure presented a rather unique policy making environment, as an independent Crown Corporation would appear to present a formal, rigid relationship between $\mathrm{CN}$ and its political masters. In reality, however, $\mathrm{CN}$ experienced heavy political interference in all its operational decisions during this time from Cabinet ministers and members of Parliament of all political stripes.

Comparing the record of the two major federal parties reveals that the Progressive Conservatives engaged in greater political interference of CN's operations than the Liberals. The Conservative Minister of Transport, Don Mazankowski, often gave direct personal advice to CN's board of directors, such as instructing them to divest all of CN's unprofitable assets in the late 1980s and recommending that the corporation focus nearexclusively on direct rail operations. Ironically, however, Mazankowski twice denied Ronald Lawless' requests to privatize CN. As a Western Canadian, Mazankowski was more focused on better rail services, deregulation and granting more power to shippers, which were much greater political issues in his region than privatizing $\mathrm{CN}$.

Perhaps most interesting to the political-bureaucratic relationship in this chapter is the swift emergence of senior bureaucrats at Transport Canada into CN policy discussions during the early 1990s. Furthermore, this period featured a predominantly harmonious relationship between the bureaucracy and political leadership. The new Minister of Transport, Doug Young, issued instructions for senior bureaucrats to conduct 
a thorough review and valuation of CN's assets and investigate the possibility of privatization. Due to strong bureaucratic leadership, however, the bureaucracy had already commenced an internal review process and was in effect 'on the same page' as Minister Young. In this case the bureaucracy was demonstrating its ability to adapt to macro and political realities, most likely from the realization that high federal deficits and crumbling transportation infrastructure meant that urgent reforms were required. The political maneuvering during this era was Doug Young's determination to convince his fellow Cabinet members to approve a full privatization of CN's assets, despite opposition from other 'statist-minded' ministers to retain ownership of certain $\mathrm{CN}$ assets. A rarity in public policy, the $\mathrm{CN}$ privatization experience was an idea that was simultaneously supported by the bureaucracy, CN management, and political leadership.

\section{Concluding Remarks}

This chapter presented an example of an arm's-length Crown Corporation that was forced to compete against private sector rivals, only to be restricted by its public governance framework. Since the appointment of Robert Bandeen as its President and CEO in 1974, CN strongly lobbied its political masters for permission to conduct itself like a private corporation, such as through laying off redundant workers, abandoning unprofitable rail lines, and divesting non-rail entities that contributed to its expanding debt. Some ministers, such as Otto Lang, lent personal moral support to CN's lobbying efforts, although none were willing to take a stand in support of $\mathrm{CN}$ by engaging MPs or refusing to make political patronage appointments to $\mathrm{CN}$ 's board of directors.

The election of the first Progressive Conservative government in nearly thirty years brought false hope to CN's desire to obtain more operational independence. 
Despite the presence of a pro-privatization, neoliberal ideology, the Conservatives repeatedly denied CN's verbal requests for privatization for fear of a perceived high political risk. Initially led by Don Mazankowski, the government's focus on the rail sector was limited to deregulation for the benefit of shippers and suppliers.

By the time the federal Liberals returned to power, there emerged a perfect storm of policy conditions in favour of privatization. The forces for change were led by an urgent need to resolve debt and deficit issues, a strong minister who was prepared to take the political risks, an energetic and highly capable public service, and a determined head of CN. The term "policy miracle" is used to describe these events, which took an organization that was on the verge of requesting a third recapitalization from a government that could not afford it to a fully private enterprise in less than two fiscal years.

In the years following privatization, $\mathrm{CN}$ Railway has been held as a model for government divestiture. The current CEO, Claude Mongeau, has frequently spoken of the need for governments to become more innovative and willing to reduce the regulatory burden on businesses, citing $\mathrm{CN}$ as a success story. In particular, he claimed that $\mathrm{CN}$ pays over a billion dollars per year in taxes to the three levels of government, has invested in various retirement funds, and has modernized the Canadian rail network to the benefit of other supply chain partners (Abma, 2012). In Mongeau's view, "[i]t took courageous public policy to decide that the way to get $\mathrm{CN}$ to the next level was to privatize it and make it a publicly traded company" (Abma, 2012, p. B6). 
The research in this chapter has revealed a rare occurrence of agreement in favour of public policy reform by public servants, the general public, the political elite, and the private sector. As Kingdon's theory of policy windows demonstrated, such a corresponding occurrence of events requires many factors, most notably strong leadership and a quick response by policy makers to implement reforms. In fact, differences in political and policy circumstances, as well as timing, occurred a different points in time and to different degrees in airport and port governance reforms, resulting in substantially different policy outcomes, as the next two chapters will demonstrate. 


\section{Chapter Four: Federal Airport Reforms in Canada}

There is no reason why airports should not be economically self-supporting and operated for passenger comfort. $^{41}$

\subsection{Historical Summary}

\subsubsection{The Origins of Airport Governance Reform: 1970-1984}

\section{Sparking a Revolt: The Choice of Pickering Township}

By the late 1960s, the addition of jet engine aircraft to commercial airline fleets enabled air travel to surpass rail transit and the automobile as the number one choice for long distance passenger travel in Canada and the United States. Canada's major airports - Toronto ${ }^{42}$, Montreal and Vancouver - were quickly approaching maximum passenger capacity, which prompted the federal government to consider long-term plans for new airport infrastructure (Budden and Ernst, 1973; Stewart, 1979; Feldman and Milch, 1983). Following two years of internal analysis, the Liberal Minister of Transport, Paul Hellyer, announced in December 1968 that his department had established a short list of four potential suburban sites for a new international airport in Toronto (Ibid). Much to the surprise of the Minister and Transport Canada officials, significant public opposition

\footnotetext{
${ }^{41}$ Mr. Justice Hugh F. Gibson, Chairman, Report of the Airport Inquiry Commission (Canada, 1973, p. 210).

${ }^{42}$ According to Feldman and Milch (1983), the federal government's controversial decision to build a new international airport in suburban Toronto had the greatest impact on airport governance reforms in the late 1970s. Consequently, the analysis in this thesis will focus solely on the Toronto airport decision and will not discuss the Montreal or Vancouver airport cases due to space and scope constraints.
} 
to the announcement ensued from virtually all key stakeholders associated with the planned airport development.

The main opposition to the four proposed airport sites originated from local residents, who feared that a new airport development would negatively impact residential property values and create significant noise disturbances (Budden and Ernst). As a result of this pressure, Transport Canada announced in early 1970 that it would conduct further internal research into other proposed airport sites in the Greater Toronto Area (GTA) (Ibid). Following two years of research, the next Minister of Transport, Don Jamieson, announced in March 1972 that the new airport would be located at Pickering Township (Budden and Ernst; Stewart; Feldman and Milch). Local stakeholders, such as local municipal governments, businesses and residents were outraged with the decision, and claimed that "the federal... authorities had made their final selection of a site for Toronto II without any public participation in the planning” (Budden and Ernst, p. 99).

The 1972 federal election reduced the governing Liberals from majority to minority status in Parliament. Further stakeholder pressure ensued to convince the new Minister of Transport, Jean Marchand, to reverse his predecessor's Pickering decision and hold public consultations on the issue. Transport Canada conducted public "consultations" (but not "negotiations") for the next two years with no clear replacement for Pickering (Budden and Ernst). In the provincial election of 1975, the Ontario Progressive Conservative government lost its majority status and subsequently withdrew support of the Pickering site to avoid potential political storms in a minority legislature (Ibid). As the lone officially recognized partner in the airport development project, the departure of the Ontario government left the Minister of Transport with no pro-Pickering 
supporters. Realizing the project was now politically dead, Minister Marchand formally announced the cancellation of the Pickering project in September 1975 (Ibid).

\section{Emergence of the Non-Profit Airport Authority Concept}

Due to the public and political turmoil generated by the Pickering issue, Minister Jamieson announced plans on the eve of the 1972 federal election for a commission of inquiry to study the federal government's location of the airport (Feldman and Milch). Nearly a year later in October 1973, the government launched the commission and prescribed two goals: identify any potential new evidence not previously considered by the government in the choice of Pickering; and offer recommendations on the development of the new Pickering airport, such as a suggested opening date and proposed solutions for ground transportation access to passenger terminals (Canada, 1973).

Despite the narrow scope of requirements for the inquiry, the commission widely diverged from its mandate in three key areas. First, it criticized the airport decision making process at Transport Canada. For example, the commission argued that the decision to forecast airport growth in the GTA until 1980 was too short a time frame and instead recommended forecasts until the year 2000. In addition, it claimed that Transport Canada should shift its planning objectives to ensure that passengers, and not airlines, become the primary focus of airport operations.

The second divergence occurred with the commission's recommendation for the federal government to improve its collaboration with major stakeholders in airport governance, such as the provinces, industry, municipalities, and local community groups. Of all these stakeholders, the commission argued that local communities are one of the 
most important given that strong community cohesion contributes to forming the economic foundation for an airport. The commission also chided the federal government over past lacklustre airport planning choices that led to poorly designed terminals, inconvenient airport locations, and insufficient public transit infrastructure.

The third and perhaps most dramatic divergence from the government's terms of reference was the commission's recommendation for the establishment of a non-profit, arm's-length airport authority for southern Ontario. According to the commission, this airport authority model would be beneficial to all parties, since (Canada, 1973, p. 242) [emphasis added]:

The Ministry of Transport, Canada, would be freed from the day to day problems associated with the development and operation of airports. It could concentrate on the development of a comprehensive balanced plan...so vital for an efficient and economical national air transportation system.

The commission further argued that there should "be no valid reason why our airports should be operated at a financial loss" (p. 242). It also argued that each airport authority should feature a part-time board of directors, composed of local community members who could contribute to policy and planning decisions.

\section{The Task Force on Airport Management}

As outlined in Chapter Two, the fiscal realities of this period prompted senior Transport Canada officials to engage in discussions over the future of the national transportation system in May 1977. Several working groups were struck that examined all major programs and operations within the department, resulting in the primary conclusion that " $[\mathrm{m}]$ any of the facilities owned and operated by Transport Canada are not 
now financially self-sustaining" (Transport Canada, 1979b, p. 17). In light of this decision, senior management proposed the following two policy objectives (Ibid, p. 18):

To minimize federal involvement in those areas that are under the jurisdiction of, or can be more efficiently provided by, other levels of government or the private sector; [and] [t]o create decentralized, locally-administered and financially selfsupporting operating subsystems of the national transportation system under federal jurisdiction.

For sites such as airports, senior management recommended that "a policy of establishing self-supporting facilities is a feasible alternative to departmental ownership and operation" (Ibid, p. 19).

The department responded to this call to action by creating the Task Force on Airport Management in December 1977. The Task Force was assigned a relatively broad goal, namely "to examine the extent to which decision making powers on the future operation and development of Canada's major airports can be transferred to local communities" (Canada, 1979d, p. 1). Following more than 12 months of national consultations with local communities, non-profit associations and business groups, the Task Force released a two volume progress report in July 1979. The main conclusion from the consultation process was "that there was a high degree of interest in having a new management structure which would provide for increased local participation in airport operations and development" (Canada, 1979c, p. 1). As a result of this process, the Task Force announced that it had adopted four specific objectives for future work (Ibid, p. 3):

(i) Local autonomy;

(ii) Financial viability;

(iii) Airport system integrity; [and]

(iv) Managerial efficiency, effectiveness and accountability 
Despite only reaching the midpoint of its mandate, the Task Force was overwhelmingly convinced of the need for airport governance reforms. It therefore concluded that the non-profit, arm's-length airport authority structure should be implemented across all large and medium sized Transport Canada controlled airports (Ibid). The Task Force highlighted several benefits of this governance concept, namely increased "local involvement in an executive capacity," the "transfer of maximum decision-making powers to the local level," and "improve[d] managerial efficiency and effectiveness by reducing the number of decision-making levels" (p. 96).

As discussed in Chapter Two, the newly elected minority Progressive Conservative government embraced the Task Force's recommendations but lost the confidence of the House of Commons while attempting to pass its first budget in December 1979. The resulting federal election of February 1980 returned a majority Liberal government to power, while poor national economic performance dominated the government's fiscal agenda. Consequently, airport governance faded from the list of federal transportation priorities for the remainder of its four year mandate (Farquhar in Senate of Canada, 1991a; Dion, 2002).

\subsubsection{The Creation of Local Airport Authorities: 1985-1992}

The newly elected Progressive Conservative government wasted little time implementing its new transportation policy agenda upon assuming office in late 1984. In his inaugural budget speech in May 1985, the Minister of Finance, Michael Wilson, announced (Finance Canada, 1985, p. 40):

[T] he government will pursue the development of a new management structure for the federal airport system in Canada. Options will be presented for 
consideration this year to provide for a self-sustaining system, incorporating the principle of cross-subsidization of smaller airports, which will allow for the independent operation of local airports.

In addition, the Minister of Transport, Don Mazankowski, commissioned an Airports Task Force in October 1985 composed of private industry representatives, local government officials and senior managers at Transport Canada to study the management structure of Canada's federally owned and operated airports and propose recommendations for more effective and effective future airport operations.

As discussed in Chapter Two, Minister Mazankowski next released the policy blueprint, Freedom to Move, in June 1985 with the goal of transforming the federal transportation system into one of less regulation, more efficient management structures, and more commercialized operations. The document noted, for example, that airport "operational activities will be conducted in a more commercial manner and will encourage freer competition” (Transport Canada, 1985, p. 22). In September 1986, Mazankowski's successor, John C. Crosbie, released the Airports Task Force Report, entitled, The Future of Canadian Airport Management. The Task Force had three objectives, namely to improve "accountability, effectiveness and efficiency" of federal airports' management, achieve "commercial viability for as many airports as possible" and "enhance local economic development" (Transport Canada, 1986, p. 3). Similar to the 1979 Airports Task Force, the 1986 version recommended the establishment of local airport authorities that received the support of provincial and local governments. The Task Force also recommended the streamlining of airport services at Transport Canada and an increase in the department's "commercial orientation" (Ibid, p. 5). 
The momentum towards the creation of airport authorities continued with the release of the federal policy statement, A Future Framework for Airports in Canada in 1987 (Valo, 2001; Tretheway, 2006). The document indicated the federal government's readiness to solicit proposals from interested parties to assume airport operations. Along with eight broad principles on transferring airports, the government cited three main reasons for transferring ownership of airports: namely to recover its investment costs, maximize airport revenue streams, and contribute to the economic well-being of the federal government. Public feedback to this policy framework was lukewarm, with most criticisms focussed on the ambiguous nature of the document (Ibid).

As a result this ambiguity, the federal government released the Supplementary Principles for the Creation and Operation of Local Airport Authorities in May 1989 (Transport Canada, 1997; Valo, 2001). The 36 principles were divided amongst five sections: general policy matters; personnel matters; safety and security issues; financial matters; and community relations. The major themes of the supplementary principles were that divestitures would be operated with a private sector mindset and would be initiated by local community interests with the goal of contributing to the region's economic development.

After nearly two decades of planning, the first significant initiative began with the creation of Local Airport Authorities (LAAs) between 1987 and 1993. The Airport Transfer (Miscellaneous Matters) Act of 1992 provided the legislative framework for airport divestiture, including the right of the federal government to select airports for conversion to LAAs (Senate of Canada, 2012). The Minister of Transport, Doug Lewis, formally announced the transfer process as follows (House of Commons, 1991, p. 1:11): 
Our aim with this policy is to enhance the efficient commercial operation of the federal airports through a more locally responsive management structure. With local authorities at the controls, airports should be able to respond quickly to changing needs and market forces with innovative ideas. The flexibility that will be afforded to the local airport authorities will enable them to take advantage of the entrepreneurial opportunities that present themselves, and will help them to contribute directly to regional development initiatives.

The four cities chosen for airport divestiture were Vancouver (International Airport), Edmonton (International and Local Airport), Calgary (International) and Montreal (Dorval and Mirabel) (Brooks and Prentice, 2000; Valo, 2001). As Brooks and Prentice outlined, these airport authorities operated as private, non-share capital authorities and leased the airports from the federal government for a minimum period of 60 years, in exchange for mutually agreed rent payments. Valo explained that the agreements were finalized after many negotiation breakdowns that resulted in unique contracts for each of the airports. Under the final agreements, the department remained responsible for air navigation and safety and security services, while the newly created LAAs administered day-to-day business operations. As Minister Lewis remarked, "Transport Canada will take care of the air side of things, and all of the commercial ventures will be handled by the local airport authority" (House of Commons, 1991, p. $1: 24)$.

\subsubsection{The Emergence of Canadian Airport Authorities: 1993-2000}

Although the principle of divestiture was unopposed in the LAA process, the lack of accountability mechanisms in the LAA governance structure became a popular topic in the 1993 federal election (Tretheway, 2006). Most notably, the Liberals accused the Conservative government of political favouritism during divestiture negotiations with 
LAAs. The political controversy emerged as one the major transportation issues during the election campaign and resulted in a promise by the federal Liberal Party to revise the airport divestiture process if elected to government (Brooks and Prentice, 2000). ${ }^{43}$

When the new Liberal Minister of Finance, Paul Martin, rose to present his government's first federal budget on February 22, 1994, he announced "[t]he era of closed door budgets is over," and declared that the public demanded "[a] Canada where our public finances are in order, not ruin" (Finance Canada, 1994a, p. 1). Consequently, the federal budget pledged to reduce government spending over the next three fiscal years, with the goal of lowering the deficit to three percent of national GDP by 1996-97 (Finance Canada, 1994b). With respect to Transport Canada, the budget noted (Ibid, p. 29):

In order to improve efficiency and achieve long-term savings for the Crown, the Department of Transport will review the potential for commercialization of a number of its major activities...in close consultation with all affected parties. (p. 29).

In response to this budget, the new Minister of Transport, Doug Young, rose in the House of Commons on March 10, 1994 to outline his department's new approach to national transportation policy ${ }^{44}$ (Young, 1994):

\footnotetext{
${ }^{43}$ The Liberals also followed through on an election promise upon assuming power and promptly cancelled the planned private sector terminal expansion of Toronto's Pearson International Airport and subsequently replaced it with a non-profit, arm's-length model derived from the CAA governance framework (Brooks and Prentice, 2000; Valo, 2001).

${ }^{44}$ This speech by Minister Young was a prelude of his much publicized "Thunder Bay Speech" which was presented to the Thunder Bay Chamber of Commerce shortly after it was delivered in the House of Commons on June 3, 1994.
} 
We are spending a lot of money in this country for transportation....We have to recognize that some of Canada's transportation systems are overbuilt and far too heavily subsidized....We must separate the desirable from the essential - and the essential must be the focus of the transportation system of the future. There are tough decisions to be made.... The time has come for government to look at new ways of providing services....Times have changed and we are going to have to reflect that.

With respect to airports, Minister Young and his department wasted little time in announcing a new national governance strategy. The Minister publicly announced the National Airports Policy (NAP) in July 1994, which created several classes of airports, ${ }^{45}$ including newly renamed Canadian Airport Authorities (CAAs) under the National Airports System (NAS) for the nation's largest sites (Ventura, 1995; Brooks and Prentice, 2000; Valo, 2001; Tretheway, 2006). Airports were classified as CAAs based upon their position of serving at least 200,000 annual passengers and/or situated in a provincial/territorial capital.

In addition to rebranding the proposed airport entities as CAAs, the federal government also brought forward additional accountability provisions when negotiating the new airport governance framework. Of note, the new principles sought to further define the composition of the boards of directors and the qualifications of its members, as well as expand requirements for financial audits and consultations with local communities (Transport Canada, 1994a; Tretheway, 2006). For example, similar to the

\footnotetext{
${ }^{45}$ The classes of airports under the NAP included: (i) the "National Airports System" for airports with more than 200,000 annual passengers and/or serving a provincial or territorial capital; (ii) "Regional and Local Airports" with annual passenger traffic below 200,000 passengers; (iii) "Small Airports" for sites where the federal government traditionally provided federal funding assistance but do not host regularly scheduled passenger traffic; (iv) "Remote Airports" for sites where air service is the only year-round transportation service option; and (v) "Arctic Airports" for sites located in the three territories that were traditionally funded by the federal government (Transport Canada, 2010)
} 
previously divested LAAs, CAAs were defined as non-share capital corporations, but faced significantly different appointment processes. Nominees for Boards of Directors were required to include appointments from Transport Canada, the relevant provincial transportation ministry, and other stakeholders such as the business community and union representatives.

By the time the Minister of Finance released his second budget in February 1995, Transport Canada had signed more than 40 letters of intent to develop CAA agreements with individual airports, and had accomplished the divestiture of nearly all federal Arctic airports to the Government of the Northwest Territories (Ventura, 1995). The department had also projected cost savings of $\$ 110$ million and employment reductions of nearly 2,000 employees between fiscal years 1995-96 and 1997-98 from the planned implementation of the National Airports Policy (Transport Canada, 1995). Talking points prepared for Minister Young at the time noted that the CAA approach was "a bold airports' initiative which, while being uniquely Canadian, is consistent with what many other nations are doing and...is something we can ill afford not to do" (Transport Canada, 1994b, p. 13).

\subsection{Meso Analysis}

\subsubsection{Micro Influences}

The Pickering Era: 1970-1975

The organizational culture within the airport management groups of Transport Canada in the early 1970s was very uniform and technocratic in nature. Expressed in terms of Schneider's (1987) ASA framework, employees were similarly "typed" in their 
beliefs that only Transport Canada possessed the knowledge, experience and technocratic expertise to administer current airport sites and plan for new developments. Little discussion or analysis occurred outside the department, except in situations that required contributions from external consultants. Such consultant contributions were usually limited to piecemeal projects, however, and authors were seldom privy to major decision making activities. Moreover, Transport Canada officials did not consider formal discussions with external stakeholders necessary to their decision making, with the exception of occasional meetings with provincial counterparts on transportation matters outside federal jurisdiction (Buddent and Ernst, 1973).

From a leadership perspective, Transport ministers Don Jamieson and Jean Marchand were not of the transformational leadership calibre described by Denis et al. (2007). Their political leadership was neither entrepreneurial nor transformative, and they often made decisions that favoured political choices over bureaucratic policy recommendations. From Magee and Frasier's perspective, Jamieson and Marchand possessed the power to hold firm on their decision of Pickering as the choice location for an airport. However, they clearly lacked the status, or what the authors termed the "degree of respect" that includes concerns for other stakeholder interests. Furthermore, Magee and Frasier argued that status and power are based on the environmental context of the decision, as many stakeholders and environmental factors are likely to influence policy decisions. In this case, it was clear that the decision by the ministers of Transport and Transport Canada officials to not engage local stakeholders directly contributed to the eventual cancellation of the Pickering airport location. The ministers in these cases 
lacked not only an entrepreneurial vison but what Magee and Frasier described as a reasonable degree of flexibility in their responses to changing policy conditions.

The decision to unilaterally proceed with Pickering as the location for the new Toronto airport was enacted based on political and not organizational strategies. In the terms of Mintzberg and Jorgensen (1987), the decision was neither a deliberate nor an emergent strategy of public policy decision making. It was not a deliberate decision, as it was a planned but eventually unimplemented decision. The choice of Pickering was also not an umbrella strategy of guidelines dictated from the Minister for implementation by senior management. Feldman and Milch, for example, noted that several senior members of the Transport Canada Aviation Group resigned in the early 1970s as a protest to the Minister's decision to remove them from departmental task forces and adopt Pickering as his preferred location for the airport.

The Pickering decision also did not meet Mintzberg and Jorgensen's criteria of an emergent strategy, as the origin of the decision occurred from the Minister and not from within the Transport Canada bureaucracy. More specifically, Budden and Ernst's research noted (1973, p. 118):

These [declassified government] documents...provide evidence that the [Minister's] assumptions were part of the mental baggage of the politicians, rather than the [bureaucratic] planners. There are many instances where planners recognized their inherent weaknesses, and presented evidence based on sound technological facts to counter them. But the politicians either ignored or contradicted that evidence.

It is evident that a clear disconnect occurred between the Minister's political choices and bureaucrats' policy choices. Such an occurrence most likely led to an unhealthy work 
environment, particularly concerning the relationship between senior management and the Minister's office. Moreover, the bureaucracy's loyal and impartial role of publicly defending the Pickering decision cast public doubt as to the ability of the public servants to conduct responsible and effective airport governance and planning.

\section{Emergence of the Non-Profit Airport Authority Concept}

The political and bureaucratic actions surrounding the location of Pickering were analysed in detail by the Airport Inquiry Commission in 1973. As previously mentioned, the report recommended that airport governance responsibilities be transferred from the federal government to arm's-length airport authorities. The commission argued in favour of devolution due to the complex nature of airport management that was, in its view, not conducive to bureaucratic control (Valo, 2001). In particular, the commission concluded, "[t]here are good capable people in government, but they cannot be asked to accomplish great things with poor machinery" (Canada, 1973, p. 245).

From a strategic perspective, this policy recommendation occurred outside of the political and bureaucratic spheres of airport decision making. The inquiry's commissioner, Hugh F. Gibson, was a respected federal court judge and was not politically pressured into endorsing the Pickering location, as observed by his three major divergences from the terms of reference outlined above. It is also apparent that the commission's primary recommendation that an arm's-length airport authority concept be applied to federal airport planning served as the original seed of an idea that germinated in the Department of Transport until it was finally implemented in 1986. Consequently, the airport authority concept provided a unique case of transportation policy that was 
implemented by an independent commission and not through political or bureaucratic channels.

\section{The Task Force on Airport Management}

As introduced in Chapter Two, widespread criticism of the federal government's fiscal spending practices in the 1970s led to a review of Transport Canada's policy priorities. The policy document, Transport Canada: Its Roles and Objectives, was created and written entirely by senior bureaucrats (i.e., without any direct political influence) and wasted little time addressing the need for reform. Likely influenced by previous critiques from observers such as the Airport Inquiry Commission, the document summarized the results from senior management working groups conducted in May 1977. The first objective originating from the discussions emphasized "[t]he need for effective communication of departmental purpose within Transport Canada" (Canada, 1979b, p. 1). Stated more specifically, senior management indicated (Ibid, p. 2):

It became apparent at that time that, if Transport Canada were to make the best resource allocation decisions possible in response to the changing priorities of government, it must develop common agreement, understanding and commitment to a set of objectives which would provide an appropriate framework for the setting of priorities and serve as a guide both for future policy decisions and for communicating among the various groups in Transport Canada and externally the kinds of projects that would be necessary.

From a leadership perspective, it is clear that senior management collectively agreed to realign the department's policy priorities towards the needs of its stakeholders to achieve cost savings and a more targeted, efficient provision of services. Interestingly, the research conducted has revealed that such a transformational decision was implemented collectively by the senior management working group and not one specific individual. However, this strategic reorientation provided a clear and attractive vision of 
the department's immediate future that laid the foundation for governance reforms (Denis, Langley and Rouleau, 2007).

In terms of strategic planning, the department's senior management implemented a top-down approach to future decision making. Senior managers were henceforth instructed to ask themselves "What business are we in?" when considering options for governance reforms within Transport Canada (Canada, 1979b, p. 7). When examined from the lens of Mintzberg and Jorgensen (1987), this top-down approach was intended as a deliberate strategy, but it was not fully implemented until the late 1980s. It is worth noting, however, that this approach qualifies as a disconnected strategy, in that it involved a planned shift in organizational culture that was well received by the department's employees. Unfortunately, a lack of political will to proceed with the recommended reforms resulted in the postponement of the governance changes until the Mulroney era.

\section{Creation of Local Airport Authorities}

The implementation of the Local Airport Authority framework at Transport Canada provides an interesting example of the interaction between organizational culture, leadership and strategic decision making. Research has revealed that when the Progressive Conservatives assumed power, the organizational culture at Transport Canada was divided as to the future approach to airport governance. According to Michael Farquhar, the Deputy Executive Director of the Second Airports Taskforce (Farquhar, 2014):

[T]he Conservatives instructed the department that they wanted to proceed with the airports divestiture policy and begin exploring how to divest airports. Initially, the department was hesitant and no major developments occurred for the first year or two of the Conservatives' mandate. As I understand it, ministers finally 
instructed the Department that if it did not proceed with the divestiture then it would establish a political task force to begin the process.

Following ministerial decree that the department proceed with airport reforms, a constructive but unorthodox proposal emerged on airport divestiture from the Executive Director of the Airports Transfer Task Force. According to Dr. Lloyd McCoomb, a former Transport Canada Director General (McCoomb, 2014):

At the same time within Transport Canada, the Executive Director of Airports made a significant attempt to demonstrate to the federal government that the same type of cost savings and efficiencies could be obtained by converting the airports to government agencies. He constructed a Crown-corporation type model, but he was moving against the strong belief by the Minister and Deputy Minister that the airports be devolved. The Executive Director made the argument that there could be efficiencies from areas such as mass purchase of equipment, critical numbers to train staff, and a career development process whereby you could promote individuals from smaller airports to larger ones as they gained experience.... Despite the amount of good work under this proposal, it was not aligned with the political philosophies of the political masters and senior bureaucrats of that time.

Upon examining the organizational culture of this period, the evidence suggests

that the department's senior management was not operating in unison with the political leadership of the period. It is therefore most likely that the political leadership decided to release the abovementioned policy statement, A Future Framework for Airports in Canada, in 1987, which provided the original eight fundamental principles to guide the department's bureaucrats in the negotiation process for airport devolution. Although this document was publicly criticized for its vagueness, it appears to have been well received internally by the department's bureaucrats as 'marching orders' for airport transfers. For example, former Transport Canada Senior Legal Advisor, Jacques Pigeon, commented (Pigeon, 2014): 
[T] here was a very skeletal policy statement, which was called the eight fundamental principles, and then it was supplemented by 36 supplementary principles. When we started this initiative, we didn't have much of a formal statement of policy. The outer boundaries were well defined. In [the eight fundamental principles], there was enough so that we knew where the outer boundaries were, but inside them, the bulk was pretty much up to us....In other words, the broad parameters were spread out, but then [the Minister] said go negotiate, and of course the power to negotiate was all ad-referendum the cabinet. So if we had strayed from policy intentions, or even if we had strayed from unstated policy intentions, the approval would not have been forthcoming. I believe this policy was a great success.

From an organizational perspective, the department's bureaucrats were in favour of airport reform but had not achieved universal agreement on an approach to devolution. The political cadre (e.g., Ministers Mazankowski and Crosbie) responded with strong leadership and provided the department with guidance through the eight fundamental principles on the government's desired plan for airport governance. Following Magee and Frasier's (2014) approach, these political leaders not only possessed the power to implement policy changes, but they also achieved status and respect from bureaucrats over the decision to provide broad direction from the eight fundamental principles and permit bureaucratic discretion in implementing the details of these reforms.

The eight fundamental principles subsequently led to 36 supplementary principles and a mutual level of respect between ministers and senior departmental managers. By placing ministers and bureaucrats 'on the same page', the department was able to effectively and confidently implement a quality policy framework for airport governance. Cloutier (2014), noted, for example that:

The supplementary principles also worked to help us clarify the airport divestiture issues....As we went along with the process and [stakeholders] would raise issues, we would address them through the establishment of a principle. It also helped to ensure that we had a very strong negotiating mandate. 
From a strategic management perspective, the political leadership provided what Mintzberg and Jorgensen (1987) termed an "umbrella strategy" with the eight fundamental principles to guide the bureaucracy in negotiations. The decision of political masters to provide guidance proved critical, as Pigeon (2014) noted that further bureaucratic disputes over the form that divestiture negotiations should take were at times intense but were always resolved when considered in the context of the eight fundamental principles. The subsequent decision of political masters to avoid micromanaging the divestiture details was also greeted with appreciation by bureaucrats and contributed to a general level of mutual respect between the two groups that continued well into the 1990s. As Farquhar (2014) commented:

I believe that every ministerial engagement on this file was cast as a good news story. Regardless of the political stripe of the government, there was always a political will in favour of the reforms. It's quite remarkable that there was even little to no time lost between the shuffle of governments.

\section{The Creation of Canadian Airport Authorities}

By the time the federal Liberals assumed power in late 1993, the transition to nonprofit, arm's-length airport authorities was already well underway. By mid-1994, however, the pace of reforms quickly accelerated and had cemented the shift towards a reduced federal role in transportation. Such a dramatic shift in airport divesture brought a subsequent shift in organizational culture. From a department-wide perspective, departmental documents began referring to "The New Transport Canada," where (Transport Canada, 1995, p. 9): 
No longer will the department own, operate and subsidize large parts of the system. Instead, it will:

- Focus on its core roles of:

- Developing policy and legislation; and

- Formulating and enforcing standards for safety and security

- Act as landlord, in cases where commercialized assets remain federal property; and

- Continue to ensure reasonable service to Canada's remote communities and for Canadians with disabilities.

This state of rapid governance changes revealed the diversity of several departmental subcultures at Transport Canada that were not as prominent in the previous periods studied. In general, a difference of perspectives emerged between the policy analysis stream of employees and the operational stream (e.g. program officers) within the department. According to Moya Greene (2014), the former Assistant Deputy Minister, Policy:

In the Policy Group, I think there was a clearer understanding that the approach that the government was taking to transportation was not sustainable. It was neither leading to good commercial organizations, modern infrastructure, and it was spending a huge amount of money on the wrong things.... These subsidies were highly distortionary, and so it created a lot of regional economic distortion.... So I would say that inside the Policy Group...there was a clear understanding that it was not incremental change that was required, it was really wholesale change that was required.

In the wider department, I'd say there was more resistance. There were a lot of people who had built their careers justifying these subsidies, and justifying the complexity that was inherent in many of these subsidy programs, because there was a kind of specialized expertise that you only acquired if you were directly involved in the payment schemes that were the essence of them. When you call for the elimination of these subsidies, there are many, many interest groups who come to fore and say that there will be disastrous consequences for the country or for the region if they are eliminated, and there were many people inside Transport Canada who shared that view.

I think it depended on where you sat, actually. 
Such a wide divergence of opinions towards reforms poses the potential to significantly disrupt the harmony of any organization. At Transport Canada, senior managers were faced with the dilemma of implementing change in line with the wishes of their political masters while also facing the disdain for change from thousands of their operational employees. Stated another way, senior managers were not only forced to address the current issue of divestitures, but were also challenged to maintain the morale of potentially affected employees, not to mention the reputation of "The New Transport Canada." Furthermore, the potential for labour disruptions and low employee morale threatened to compromise airport divestiture efforts, which would have in turn jeopardized the federal government's commitments to deficit reduction.

Bureaucratic leadership was therefore a crucial component of success for the airport divestiture process. As previously mentioned, when Jocelyne Bourgon became Deputy Minister in June 1993, she immediately began a review of "the whole" of Transport Canada's policies and operations in order to prepare the transition process for the next government following the federal election that October. Moya Greene offered the following comments about this period:

[W]e did a huge amount of work in Transport in the year-and-a-half before the Chretien government came to office, to design and build-up the argumentation that would support a massive reduction in these subsidies.... We presented that and became the first department to get our budget approved....In Paul Martin's first budget [1994], I believe it was Transport that contributed the most immediate and important reduction in government expenditures, simply because we had spent a year-and-a-half before getting ready.

Following her promotion to Clerk of the Privy Council in March 1994, Bourgon recommended the appointment of former Transport Canada senior manager, Nick 
Mulder, as the new Deputy Minister. This proved to be an important decision, as Mulder possessed a detailed knowledge of the national transportation system and enjoyed a high level of respect amongst his colleagues and major stakeholders. It was during his time as the department's chief bureaucrat that Mulder displayed the characteristics of an inspirational leader outlined by Denis, Langley and Rouleau (2007). In particular, Mulder fundamentally believed that "government should steer, not row" and he fully embraced the airport divestiture process advocated by the Minister of Transport, Doug Young. As Magee and Fisher (2014) explained, a strong leader is someone who employs his/her status and power to convince stakeholders (e.g. employees) of not only the need for change, but also to encourage their participation in reforms. Instead of unilaterally prescribing change, Mulder sought to ensure employees were always kept abreast of new developments and had the opportunity to provide feedback during the divestiture process. According to one of his successors, Louis Ranger (2014):

The management of the day made a commitment that there would no one fired. There was quite a lot of risk taken by saying that. I think that you remove about 75 percent of the push-back and criticism when you say that....There were all kinds of comforts that were provided. It was much more easily accepted than one might think....Y You could either be no worse off or you could see an opportunity to be part of a new organization and be in a position of authority.

Sure, there was some push-back, but there was an incredible amount of communication done with the Deputy Minister [Nick Mulder] having monthly video conferences across the country with groups in every region and in Ottawa, and there would be no dirty questions. There were some tough decisions that had to be made, and even though the Deputy went through a process to outline some options, it was pretty clear that he had an idea of where he wanted to go with this. In the end there was no surprise that he declared his intention for reform. During the process, employees were asked to rank the three positions they'd like to be in, and the Deputy did his best to make sure one of those preferences would occur. 
Mulder's ability to implement dramatic reforms at Transport Canada while maintaining high employee morale was also a testament to his strong leadership team. Many of the department's senior managers, such as Moya Greene and Victor Barbeau, had worked with Mulder in previous positions and also possessed a high level of transportation expertise and experience in dealing with its many stakeholders. As Mulder (2014) commented, "we had a unique combination of individuals who all knew one another....So there were no interpersonal relationship problems at all.”

In addition to the morale and implementation challenges present within the bureaucratic ranks of Transport Canada, significant political hurdles had to be overcome in order to make the revised airport divestiture strategy a reality. As previously described, the Minister of Transport, Doug Young, took great interest in his new portfolio and became determined to reform the transportation system into a more sustainable sector. In the words of former senior manager, Gerard MacDonald (2014), "I think that Minister Young took [the department's senior bureaucrats] quite by surprise.” Minister Young was not only prepared to advocate for change at Transport Canada within the department, but also within Cabinet. Former Chretien Cabinet minister, David Collenette (2014), recounted the Cabinet discussion over the proposed airport reforms:

There were a lot of...ministers who felt that the taxpayers of Canada, like what had been done with $\mathrm{CN}$, had invested so much money in the airports over the years....It was quite the tough debate....[b]ut [Minister Young] came back with an option we called commercialization....I think it has been one of the most successful policies we've had in transportation, because it has resulted the refurbishment, or...the total rebuilding of airports.

Doug Young clearly displayed what Denis et al. (2007) termed an "entrepreneurial view" of leadership whereby he demonstrated innovative and flexible 
decision making that was amenable to political, regulatory and policy considerations. As will be further described below in the meso subsection, Young's leadership was similar to Kingdon's version of policy entrepreneurs, as he recognized the 'big picture' and was ready to act when certain policy windows opened. Cloutier (2014) for example, noted [emphasis added]:

The second wave during the Liberal era, which began with the updated 1994 National Airports Policy, was greatly assisted by the arrival of Doug Young as Minister. He was very supportive of our efforts, and at times was even thinking a few steps ahead of us. There was one occasion where the negotiations had slowed and we informed the Minister of our belief that the airport authorities felt we had yet to reach our bottom line of negotiations. We asked Minister Young to meet with the authorities and inform them that we were negotiating under his directive and that no more concessions would be offered. In Toronto and Winnipeg, it only took the Minister about 20 minutes to deliver his message to the airport authorities.

Considering next the strategic management aspects of airport governance reforms reveals that virtually all of the policy decisions that occurred were in fact planned by senior management. Using Mintzberg's (1977) terminology, the airport reforms were therefore a deliberate strategy. In other words, the airport reforms that formed were also formulated. The delegating approach from the Minister to the Deputy Minister, and in turn from the Deputy Minister to his senior management team, occurred as described in Mintzberg and Jorgensen's (1987) umbrella strategy. The primary difference, however, between airport reforms and Mintzberg and Jorgensen's guidelines for an umbrella strategy was that top-down direction was provided but reforms were implemented through a collective effort by many of the department's employees. As discussed above, Nick Mulder's transparent and collective approach with his senior management team and line employees assisted in maintaining civility within the organization and avoided labour 
disruptions during the critical 1994-96 transition period. Morale within the department and the newly established airport authorities remained high, which provided a unique example of a peaceful transition between management structures in such a large organization.

\subsubsection{Macro Influences}

The Pickering Era: 1970-1975

The policy making environment of the early 1970s clearly exhibited the features of Dwivedi and Gow's (1999) administrative state. Jurisdiction over federal airport governance and planning resided amongst a complex web of federal departments and agencies (Feldman and Milch, 1983). For example, airport planning at Transport Canada

for projects affecting urban areas required the approval of the Minister of State for Urban Affairs, as well as the Department of Regional Economic Expansion. Ecological and environmental issues were to be considered by the Departments of Fisheries and the Environment. Financial transactions required authorization by the Treasury Board, and land expropriations were administered by the Departments of Justice and Public Works. According to Feldman and Milch, "the Ministry of Transport saw most of this involvement as 'interference,' but the others saw themselves contributing to comprehensive planning" (1983, p. 24).

Further complicating airport governance in the early 1970 s was political interference from other ministers and MPs who had a vested interest in airport affairs. Feldman and Milch noted that regional ministers and local MPs routinely voiced opinions over the potential locations of proposed airports, which often hindered collective decision 
making at the cabinet, caucus and regional levels. In light of this policy ambiguity, the authors concluded (1983, p. 25):

The federal government, then, cannot be understood as simply the single responsible ministry, or the cabinet, or even the federal bureaucratic establishment. The federal government was seen by opponents throughout the conflicts as a monolithic abbreviation for the Ministry of Transport, but the decision process is more complicated and the federal structures, even at the center, more diffuse.

The culmination of these events also led to serious public doubt as to the effectiveness of the federal government and Transport Canada in the administration of airport services. Major policy errors, such as the proposed airport site of Pickering, angered members of the general public, local businesses and residents, as well as local governments and municipalities. Considered through the lens of historical institutionalism, the Pickering example was the turning point or critical juncture that began to shift federal airport policy away from public operation and towards an arm'slength administrative structure. According to Feldman and Milch, "[t]he record of incompetence, punctuated by periodic malevolence, did not justify the federal government's claim to be the most able and legitimate government [in airport administration] for all Canadians" (p. 27).

Upon closer scrutiny of this critical juncture, the fatal flaw for airport management at Transport Canada during the 1970s was a failure to recognize and incorporate local stakeholders into the federal airport governance framework. Detailed analysis of the policy interactions of this period has demonstrated that there was little interest at both the political and bureaucratic levels of Transport Canada to engage local interest in national airport planning. For example, Minister Jamieson routinely refused 
meeting requests from concerned community groups opposed to the Pickering location, while a senior Transport Canada bureaucrat made national headlines in 1971 when he responded in writing to a local Pickering resident opposed to the airport with: "[ $[$ ]hank you for the time you have taken. You are entitled to your opinion, but in fact, you know that is it" (Budden and Ernst, 1973).

\section{Emergence of the Non-Profit Airport Authority Concept}

The abovementioned public opinions of bureaucratic and political failures in airport planning was also highlighted by the 1973 Airport Inquiry Commission. One of the key conclusions from the report was the commission's belief that local governments and stakeholders must play a central role in airport governance matters. Specifically, it stated that "[a]irports must be, and can be, planned and built to establish an accommodation with the community in which they are located and should be planned and built primarily for the convenience of the public" (1973, p. 255). If the Pickering decision was the critical juncture that began the federal policy shift towards the airport authority concept in Canada, then the commission's report served as the mechanism that "locked-in" this new governance path. In particular, it noted (p. 255):

If we are to avail ourselves of the present opportunity to preserve and expand the central Ontario transportation system, so that it may make its important contribution to the well-being of the nation, all governments will have to surrender some of their jurisdiction to the Airport Authority.

It is also noteworthy that the commission's report was well ahead of bureaucratic and political financial management practices of the time. The commission's recommendation that all federal airports should be financially self-sufficient was at odds with current government policy of cross-subsidization, where profits from a few large 
airports were diverted to cover operating costs at smaller sites. The commission believed that such practices were irresponsible and unsustainable in an era of growing demands for greater and more efficient air services that were constrained by an environment of fiscal restraint. Such conclusions clearly sent a message to the political and bureaucratic establishment that the status quo was not acceptable and that new innovative approaches to airport management should be considered to ensure the competitiveness of the Canadian air sector into the $21^{\text {st }}$ century.

\section{The Task Force on Airport Management}

The negative public feedback from the Pickering decision and governance criticisms from the Airport Inquiry Commission were not the only external factors that encouraged changes to airport governance at Transport Canada. As Chapter Two highlighted, the 1976 Auditor General's report stressed the need for federal departments and agencies to control spending and establish more transparent and effective accountability measures. In addition, the Minister of Finance's quest in 1975 to reduce the rate of annual growth in public expenditures to a rate lower than the annual growth in GNP further encouraged a culture of cost control. The most dramatic and effective call for expenditure reduction occurred with Prime Minister Trudeau's post-Bonn declaration in 1978 that the federal government must shift its priorities to focus on a core social policy mandate.

Transport Canada officials clearly sought to adopt the new federal culture of cost control and program efficiencies in its operations. Following the department's executive retreat in 1977, senior management stated that the "current climate of economic restraint and budgetary cutbacks has caused Transport Canada...to reassess its basic purpose and 
redefine its longer term objectives" (Transport Canada, 1979b, p. 1). Moreover, senior managers were aware of the need to find a compromise between two major possibilities federal transportation leadership, as they admitted that " $[t]$ he department cannot neglect entirely the overall responsibilities of the federal government with respect to 'efficiency' objectives, nor can it afford the levels of expenditures implicit in making a major contribution to 'non-transportation' objectives” (Ibid, p. 9).

The previous subsection described circumstances surrounding how the Airport Inquiry Commission served to "lock-in" the department to the arm's-length airport authority model. It therefore follows that the federal government's decision to reorient policy priorities to social matters in turn encouraged senior managers at Transport Canada to reconsider the department's role in airport operations. More specifically, the department stated its intent at "[r]educing the overall presence of the federal government by...turning some transportation operations over to other levels of government or to the private sector" (Transport Canada, 1979b, p. 1). Expressed in terms of historical institutionalism, the shift in federal priorities to a social policy role provided what Pierson (2000a) described as the increasing returns of a policy decision. In other words, the new policy framework further entrenched the idea of an arm's-length, non-profit airport authority model.

As previously mentioned, the 1978 Task Force on Airport Management was quite direct in expressing its convictions over its preferred choice of airport governance model. It claimed to have been inspired by a quote by Prof. J.H. Perry in 1956, in which he stated, "[s]tarting with the proposition that government departments are neither by structure nor tradition designed for carrying on commercial activities it is not unexpected 
that government would turn to some other form of organization for this purpose (Transport Canada, 1976c, p. 22). The Task Force therefore concluded that "the form or organization, and that the management of a commercial-type activity should not be embedded in a government department" (Ibid, p. 2).

Although on the surface the department's shift to the arm's-length authority model appears neoliberal in character, it was in fact directly motivated by the federal government's call to reorient departments away from non-core social priorities. Delving further into the policy changes of this era reveals that the federal government's intentions were in turn motivated by the need to establish greater accountability controls on federal spending and ensure such spending does not rise at a higher rate than domestic economic growth. Policy documents, such as the Airports Task Force, recognized the need for greater accountability and devolution of management responsibilities to front-line managers most familiar with stakeholder issues, as originally recommended by the Glassco Commission in 1969.

\section{The Creation of Local Airport Authorities: 1985-1992}

As discussed in Chapter Two, the new Progressive Conservative government announced that tackling the national debt and reducing the national debt and deficit would be its most important fiscal policy upon assuming office. It therefore followed that cost savings from divesting federal airport infrastructure to non-profit agencies provided a strong incentive for governance reform. In the words of Michael Farquhar (2014):

The change was mainly driven by fiscal pressures. The airports needed major capital investment and the government did not have the political will - no government of any stripe would have either - to introduce passenger facility 
charges. Revenue wise, the airports were starving and the large airports like Toronto and Vancouver were cross-subsidizing the other [smaller] airports.

The ascent of the Conservatives to power in 1984 also marked the official beginning of neoliberalism at the federal level in Canada. Chapter Two outlined how neoliberal governance reforms in the early 1980s, such as privatization and economic deregulation, spread from the United Kingdom and the United States to other Western democracies, including Canada. According to Aucoin (1988), the new PC government embarked upon a neoliberal agenda with the elimination of previous Liberal initiatives such as the National Energy Program and the passing of a budget that encouraged fiscal restraint. During this time, Transport Canada was directed to review all policies, programs and subsidies in light of the budgetary pressures facing the government (Tretheway, 2006). As part of this federal process, "program reduction, deregulation and downsizing were the intended results of this massive, across-the-board review" (Aucoin, 1988, p. 146).

From a theoretical perspective, the divestiture of airports during the Mulroney era is best described by Larner's (2000) framework of neoliberalism as a form of governmentality. As previously described, this theory presents neoliberalism through a limited economic role for government but with continued public sector involvement in other governance aspects, such as safety and security regulation in the case of federal airports. In Larner's view, such an approach encourages entrepreneurial and innovative strategies within each institution that contributes to organizational well-being.

The Conservative government frequently invoked the flavour of Larner's neoliberalism when promoting airport governance. For example, when outlining the 
Local Airport Authority framework in Parliament, Conservative Senator Normand Grimard stated (Senate of Canada, 1991, p. 189):

It is consistent and complementary to the government's desire to bring rationality to national air transportation. The government believes that this can best be accomplished by the application of the spirit of competition that resides in the private sector. This policy, however, will in no way diminish the one fundamental constant in the Canadian transport industry; namely, safety and security....This has been the constant thread in the tapestry of the department's policies over time. The federal commitment in this regard is sound and wellknown.

With respect to the entrepreneurial features for airports from Larner's neoliberal model, Minister Lewis offered the following comments (House of Commons, 1991, p. 1:11):

Our aim with this policy is to enhance the efficient commercial operation of the federal airports through a more locally responsive management structure. With local authorities at the controls, airports should be able to respond quickly to changing needs and market forces with innovative ideas. The flexibility that will be afforded to the local airport authorities will enable them to take advantage of the entrepreneurial opportunities that present themselves, and will help them to contribute directly to regional development initiatives.

The next stage of the analysis is to consider the timing and sequencing of airport reforms during the Mulroney era. As explained in Chapter Two, historical institutionalism provides a valuable tool to consider significant shifts in policy direction over time. The first step is to examine the context of reforms to identify the beginning of the shift towards airport devolution (Falleti and Lynch, 2009). During the short-lived Progressive Conservative government in 1979, the Minister of Transport, Don Mazankowski, embraced the newly released progress update from the Airports Task Force that called for the establishment of arm's-length, non-profit airport authorities. Despite losing power in the 1980 federal election, Chapter Two illustrated that 
Mazankowski continued work on transportation reforms while in opposition, which led the way to significant governance reforms when the Conservatives reassumed power in 1984.

As previously mentioned, Pierson (2000a) claimed that the costs to governments of moving from one policy track to another are usually high, which implies that current policies are usually "locked-in" for substantial periods of time. It therefore follows that a government would weigh the benefits and costs of adopting a new policy before committing to future action. Given that the Conservatives received a strong mandate in the 1984 election running on a platform of smaller government, there was a low political risk in adopting a neoliberal governance agenda. Consequently, the "exogenous shocks" to airport governance reforms were the election of the Mulroney government and Mazankowski's subsequent publication of the policy document, Freedom to Move. Dr. Mary Brooks (2014) offered the following synopsis of this period:

Mazankowski, of course, released his Freedom to Move masterpiece. I call it that because it changed direction substantially for the regulatory environment in Canada. It was a classic policy paper. The "privatization" of the first four airports grew out of that process, and they went much further along the continuum than subsequent governments were comfortable with. These first four privatizations put an enormous amount of power into the hands of the [local] corporate boards that were created for these entities.

The next stage is to break down the layers of change that were involved in the reforms, and for that it is helpful to employ Falleti's theory of decentralization (2005, 2010). Given that Falleti's theory is based upon the influence of territorial interests in policy making, it provides a useful medium to analyse the devolution of airport operations from federal to local management. As discussed in Chapter Two, the first step 
in Falleti's analysis is to classify the type of decentralization as either administrative, fiscal or political. In the case of airport reforms, the federal government implemented fiscal decentralization to local airport authorities in an effort to provide them with revenue alternatives to federal financing. The principal evidence in support of this type of decentralization is the high level of responsibility delegated to local airport authorities in the running of their airports. For example, all newly created Local Airport Authorities were granted freedom to set fees and passenger charges, develop airport lands, expand and develop retail business in terminal areas, and finance capital expansions. These freedoms were provided in addition to already conceded rights to local management, representation and decision-making in airport governance.

The next step in Falleti's framework is to classify the bargaining activities of primary stakeholders in the devolution process. Under the airport devolution process, stakeholders were of a territorial, rather than partisan nature and mainly included local (municipal) governments, the newly created Local Airport Authorities, and unions representing Transport Canada airport employees. Falleti claimed that partisan and territorial stakeholder interests are interrelated as parties jockey for representation of their interests in the legislature. Under airport governance reforms, however, the proposed divestitures were well received by federal opposition parties and provincial governments, thereby avoiding political manoeuvring during the transfer process.

The final aspect of the decentralization framework is to determine the preference ordering of policy interests and the subsequent sequence of policy reforms. As discussed in Chapter Two, Falleti emphasized that decentralization occurs as multiple layers of policy changes, with the first layer of reforms as critical to determining the subsequent 
layers. Such logic was given serious consideration by Transport Canada bureaucrats during the airport reform process, as Farquhar (1989a) noted at the time that "it will be important in our negotiations to ensure that we take the necessary time with the first agreement to do it right. Clearly, it will be the model for all subsequent negotiations." Such a first-mover advantage allowed the Airports Transfer Task Force to set the parameters of the negotiation process for all airports, while also sending a signal to the other airports that the department would be taking a leadership role in the reform process. John Cloutier (2014), noted:

One of the principles was that there would be consistency of treatment across all airport authorities. That was critical, because you couldn't afford to give an airport something that you weren't able to give another. If you did, the other airport authorities would have demanded the same, and the government simply couldn't afford that. The airport authorities were in constant contact with each other during the divestiture process, and each authority knew exactly what was being discussed.

A key difference in Falleti's framework and the Local Airport Authority process was her prediction that national (i.e., federal) governments would prefer administrative decentralization over fiscal and political decentralization reforms. As previously mentioned, one of the cornerstones of the airport divestiture process was to provide revenue streams to newly divested airports through mediums such as passenger charges and financial capital borrowing. This decision, as opposed to a strictly administrative transfer of responsibilities with no financial avenues for airports, was most likely granted due to the dire need of infrastructure upgrades and investments at Canada's major airports. Such needs for reforms were recognized by both Liberal and Conservative governments and were treated as facts as opposed to political opinions. 
Despite the decision to proceed with fiscal decentralization, research has revealed that the federal government gave a somewhat lukewarm consideration to political decentralization (i.e., privatization of airports) during the late 1980s. For example, the report, The Future of Canadian Airport Management in 1986 was the first study of the Mulroney era to examine the privatization concept. It concluded (Transport Canada, 1986, p. 26):

Private sector management was considered unlikely to be sufficiently sensitive to the various publics that use the airports. The prime objectives of improving responsiveness to local circumstances and enhancing the airports' [sic] relationship with the local economy were considered more attainable through the other organizational alternatives and could not be sufficiently ensured under private sector management.

Furthermore, Farquhar commented at the start of negotiations that (1989a, p. 8):

The Minister of Transport generally favours the lease option as likely being more acceptable to the public at this time....As public confidence in the performance of the LAA increases, the federal government likely would look favourably on the option to sell the airport outright.

Interestingly, by the end of 1989 the Transport Canada Airports Transfer Group effectively ruled-out any potential for near- or medium-term privatization of the major airports (Farquhar, 1989b, p. 2):

When it comes to airports, however, we have avoided using the term privatization. To us this implies a commercial sale to the highest private sector bidder. Rather, we prefer to use the word devolution or transfer, which better describes the Canadian approach of gradualism. Despite considerable private sector interest our airport transfer policy is not one which envisages private interests owning outright major Canadian airports. 
A major divergence between actual airport reforms and Falleti's framework occurs when considering the actions of subnational governments (i.e. airport authorities) and other stakeholders (e.g., airport employees). According to Falleti, subnational governments demand political decentralization at the first sequence of reforms, which in the context of this thesis is full airport privatization. Research has suggested that airport authorities took the opposite approach to reforms, in that they initially sought general guidance and direction from Transport Canada for specific governance changes, and focussed on their primary concern of increased local involvement in the management process. Farquhar (2014) noted, for example that "[i]n general, I would say that all the parties mentioned above were interested in a new direction. We carefully reviewed the supplementary principles with every major stakeholder, and we wanted to ensure we had sufficient input into the process."

A similar reform outcome also occurred during negotiations between the Airports Transfer Task Force and airport employees. Farquhar (2014) offered the following comments on the negotiating process:

Airport employees were the group that was the most opposed to reforms. One of the main reasons why the Task Force omitted anyone from airport management was that they were perceived as having the greatest vested interest in the reform process. From the creation of the Task Force until the first airport was divested, it was a difficult time....In particular, it was difficult to convince employees that this was a policy and political issue, not solely an operations issue. One of the principles of the transfer agreement was that the airport employees must be transferred to the new airport authority for a certain period of time and with all their collective bargaining and pension benefits intact.

Two major reasons why such a dramatic reform process occurred without any labour disruptions or challenges was the transparent and inclusive nature of the 
negotiating team, as well as the department's assurance that all airport employees would keep their pay and benefit structures for a minimum period of two years under the new airport authority. John Cloutier (2014) offered the following observations to describe his interactions with airport employees:

We asked airport management if we could speak directly with airport staff so that our messaging wasn't being filtered. We would meet with airport staff in an open-mike format. As part of our work in developing the transfer principles, we ensured that employee compensation and benefits would remain equal or higher than current TC levels. This proved critical, as we had to initially deal with the national unions and then the individual employees.

With respect to political behaviour, Stone (1988) argued that broad political factors trump rationalist decision making in the formation of public policies. Consequently, there are several key elements of Stone's polis that are relevant for discussion of the airport transfer experience. First, cooperation amongst sub-policy groups leads to loyalty and hence power in the policy making process. Following initial disputes amongst senior managers at Transport Canada as to the general approach to airport divestiture, a consensus emerged with the Minister of Transport's decision to establish eight fundamental transfer principles. As mentioned above, senior bureaucrats accepted these guidelines and generally worked well as a cohesive unit to achieve airport reforms. Once the political leadership observed the bureaucratic implementation of the transfer process and the subsequent expansion of its eight fundamental principles into 36 , Farquhar (2014) noted that a professional and healthy working relationship ensued:

Regardless of the political stripe of government, we had an excellent rapport with the ministers, and their assistants. We were in a position where we could brief them on all sorts of issues. Our relationship was very candid, and we received excellent feedback. 
Another major sub-group in the divestiture process was local government and business representatives that requested the establishment of a Local Airport Authority framework for their region. On the surface, such a broad regional diversity of local government stakeholders across Canada could have potentially led to chaotic and contradictory negotiations with senior Transport Canada representatives. For example, Cloutier (2014) noted that airport divestiture negotiations did not occur simultaneously, which meant that local airport authorities frequently contacted each other to familiarise themselves with the federal government's offers and negotiation positions. In order to prevent deadlock in negotiations, senior Transport Canada negotiators implicitly invoked Stone's most valuable principle, which is subverting individual interests to the preferences of the polis, or taxpayers in this situation. As one of the lead negotiators, Farquhar (2014) claimed, for example, that success occurred by setting a respectful tone during transfer discussions:

One of the fundamental reasons was that we were honest and we conveyed that honesty to those we dealt with. We also worked with senior CEO's of major corporations who sat on the boards of airport authorities, and they were very pleasant to deal with. We had credibility, and for the most part, the parties across the table understood when we would not agree to their demands.

Cloutier (2014) also noted the importance of remaining firm and consistent with stakeholders during local airport transfer negotiations ${ }^{46}$ :

\footnotetext{
${ }^{46}$ As further explained in Chapter Six, Peacock and MacKinnon (2013) argued that the across-the-board, one-size-fits-all negotiating techniques by Transport Canada negotiators was ill suited for application to smaller airports within the National Airport System's 26 major airports. Such circumstances were primarily due to a lack of local financial infrastructure resources and the inexperience of local airport authority negotiators when compared to their Transport Canada counterparts.
} 
Our mindset throughout the negotiations was that we represented the taxpayer.... Between 1987 and 1991, not one group came forward to oppose the policies and the divestiture process. Airport divestitures had the potential for many individuals to oppose the reforms. Employees and the national unions could have stalled it as well. Addressing issues with these individuals before we entered negotiations meant that we had sorted out the major concerns and prevented sabotage of the entire process.

\section{The Creation of Canadian Airport Authorities}

Chapter Two illustrated that the federal Liberals were faced with a significant deficit and public debt upon assuming office in late 1993. A diverse range of stakeholders, from academics to private sector financial analysts to senior federal bureaucrats were calling on the government to take immediate action to put Canada's fiscal house in order. As Moya Greene (2014) explained:

[I]n the lead-up to the first Chretien government, there was a very clear understanding that the finances of the company were in severe difficulty. And transportation was a crucial sector for the government, and if the government wanted to cut expenditures, we had some very big subsidies in Transport.

When the 1994 federal budget instructed Transport Canada to investigate the potential commercialization of many federal transportation assets, the department responded with the release of the National Airports Policy less than six months later. As Doug Young mentioned at the time, and also in retrospect (2014):

The single biggest catalyst for all of this was to try to get the government out of things that they had to be in to 75 or 100 years ago and concentrate on education, justice, health, transfers to the provinces, fiscal integrity, balanced books, etc.

In other words, there was only so much federal money to be spent on public services, and the federal government decided that it would be spent on social policy areas in lieu of 
operating transportation services. It is also noteworthy that Doug Young's statement was very similar to the rationale mentioned in Chapter Two that was provided by Prime Minister Trudeau in 1978. It is clear that in both circumstances the federal (Liberal) government recognized the need for airport reforms, however, it was only during the Chretien era that a Minister of Transport was chosen who possessed the determination and leadership to build alliances and ensure the implementation of desired reforms, as the previous subsection demonstrated.

Larner's (2000) typology of neoliberalism as a form of governmentality continues to apply to the CAA model, as per its rationale in explaining the creation of the LAA governance framework. The Liberal government's rationale for the continued use of the non-profit, arm's-length model (albeit with a different name and enhanced accountability provisions for aspects such as the appointment of boards of directors) remained similar to arguments expressed during the Mulroney era. For example, Nick Mulder (2014) commented:

Government should focus on main priorities, main directions, main standards, main sets of rules and regulations, and then leave all the day-to-day rowing up to others, particularly the private sector. So you should have a view as to what you want to do with airports and have policies and broad regulations, but then leave it up to somebody else to manage the airports.

Historical institutionalism is also a useful method to analyse the factors that led to a continuation of airport divestiture from the Mulroney to Chretien eras. As previously mentioned, the exogenous shock that initiated the LAA process occurred with the election of the Progressive Conservative government in 1984. Although the directional path did not change under the federal Liberals, it is constructive to nonetheless consider 
the rationale behind what motivated the new Liberal government to continue along the non-profit, arm's-length governance path. In the terms of Thelen (1999) and Pierson (2000a), the issue to examine is the factors that encouraged the airport governance framework to be "locked-in" as the preferred policy option.

The most obvious response to this issue was the abovementioned fiscal concerns and the federal government's preference to reorient federal priorities toward social policies and away from non-core areas such as the operation of transportation assets. An examination of Cabinet documents prepared by the Airports Task Force for Minister Young in May 1994 reaffirm these rationales and further present them within a neoliberal framework (Transport Canada, 1994b, p. 1, 2):

Our "bottom line" is that transportation is a business and should be used only to meet clear transportation needs; distorting economic realities through transportation subsidy piled upon transportation subsidy is a disincentive to commercialization and economic growth. Our fundamental national socioeconomic goals can better be achieved through other more directed mechanisms under the mandates of other federal departments and other operators.

Today our government has a wonderful opportunity to reorient the Canadian air transportation system to bring...our airports into the $21^{\text {st }}$ century while at the same time contributing significantly to economic recovery.

Falleti's theory of sequential decentralization reveals similar results for the CAA model as the previous analysis of the LAA framework. The new Liberal government continued with devolution in the form of fiscal decentralization, which granted the newly created CAAs the authority to charge user fees and generate revenues without a longterm need for federal financing. As previously mentioned, however, the primary difference between the transfer conditions of CAAs and their LAA predecessors was the 20 additional accountability mechanisms prescribed by the political leadership for 
implementation in all future divestitures. These revised terms and conditions produced what might be termed "fiscal decentralization lite" in that they featured increased federal intervention in the forming of airport boards and greater conditions on the qualifications and suitability of potential applicants for the boards of directors. According to Dr. Mary Brooks (2014):

[T]he Liberals switched to the new model for airports, which had less of a cowboy capitalism attitude. The airport boards now became a little more manageable from two perspectives: serving the public but with the business discipline of a management entity....I think the structures of Doug Young's early boards reflected the need to balance the skill sets within the boards with the need to represent the public interests of the different levels of government.

The bargaining activities of the major stakeholders in the CAA transfer process remained virtually unchanged from the LAA model previously described. The stakeholders continued to include largely non-partisan local governments and airport operations employees at Transport Canada. Doug Young (2014) commented that, "there was quite the level of excitement with the model we presented, because various places, like Calgary and Winnipeg, wanted to develop their airport. There was excitement that they were now going to control their destiny." That the fundamental principles of airport divestiture had already been established during the LAA era also likely contributed to the continued positive stakeholder reaction during the Liberal era and subsequently led to a relatively efficient transfer process.

The preference ordering of the CAA transfer process and the sequencing of reforms largely followed the LAA devolution framework. In the case of CAAs, however, the political arguments over LAA accountability provisions encouraged the new Liberal 
government to adopt a more stringent framework for future divestitures. Gerard

McDonald (2014), noted, for example:

Part of the problem was that Prime Minister Chretien was elected on a platform that said the Local Airport Authority model, which was the first sort of model, was flawed. And he made a commitment that he was going to either rescind it or look at something different. Part of the challenge for Minister Young was to come up with something that was different enough to sway some of the concerns that had been raised in the election.

Transport Canada also encouraged airports that were divested under the LAA model to adopt the new accountability provisions of the CAA framework in an effort to demonstrate transparent governance practices. From a bureaucratic perspective, the negotiation process remained largely unchanged from the LAA model, with continued emphasis on consistency across divestiture agreements to ensure that a fair return was obtained for the taxpayer.

It is also worth noting that the abovementioned assumption under the LAA analysis that the federal government favoured fiscal decentralization over administrative decentralization remained a consistent finding during the CAA process. The underlying assumptions that Canada's major airports required significant capital investments to remain competitive in global air travel markets, combined with significant federal financial issues, ensured the government's messaging on airport reforms remained consistent under both Conservative and Liberal governments. Talking points prepared for Minister Young by the Airports Task Force (1994b, pp. 6-7), for instance, noted:

Can we continue to afford all of these airports; is the level of service offered commensurate with realistic community needs; and, is the degree of cost recovery appropriate in light of our harsh fiscal reality? The answer to these questions is no, which means we need to pursue a new affordable policy approach. 
Stone's (1988) theory of political behaviour also reveals further insights into the CAA transfer process during the mid-1990s. Contrary to the beginning of the LAA era, senior management at Transport Canada were in full agreement on the need for continuing the divestitures of large airports to local, non-profit authorities. When the new Liberal government assumed power and Doug Young arrived as Minister of Transport, Gerard McDonald (2014) noted that the Minister's commitment to continuing with airport reform "took [senior management] quite by surprise." This situation contributed to a professional and loyal working relationship between the Minister and senior bureaucrats, which according to Stone is one of the most powerful elements of a polis. As McDonald described:

Things like airport privatization had been started under the Conservative regime....When Minister Young came in....he ruminated for two or three weeks on what should be done and basically gave the department their marching orders. And I think the department was a little taken back by the aggressiveness of it, but he was very adamant that we should move aggressively. And to his credit, he got everyone to buy into his way of moving forward.

As Stone argued, loyalty is a primary contributor to the decision of policy actors to subvert personal interest in favour of the common good, which in this situation was the taxpayer.

A prominent distinction between the LAA and CAA processes was the strong political support in favour of divestiture during the 1990s. In Stone's terms, this refers to the power of influence, in which persuasion and sometimes coercion are used to convince stakeholders to adopt viewpoints favourable to certain individuals. Many MPs from both government and opposition recognized the economic potential of airport divestiture for 
their local constituencies and aggressively lobbied the Minister of Transport and senior Transport Canada officials to be one of the first sites divested under the new airport transfer framework. These MPs also encouraged local stakeholder groups within their ridings to apply for divestiture of their local airports. These approaches were likely motivated by MPs to ensure that their airports received sufficient transition funding under the divestiture before such funds were exhausted, and also to allow sufficient time for divestiture to occur and the political benefits from the transfer to be accrued in time for the next federal election. As one of the most vocal proponents of reform for his constituents, Robert Nault (2014) described the process as follows:

Part of the concern of any municipal government taking over an airport was what kind of finances would be available so they wouldn't have to go in the red right away....I took it upon myself to see this as a way of the airports in my region getting a significant amount of financial resources at the early part of the negotiations and discussions, and Transport Canada were keen to have recipients of the program from the get-go.... I started very early on, because I thought from my own constituents' point of view we would get more financial resources, because we were early in the game, and we really didn't have much choice, because it was really clear that Transport Canada was going down this road.

\subsubsection{Meso Influences}

The previous two chapters have illustrated how the interaction of micro and macro layers of reform reveals the sequential processes and patterns behind major policy decisions. Such meso processes consider the influence of broad organizational variables on micro factors, as well as the influence of behavioural variables on macro factors. As the sole policy reform case in this thesis to remain nearly exclusively within the realms of the Transport Canada bureaucracy and the office of the Minister of Transport, the airport 
divestiture process is a prime candidate for examination using Hodgett's (1972) framework of the physiology of the public service.

According to Hodgett, the federal public service has naturally evolved to alter its institutional structure in response to changing internal and external circumstances. This chapter revealed that from the early 1970s, political and bureaucratic officials at Transport Canada conducted airport operations with little to no consideration of local viewpoints in their decision-making. The controversy surrounding Minister Jamieson's decision to locate a new airport development project in Pickering resulted in significant local opposition, which eventually lead to a public inquiry headed by Hugh F. Gibson in 1973. The inquiry's results proved to be an external shock to policy making at Transport Canada, primarily due to its recommendation that the governance and operations of Canada's major airports be managed under an arm's-length airport authority structure that would regularly consult and consider regional and local matters in reaching its decisions.

Following the Gibson inquiry and amid warnings from Prime Minister Trudeau that cost reductions and greater efficiencies must occur, senior management at Transport Canada launched a paradigm shift in favour of less direct involvement in airport governance. The 1979 documents, Transport Canada: Its Roles and Objectives, and the two volume report of the Task Force on Airport Management, established a well-defined rationale for airport divestiture that specified a new governance structure. For reasons that will be further examined below, the political will to pursue reforms did not exist until the beginning of the Progressive Conservative era in 1984, and was not launched on a wide scale until 1994, following return of the Liberals to power. Applying Hodgett's 
model to airport reforms concludes that bureaucratic and political spheres do not always align together during the same policy periods. Rather, the timing of political and bureaucratic decision making clearly played an important role in the evolution and outcomes from proposed airport reforms in Canada.

The next stage of the meso analysis is to consider airport divestiture in terms of Mintzberg and Jorgensen's (1987) challenges to strategy development. Mintzberg and Jorgensen argued that the federal public service was historically created in a much simpler policy environment than what is observed today. As a result, the bureaucratic structure is based on a strict hierarchical echelon that supports deliberate strategies and suppresses emergent strategies and innovation. Research, however, has revealed these claims as inaccurate to chronicle airport divestiture. First, the previous analysis using Hodgett's framework has revealed that the airport policy environment, including the core public service governance structure, evolved over a 20 year period to produce a more efficient and cost effective arm's-length airport structure. Second, although the governance changes occurred slowly over three decades, there were many opportunities for innovative policy discussions at both the bureaucratic and political levels. The many airports task forces sought input from virtually all major stakeholders and encouraged frankness and openness with all task force members. The end result was a transparent, efficient governance framework that was greeted with near unanimous support within the polis.

The airport divestiture process also challenges Downs' (1967) popular hypothesis that the degree of risk averseness increases with the rank of senior bureaucrats. Maor (1999) extended Downs' claim further to state that senior management in public 
organizations seek to avoid changing policies to such an extent that substantive policy change only occurs through legislation mandated by political masters. Perhaps the most notable outcome from the airport transfer process was the variance in desire to implement reforms from both the political and bureaucratic players. In the late 1970s, the Transport Canada bureaucracy prepared a special task force report calling for the divestiture of airports to non-profit authorities. However, the political leadership during Prime Minister Trudeau's final term lacked interest in implementing the recommendations. The environment changed somewhat during the Mulroney and early Chretien eras, which featured strong leaders in Don Mazankowski and Doug Young, who both encouraged airport reforms and continuously pushed senior bureaucrats to achieve governance transitions across Canada. The extensive work completed by the bureaucracy during these periods of reform demonstrated a public service largely committed to change and willing the challenge the status quo of public airport governance.

The final stage of the meso analysis is to examine airport divestiture in the context of Kingdon's (1984) theory of policy windows. As previously discussed, Kingdon claimed that policy outcomes result from the union of problem, political and policy streams. The problem stream was first identified by Transport Canada in the late 1960s as the need to finance airport infrastructure to support a rapidly expanding demand for commercial air travel. This problem stream broadened beginning in the late 1970s to include significant shortfall in federal financing that was required to renovate and expand existing airport services.

The political stream involved the decisions of federal politicians to promote a neoliberal ideology that market forces could provide airport services at lower costs and 
with greater efficiencies than the Transport Canada bureaucracy. Kingdon's belief that the national mood plays an important role in political decisions was not a major factor in airport reforms until the Chretien era. Although the Progressive Conservatives were elected to two majority mandates, airport governance reform emerged from the political will of Don Mazankowski and not from the public's desire to see airports commercialized. During the Chretien era, however, significant annual deficits and the ballooning national debt created the conditions where the public was more acceptable to reforms, such as in the transportation sector. As a result, Doug Young's attempt at divesting assets such as airports in order to preserve social policies and programs was met with general public support.

The "policy primeval soup" floated the idea of airport reform beginning in the late 1970s with the publication of the inaugural airport task force's two volume report. The policy stream within the Transport Canada bureaucracy was placed on the track to divestiture, which aside from a brief consideration of alternatives during the second airports task force in 1986, remained consistent over three decades. Perhaps the most interesting aspect was that the original non-profit, arm's-length model first proposed in 1979 remained largely intact through the LAA and CAA periods, despite the passage of time that featured five federal elections and eight ministers of Transport.

Kingdon emphasized that one of two policy windows must open for an idea to become reality. The first category, political windows, briefly opened with the election of the Progressive Conservative government in 1984 and the appointment of Don Mazankowski as Minister of Transport. Mazankowski was an avid proponent of market forces and supported the 1979 airports task force as Minister of Transport during the 
short-lived Joe Clark minority government. Despite Mazankowski's support for airport divestiture, the LAA model proceeded slowly until the re-emergence of the Liberal government in 1994. The second category, problem windows, opened in February 1994 when the Minister of Finance, Paul Martin, delivered his first federal budget that called on the Minister of Transport to investigate the commercialization of transportation assets and programs in an effort to reduce the staggering federal deficit. Contrary to Kingdon's prediction, however, the new Liberal government was not initially in favour of dramatic cuts to federal programs, including airport reforms. The key to success, however, proved to be a significant problem window (i.e., the debt and deficit) along with a determined Minister of Transport in Doug Young.

As the main policy entrepreneur from the political cadre, Doug Young played a key role in ensuring what Kingdon described as the "coupling" of the problem, political and policy streams. The bureaucratic players behind airport reforms were Transport Canada senior managers Jocelyne Bourgon, Moya Greene and Nick Mulder. Together, these four individuals served as key "policy entrepreneurs" to bridge the dynamic gap between airport employees, local governments, the private sector, and the federal Cabinet. Transport Canada bureaucrats were well prepared with policy recommendations for airport governance in the anticipation of a policy window opening with the upcoming federal election in late 1993. As Minister, Doug Young recognized the need for urgent reforms to tackle the deficit and seized the opportunity to create a sustainable airport governance framework. He subsequently negotiated the support of the Prime Minister and Minister of Finance in support of the proposed airport reforms, which greatly contributed to the speed of airport devolution between 1994 and 1996. This case 
therefore provides a fascinating example of Kingdon's claim that new policies are not generated randomly, but rather form from the skillful integration of timing and policy readiness by senior bureaucrats and their political masters.

The coupling of these streams and the opening of major policy windows was best summarized by Dr. Lloyd McCoomb (2014), who stated:

There was a strong sense that the Department should no longer be involved in these areas, and...there was a belief that the private sector could administer these assets more efficiently....Combining the deregulation influence from the United

States with these events, it was kind of like a perfect storm where everything came together in the late 1980s and early 1990s.

\subsection{Conclusion}

\section{Relationship between Political Leadership and Bureaucratic Responsiveness}

The most intense period of political-bureaucratic tension occurred during the early 1970s over the Minister of Transport's decision to locate a new international airport for Southern Ontario in Pickering. In some cases, disagreements between senior bureaucrats and Minister Jamieson led to the resignations of some well-respected Transport Canada senior managers, as there was a perceived disconnect between ministerial and bureaucratic priorities at that time. The negative reaction to the Pickering decision also revealed that ministers maintained a low regard for bureaucratic opinions of political decisions during this period, as such views clearly ranked lower to ministers than angry municipalities, local community groups, and the Ontario government. 
By the late 1970s, the bureaucracy successfully adapted to Prime Minister Trudeau's direction to control spending and reduce the federal government's role in noncore areas such as the transportation sector. The Task Force on Airport Management focused on non-partisan, arm's-length airport authorities similar in structure to Justice Gibson's recommendations, which were also not politically controversial. The Task Force also echoed Gibson's recommendations for the adoption of the airport authority model to provide a political buffer between airport decisions and ministerial interference.

The new Progressive Conservative government requested swift bureaucratic action on airport reforms, which included the unprecedented decision to signal the government's intentions to initiate airport governance reforms in the 1985 federal budget. Further mention of airports governance reform was reiterated in Freedom to Move, as well as the Airports Task Force Report one year later, which called for a more accountable, commercial and local approach to airport governance. Unhappy with a lack of bureaucratic progress on airport management, the Minister released eight fundamental principles in 1987 designed as 'marching orders' to the bureaucracy to initiate the governance reforms. Once the bureaucracy began negotiations with Local Airport Authorities, the political-bureaucratic relationship progressed efficiently and harmoniously.

Following a majority election win that included a promise of greater accountability in airport divestitures, the new Liberal government issued revised accountability principles to the bureaucracy in 1994. The relationship between Minister Young and senior bureaucrats progressed very well during this period, as both parties were in agreement with the need to divest airport assets to achieve cost savings. The 
political conditions also provided the incentive for many members of Parliament to support airport reforms, as they realized that only a limited amount of capital assistance would be available during the divestiture process and that they should act quickly to avail of these funds.

\section{Concluding Remarks}

This chapter provided a classic example of the interaction between bureaucrats, ministers, and local stakeholders, all of whom were competing for prominence in a rapidly shifting macro environment. By the early 1970 s, the political and bureaucratic leadership at Transport Canada recognized the need for major expansion of Canadian airport infrastructure; although neither could agree on the location and methods of financing for the new airports. Stark difference of opinions, combined with a blatant ignorance of local needs led to the creation of a formal inquiry and the initial recommendation of a non-profit, arm's-length governance model for Canada's airports.

The analysis has revealed that the findings from the Gibson report proved to be the turning point that convinced the bureaucracy to adopt the airport authority model as their preference for future reforms. Unfortunately for reform advocates, little political interest in acting on the bureaucratic recommendations occurred during Trudeau's final term. It was not until 1984 with the new Progressive Conservative government that Don Mazankowski, an original proponent of the department's earlier recommendations, instructed Transport Canada senior management to proceed with what would become the LAA model. 
Airport divestitures began to occur at a slow pace in the early 1990s and did not accelerate until Doug Young arrived as Minister of Transport under the newly elected Liberal government. Already a successful businessman, Young was determined to take advantage of the mandate from the Minister of Finance for Transport Canada to pursue the commercialization of major assets and programs in an effort to control the expanding national debt and burgeoning federal deficit. The result was nearly 40 letters of intent signed with newly created local airport authorities within one year of announcing the National Airports Policy in 1994.

Since divestiture in the late 1990s, the major Canadian airports have adapted to the current governance framework and have sought to develop innovative funding mechanisms. The most common example of innovation by airport authorities is the development of retail space within passenger terminals. According to the Montreal Airport Authority, "[a]irports have evolved from being simple infrastructure providers to full-fledged, multi-faceted businesses" as "the focus of airport management has shifted from hosting airlines to accommodating passengers” (Aeroports de Montreal, 2011). Several airports have also undertaken the development of their lands for new real-estate development opportunities, such as shopping malls and condominium developments. These developments represent additional lease revenue for the authorities, but have been very controversial with local municipalities who complain that airport authorities do not seek approval before undertaking these projects, which may lead to road network congestion and negatively impact residential property values (O’Connor and Ip, 2012).

A prominent observation for policy analysis is the resulting conflict that occurs when the priorities of the senior public service do not match those of the political 
leadership. Some conflicts are obvious to a researcher, such as the disagreements between senior Transport Canada bureaucrats and Minister Jamieson over the decision to locate a new international airport for Southern Ontario in Pickering. According to Feldman and Milch's assessment of the Pickering issue, "[f]ederal policy, first with the prospect of an election and then with an ambiguous electoral outcome, had fallen hostage to local public opinion and provincial preference" (1983, p. 98). Recognizing the potential for political-bureaucratic conflict in airport management, the inaugural Task Force on Airport Management recommended that (1979c, p. 24):

One would therefore be inclined to support the concept of a strong local authority which could act as a 'buffer' for both the Minister and the overhead Public Service hierarchy, the form and size of which cannot be modified to any significant extent under the present management system.

Other conflicts are less visible and appear to operate within the traditional mechanics of governance, whereby the public service provides non-partisan analysis and advice to its political masters. For example, by the early 1990s, Canada's annual deficits were increasing while the available finances for urgent airport repairs and expansions were rare to non-existent. Senior managers, such as Jocelyne Bourgon and Moya Greene, recognized the need for a new approach to transportation governance and conducted a holistic review of the department's assets and programs in preparation for the next government following the 1993 election. As Moya Greene (2014) explained of that period [emphasis added]:

[A]lmost four years it took us to design all of these different approaches to policy that would, in a coordinated way, allow us to have less reliance on government, more reliance on outside capital, and would present for each sector of the transportation industry a structural approach and a governance approach that would attract outside capital. And that meant that the government had to recede, 
in some cases the government had to get out of the ownership chair entirely. In all cases the government had to allow the commercial vocation of each and every segment of the transportation industry to come to the forefront, and that meant, as I said, that they had to stop interfering and stop super-imposing political objectives above commercial ones, and it was only in that way that they could generate revenues to support more efficient operation, and they could attract outside capital to help defray the cost of rebuilding the infrastructure for the future.

The arrival of Doug Young as Minster in 1993 provided the final component needed to achieve airport reforms. For many years the bureaucracy, local governments, and major airlines had argued in favour of the non-profit airport authority model, only to meet with resistance from the political leadership. Doug Young's recognition of the urgent need to reduce the deficit and achieve greater efficiencies in airport governance provided the impetus to achieve the perfect storm for policy reform. Such a perfect alignment of factors are rare in policy development, as the next chapter on federal reforms will demonstrate how much different outcomes occur when stakeholders are less committed to governance reforms. 


\section{Chapter Five: Federal Port Reforms in Canada}

Ports policy in Canada is inherently politically controversial. ${ }^{47}$

\subsection{Historical Summary}

\subsubsection{Federal Command and Control of Ports: Confederation to 1980}

Following Confederation, the British North America Act (now the Constitution Act, 1867) placed all administrative matters relating to shipping, navigation and ports policy under federal jurisdiction (Ircha, 1997a: Brooks, 2007a). By the 1930s, the federal government began to designate some of the largest sites as National Harbours Board (NHB) ports under the National Harbours Board Act of 1936. The remaining ports remained under the jurisdiction of the federal Department of Transport (now Transport Canada). In addition to the 15 NHB ports, The Harbour Commissions Act of 1964 created a unified incorporation process for many non-NHB ports, transferring greater control from Transport Canada to the local harbour commissions. Under this Act, Harbour Commissions were for the first time granted equal autonomy and jurisdiction with other federal ports, and were encouraged to invite active local participation in port affairs (Canada, 1975).

Despite these attempts at port governance reform, the continued fragmented and cumbersome nature of federal ports administration led Transport Canada to attempt further port reform in the late 1960s. Ircha (1997a) noted that the 1968 Manning Report

\footnotetext{
${ }^{47}$ Dr. Edgar J. Dosman, Political Science Professor, York University. Quoted in Dosman, 1978, p. 15.
} 
called for a more unified port system but its recommendations were never implemented. According to Ircha, "[t]he lack of government action reflected the low priority given ports within the transportation sector. During this period, the government considered, but failed to adopt many recommended changes to the port system" (1997, p. 124).

Determined to achieve port reforms, Transport Canada established a Port Harbours Planning Committee in 1970 to coordinate ports of local, regional and national significance. Of the 2,200 recorded ports, the Committee determined that only 500 were of a commercial transportation interest, and recommended that the remaining 1,700 be transferred to the Departments of Public Works and Environment (Canada, 1975). Meanwhile, only 25 of the 500 commercial ports were classified as vital to the national transportation system and Transport Canada's mandate (Ibid). A National Ports Council composed of representatives from these 25 ports was then established "to advise the Minister on the efficiency of Canadian ports, improvements that could be made to the present ports system, study future plans and to advise on overall policies" (Ibid, p. 4). After just three meetings, the Council concluded (Ibid, p. 4):

[L]egislative complexities and reporting procedures...inhibited integrated policies and planning and that the problem of port reorganization would have to be resolved satisfactorily before any meaningful efforts could be made towards advising the Minister on the issues of Canadian port policy.

Another attempt at port reforms occurred in the Speech from the Throne in February 1974. As part of this speech, the government announced its intention to launch a detailed reorganization of the Canadian ports system (Dosman, 1978). Shortly thereafter the Minister of Transport announced the creation of an interdepartmental committee to study and recommend a new ports structure for Canada (Canada, 1975). 
Chaired by G.A. Scott, Senior Assistant Deputy Minister of Transport, the "Scott

Committee" released its report in June 1975. The report concluded (Ibid, pp. 5, 10, 11):

[T] he existing statutory harbour administration is no longer adequate to achieve present and future national transportation objectives effectively....It is concluded that a new administrative structure based on new legislation is required....[I]t is recommended that legislation be prepared for the purpose of presenting a Canada Ports Act to provide for: 1. The establishment of Local Port Entities as semiautonomous public corporate bodies; [and] 2. The delegation to the Local Port Entities of certain powers for making by-laws for expenditure of funds, [etc.].

The federal Cabinet formally approved the Scott Report in July 1975 and established a Ports Task Force in August to implement a new Canada Ports Act (Lacombe, 1976; Lang, 1976). The Task Force recommended the amalgamation of all core, commercially oriented transportation ports (i.e., mainly NHB and Harbour Commission ports) under one central administrative structure within the Marine Administration branch of Transport Canada. The new organization, denoted the Canadian Ports Commission (CPC) would oversee the creation of 25 Local Port Commissions (LPCs) to operate the major ports across Canada. The department also planned to create a Canadian Ports Policy Council, composed of eight members appointed by the Minister from the membership of LPC boards. The Council would advise the Minister "on new policy directions and [would] be expected to give particular attention to confirm [sic] that maximum decentralization of operating responsibility actually takes place" (Lang, 1976, p. 12).

Although Transport Canada announced its intention to introduce and pass the new Canada Ports Act by the spring of 1976, it would be another two years before it reached the Order Paper in 1978 (Lacombe, 1976; Dosman, 1978). Dosman predicted at the time 
that the proposed Act, Bill C-6, was doomed to fail due to its insistence on incorporating the new CPC within the traditional Transport Canada bureaucratic hierarchy. Specifically, he foreshadowed that "[o]nly a [sic] central ports agency with statutory independence, though subject to Ministerial direction, can prevent the total politicization of ports policy, where the political needs of the day will be serviced" (1978, p. 23). Bill C-6 twice failed to pass first reading in 1978 and was considered low priority during the short-lived Clark government of 1979. It ultimately died on the Order Paper following the government's loss of confidence and subsequent dissolution of Parliament in the spring of 1979 (McCalla, 1982; Goss, 1983).

\subsubsection{A Slow Start for Port Commercialization: 1980-1993}

Following nearly two decades of attempted reform, the early 1980s brought the first significant changes to port governance. In May 1981, the Liberal Minister of Transport, Jean-Luc Pepin, released the White Paper, Canadian Ports Policy to set the stage for legislation to replace the 1936 National Harbours Board Act. The White Paper outlined the government's goal of achieving two fundamental objectives, namely, "the need for all of Canada's ports to operate within a national framework, and the need to ensure [ports'] responsiveness to local conditions" (Transport Canada, 1981, p. i). Contrary to the department's 1975 Ports Task Force, the White Paper did not recommend the amalgamation of all existing port management structures under one centralized branch within Transport Canada; rather, it conveyed an intent to update the governance structures of ports under the legislation of the National Harbours Board Act in order to create the conditions for greater regional planning and local responsibility (Ibid). 
The most prominent feature of these reforms was the replacement of the National Harbours Board with the newly created Canada Ports Corporation (a.k.a. Ports Canada). According to Goss (1983), Ports Canada was essentially a holding company for its 15 member Local Port Corporations (LPCs). Composed of a Cabinet-appointed, part-time board of directors as well as a President and Chief Executive Officer, the corporation was authorized to create new port corporations on the condition that prospective ports had demonstrated a commitment to local autonomy and a high probability of financial success.

Nearly 10 years after legislative reform was first proposed in the 1974 Throne Speech, the Canada Ports Corporation Act received Royal Assent in August 1982 (Goss, 1983; Ircha, 1997a; Brooks, 2007a). The Act created seven independent Crown Corporations known as LPC ports in St. John's, Halifax, Saint John, Quebec City, Montreal, Vancouver and Prince Rupert (Ircha, 1996; 2001). The legislation also granted the national board of directors and Ports Canada operational jurisdiction over eight divisional ports in Belledune, Chicoutimi, Baie des Ha! Ha!, Sept-Îles, Trois-Rivières, Prescott, Port Colburne and Churchill. The official mission of Ports Canada included the commitment (Christopher, 1993, p. 1):

to maintain and promote the role of the Ports Canada system of ports, nationally and internationally, by ensuring the integrity and efficiency of the national ports system with respect to local, regional, and national economies... and in the pursuit of optimum benefits for Canadian trade and transportation.

Although this legislation did not achieve the degree of port reforms sought in the late 1970s, McCalla nonetheless concluded that "the Act is a unifying agent in port 
development in Canada since it creates a goal towards which all ports, regardless of enabling legislation, must work" (1982, p. 292).

As previously discussed, the election of a Progressive Conservative government in September 1984 brought significant changes to the philosophy of public administration and governance in Canada. Rather surprisingly, relatively few port reforms occurred during the two Conservative majority mandates, despite this dramatic neoliberal shift. Federal transportation related ports continued to be administered under Ports Canada, harbour commissions and Transport Canada's public harbours and ports branch (Gillen and Cooper, 1995). The major policy documents of the period, Freedom to Move and the National Transportation Act, 1987 focussed primarily on deregulation of the national transportation sector as opposed to direct governance reforms (Gratwick and Elliott, 1992). One of the few references to ports in the Act occurred in the context of railway rates, in which carriers were warned against setting rates that presented "an unreasonable discouragement...to the movement of commodities through Canadian ports" (quoted in Gratwick and Elliott, 1992, p. 249). As a result of this glaring omission of ports in the legislation, Gratwick and Elliott cautioned, “it remains to be seen whether this [deregulatory] approach will result in the long term health and efficiency of ports, carriers, and their infrastructure" (Ibid).

In addition to concerns expressed by academics over the federal government's lack of port reforms, LPC port executives also criticized the perceived ineffectiveness of the Ports Canada model. For example, LPCs believed that Ports Canada should focus on the operations of its divisional ports and not interfere with individual LPC activities. This belief was based on the fact that LPCs were Crown corporations in their own right 
and were not directly accountable to the Ports Canada board. ${ }^{48}$ Since the LPCs reported directly the Minister of Transport (as did Ports Canada), there was confusion in governance roles, oversight and reporting responsibilities. Ken Krauter, a former CEO of two LPCs during this era, summarized the views as follows:

I recall at one time, a chairman of the Canada Ports Corporation, was asked to characterize the role of the Corporation at a meeting of the CPC and all of the port directors. He said, well, our role is in shepherding the ports. That's really stuck in my mind, because as ports we certainly didn't feel that we needed to be shepherded, and if you want to continue the analogy, we didn't feel like sheep, and we weren't going to be sheep. I felt that was a very poor analogy to use because I felt at the time, the Canada Ports Corporation, from a ports management perspective, could have disappeared off the face of the map, and it would not have made a lot of a difference to ports, other than we would have been able to do the things that we were required to do in running a port and building trade a whole lot quicker and more efficiently if we didn't have CPC and their processes and submissions and time delays, etc. There was just too much process.

\subsubsection{The Emergence of Canadian Port Authorities: 1994-2000}

Eighteen months after delivering the famous "Thunder Bay Speech" that set the stage for transportation commercialization, Transport Minister Doug Young rose in the House of Commons to present the National Marine Policy in December 1995. Contrary to the commercialization of airports and CN Rail, the journey to port reforms took a

\footnotetext{
${ }^{48}$ LPC distrust towards members of the Ports Canada board of directors further deteriorated when evidence later emerged of extravagant spending and fraud by senior Ports Canada officials. A headline from the 'Canada Notes' section of the September 30, 1996 issue of Maclean's magazine illustrates this point:

The RCMP charged Jean-Michel Tessier, the former president of Canada Ports Corp., and Hassan Ansary, the former vice-president, with defrauding the Crown corporation of $\$ 400,000$. Tessier and Ansary face 19 charges, including theft, fraud, breach of trust, forgery, possession of property obtained by crime, and laundering the proceeds of crime. They are scheduled to appear in court on Oct. 3.
}

The two individuals were subsequently convicted. 
much longer and more complicated path. As part of the initial Transport Canada review of programs and expenditures, air related items were the primary consideration, only to be expanded to include the marine sector at a later stage (Ircha, 1996; 2001). Responding to a media inquiry as to the slow pace of port reforms, Deputy Minister Nick Mulder replied, "we're going slower on marine [reform] because we've already got too much on our plate [railways and aviation reform] and also because there is far less consensus on what should be done in the marine sector" (Ircha, 1997b, p. 90).

As part of the efforts to achieve consensus on marine reforms, Minister Young requested that the House of Commons Standing Committee on Transport (SCOT) provide recommendations for the development of a new national marine policy, including potential port governance reforms. The committee reported in May 1995 and made the following port-related recommendations (House of Commons, 1995, pp. 8-13) [emphasis added]:

- The federal government continue to have direct responsibility for a national ports system.

- The Canada Ports Corporation [Ports Canada] should be dissolved.

- A new National Marine Transportation Act be drafted to repeal the Canada Ports Act, the Harbour Commissions Act(s), and the Public Harbours and Port Facilities Act, and to establish a new national commercial ports system.

- Provisions should be made in the new legislation...for a set of comprehensive public accountability principles similar to those applied to the Canadian Airport Authorities.

As Ircha described, "a major theme emerging throughout the SCOT hearings was the desire by major ports to maintain the current system, with minor modifications to improve local autonomy" (1996, p. 124). In particular, port corporations described many benefits of their close relationship with the federal government, including low interest on 
debt borrowing, access to the federal diplomatic core, and easy liaison with other federal agencies, such as the Canadian Coast Guard (Ircha, 1997b).

Although the SCOT had advised against radical change to the Canadian ports industry, Transport Canada continued to strive for comprehensive airport-style reforms. In August 1995, Deputy Minister Mulder presented Transport Canada's proposed reforms under the new National Marine Policy (NMP) to the annual conference of the Canadian Port and Harbour Association (CPHA). In his speech, Mulder advocated for port reforms similar to those adopted for national airports (Brooks, 2007a). Specifically, Transport Canada was to be only responsible for urban commercial ports operating as "Canada Port Authorities" (CPAs) as well as "remote ports" located in isolated areas, with the remaining "regional/local ports" to be divested to the private sector or local government interests (Ircha, 1996; 1999; Brooks, 2007a).

Following the release of the SCOT report, the departments of Transport and Fisheries and Oceans conducted cross-country consultative workshops with port stakeholders. In a letter to the Chair of SCOT, the ministers (Doug Young and Brian Tobin, respectively) indicated broad stakeholder support for the committee's recommendations. Following extensive cross-country consultations, the committee reported that the new marine strategy would be "based on a program of rational divestment, more commercialized management, user influence over the level and cost of marine services, and significant subsidy reduction" (Canada, 1995, p. 2).

The 1995 National Marine Policy contained three port related objectives, namely (Transport Canada, 1995b): 
- [E]nsure fair competition based on transparent rules applied consistently across the marine transport system;

- [S]hift the financial burden for marine transportation from the Canadian taxpayer to the user; [and]

- $[R]$ educe infrastructure and service levels where appropriate.

The policy also affirmed the government's intention to commercialize Canada's largest public ports. A National Ports System was therefore established to create Canada Port Authorities (CPAs) composed of board level representatives nominated by stakeholders and all levels of government (Ibid). ${ }^{49}$ Shortly after presenting this policy to Parliament, Minister Young was reassigned to the National Defence portfolio in January 1996 and was replaced by David Anderson, a junior minister from British Columbia. Legislation to amend the national marine system was introduced but subsequently died on the order paper with the dissolution of Parliament in the spring of 1997. The Liberals were reelected with a narrow majority government in which some cabinet ministers, such as Doug Young, were defeated.

The result of the port reform process was the passage of the Canada Marine Act (CMA) by the new Parliament in late 1997. The final outcome was a mix of the former ports system and the Canadian Airport Authorities governance structure. It included the creation of non-profit federal agents ${ }^{50}$ (Canada Port Authorities) under the National

\footnotetext{
${ }^{49}$ The National Marine Policy also launched the divestiture process of medium-sized ports, designated "Regional-Local" ports to other levels of government and the private sector where circumstances permit. In addition, the government indicated its intent to retain "remote" ports under Transport Canada ownership and operation where local opportunities for divestiture were not available (Transport Canada, 1995).

${ }^{50}$ It is worth noting that Canada Port Authorities are officially defined as "federal agents" and not "agencies," the latter being Crown corporations. This nuance was introduced in the legislation to give CPAs a more arm's-length role within the federal government. Despite this nuance and the confusion it created, CPAs are often treated within the federal bureaucracy as having similar status to Crown
} 
Marine Policy. The new Canada Port Authorities (CPAs) included all of the former LPCs and four of Ports Canada's divisional ports and major harbour commissions. The responsibility of the majority of board appointments rested with the federal Minister of Transport (Ircha, 1996; 1999; Brooks, Prentice and Flood, 2000).

Despite its positive reception in political and media circles, the new CPA structure was imperfect. Criticism soon arose over flaws, including: ministerial appointments to CPA board of directors; restrictions on accessing federal funding; annual stipend payments to the federal government based on a percentage of CPA gross revenues; limits on CPAs incorporating wholly-owned subsidiaries; limits on pledging federal lands as collateral for commercial loans; and the requirement for CPAs to conform to various federal regulations such as access to information, environmental assessment panels and the Official Languages Act (Ircha, 2001). Nevertheless, Brooks argued, "[w]hile Canada's commercialization programme did not go as far as the privatization programmes seen in other countries, the commercialized nature of both CPAs and local/regional ports is a model that can deliver many of the 'benefits' of privatization" (2007a, p. 245).

\subsection{Meso Analysis}

\subsubsection{Micro Analysis}

The 1975-1980: Failed Attempts at Port Reform

\footnotetext{
corporations. For example, CPAs are required to submit business plans to Treasury Board, meet Freedom of Information and bilingual requirements and so forth in a manner similar to Crown corporations. However, CPAs generally consider themselves to be non-Crown corporations.
} 
A major hindrance to the advancement of federal port reforms during the 1970s was the myriad of governance structures and decision making techniques that rendered governance changes inherently difficult, if not possible. As previously mentioned, there were 2,200 federal registered federal ports in Canada that were administered by three departments. Furthermore, the 25 most commercially relevant ports to Transport Canada were composed of varying financial structures and ownership elements. Aside from general maritime and ports similarities, such a scattered organizational structure prevented healthy organizational cultures that encouraged retention and advancement of talented employees along the lines of Schneider's (1987) attraction-selection-attrition framework.

Research has revealed low employee morale within the ports administration of Transport Canada during this period. Dosman (1978), for example noted that the department decided to proceed with reforming the Marine Administration Branch by amalgamating the National Harbours Board and Harbour Commissions into an unofficial Canadian Ports Commission before Bill C-6, the Canada Ports Act, was introduced, let alone passed, in Parliament. Consequently, Dosman (1978, p. 4) noted that the changes had "been largely implemented...in Ottawa by guillotine." He further described a dark picture of organizational change, as (Ibid):

Treasury Board and the Public Service Commission have assisted senior Transport officials in eliminating the National Harbours Board staff, [and have] added to the turmoil that has surrounded ports administration for the last decade in Canada. Careers of many port officials have been destroyed, their replacements typically 'managers' from other line federal departments and agencies with little or no Transport experience. There were few enough senior personnel with actual port experience, but now there are practically none at all left in the central ports establishment....[I]n areas such as port administration the loss of key personnel is particularly serious because trained talent is in short supply. 
Another major contributor to repeated failures of port reforms during this period was the absence of strong leadership within the Transport Canada ports administration. In addition to the abovementioned low employee morale, ports policy was hindered by poor organizational direction and haphazard transition planning. Dosman noted that the department was officially advocating in favour of efficient port management practices with increased local autonomy, but in practice hesitated to implement reforms that would weaken bureaucratic responsibility over ports. He also argued that ports administrators devolved different levels of authority over ports to different provinces and lacked a cohesive, centralized strategy to establish local autonomy. Dosman therefore concluded (1978, p. 5):

[T] he new ports policy from the first has been heavily influenced by factors that have little to do with actual transportation or transport-related matters. Various aspects of bureaucratic politics have been quite significant. It is a telling commentary that, even after four years, the regulations which are to follow the legislation are far from complete.

Such a lack of coordinated leadership inhibits organizational coherence and prevents effective policy development. The leadership cadre of this period did not reflect the transformational nature prescribed by Denis, Langley and Rouleau (2007) as providing a vision of an organization's future that accounts for individual employee needs. Poor employee morale during this period is an indicator of low respect enjoyed by senior management in the discharge of their duties, while disjointed staffing practices illustrates poor senior management control over knowledge-based resources that impact policy outcomes. Consequently, Magee and Frasier's (2014) framework provides evidence that senior management lacked both status and respect in attempting to 
implement port reforms, which most likely explains the significant delays in developing and introducing Bill C-6.

Although poor leadership contributed to never-ending delays in implementing the proposed port reforms, a lack of strategic direction prevented the creation of a sound policy rationale in favour of reform. Using Mintzberg and Jorgensen's terminology, strategies were created but never implemented during this period. Furthermore, the loss of corporate memory through the replacement of employees knowledgeable in port reforms also reduced the likelihood of emergent strategies originating from within the port administration bureaucracy. Interestingly, most, if not all of the policy ideas on port reform during this period originated from government commissioned task forces. In fact, each task force was either chaired by a senior manager at Transport Canada or included a departmental representative in a senior executive position within the review process. There was therefore a gap between policies developed and recommended by the many task forces and the subsequent non-implementation by the department's bureaucrats.

Another strategic issue during this period is Transport Canada's publicly stated desire to develop a new ports governance structure that granted maximum local autonomy to ports while also ensuring they remain under a centrally organized structure in Ottawa. On the surface, the department presented a clear and modern policy goal for greater efficiencies within federal ports administration (Transport Canada, 1977a, p.9):

The new policy would give a high degree of autonomy to local port commissions in the management of port operations. The new administrative structure would provide for a more cohesive and integrated approach to national port planning and financial management policies. 
In practice, however, such an approach appears as a paradox when considered in terms of the department's attempt to maintain central control over ports administration. Ircha (1993) questioned, for example, why such a comprehensive array of federal ports and harbours could have possessed such divergent governance models. ${ }^{51}$ Furthermore, the implementation of a new ports model became inherently more difficult with the loss of corporate memory from employee departures and the absence of officer-level involvement in port reform policy development (as this function was handled primarily by external task force support staff). In addition, Dosman claimed that the department sought to increase its bureaucratic reach during this period and decisively rejected an independent, Crown Corporation structure for ports in favour of an in-house bureaucratic regime. In Dosman's view, a major contributor to the failure of Bill C-6 was "the unequivocal rejection of the crown corporation approach in favour of a public service takeover" (p. 12).

\section{The Early 1980s: Incremental Progress}

Contrary to the comprehensive proposed port reforms of the late 1970s, the legislative reforms of 1982 were much more modest in scope. In particular, McCalla noted that the new Canada Ports Corporation Act was "an Act to amend existing legislation, most particularly the NHB Act. It leaves much of the present legislation, except the NHB, intact" (1982, p. 287). As a result, little organizational change occurred

\footnotetext{
${ }^{51}$ It is also interesting to note from a governance perspective that American ports experienced similar economic challenges as their Canadian counterparts over the period studied, despite the lack of a federal or national role in ports governance and administration (Ircha, 1995).
} 
and it was likely that organizational morale across the Transport Canada ports governance framework remained unchanged from the late 1970s. With so many frameworks, hierarchies and financial structures, it is not surprising that morale remained low, as it was difficult for employees to define what McCurdy (1992) described as the principal component of organizational culture, namely "the way we do things here."

It is also apparent that bureaucratic and political leadership was quite weak and ineffective during this period. Senior bureaucrats in the late 1970s presented an ambitious ports reform package that was supported by task forces and the government's Throne Speech commitment to implement sweeping reforms. Expressed in terms of Magee and Frasier's (2014) framework, the relevant political leadership possessed the power to bring forward these reforms but clearly lacked the status to convince cabinet colleagues and the Prime Minister of the need to ensure the legislation passed through Parliament. By the early 1980s, the breadth of the legislation had fizzled to minor legislative changes with most of the previous recommendations omitted from the proposed reforms. In addition, research has not revealed any significant leadership efforts by senior bureaucrats arguing in favour of retaining the strongest reform elements of the late 1970s. The Minister of Transport, Jean-Luc Pepin, also appears to have resigned himself to the second-best alternative to port reform, claiming that " $[t]$ he present policy, frankly, leaves aside the grander theme of entirely restructuring port administration" (Transport Canada, 1982, p. i). Instead, the Minister claimed that these reforms were intended to provide an initial foundation upon which further reforms would be proposed and modified as required. 
The strategic policy making approach during this period also took a divergent approach from the late 1970s. If Mintzberg and Jorgensen's (1987) definition of strategy as a "pattern in action" is applied, it becomes clear that the pattern of reforms initiated with the 1974 Throne Speech abruptly ended in the early 1980s. Although the Minister indicated further reforms would eventually occur, the Canada Ports Corporation Act was noticeably remiss in describing the theme of future reforms. For example, McCalla (1982) noted that the new Ports Canada would act as a Crown Corporation reporting directly to the Minister of Transport and not via the ports administration branch of Transport Canada. In addition, each LPC was a Crown Corporation in its own right.

Without the policy support of Transport Canada, the only advisory support to Ports Canada in the Act was through an external policy council that was appointed at the Minister's discretion. McCalla noted, however, that the Act was void of a mandate to guide ministerial appointments to this council, leaving the policy direction in the hands of a non-specialist Minister. As a result, he claimed (p. 292) [emphasis added]:

While the national ports policy exists on paper, there is no strategy for its implementation. Other than the Minister, there seems to be no person or body charged with the responsibility of overseeing the development of all ports in Canada.

Without clear leadership and strategic direction, it was practically impossible for the political leadership to provide advice to senior bureaucrats on desired reforms. As a result, little direction was conveyed within the department and its many port governance organizations (e.g., Ports Canada ports - including LPCs, harbour commissions and Transport Canada ports) that could have provided clear umbrella strategies with which to guide future reforms. The consequence of such a governance framework was perhaps 
best described by Ircha (1993, p. 51) as "an example of an embarrassing failure to allocate scarce financial resources wisely."

\section{4-1993: Staying the Course}

Given the absence of major port governance reforms during the Mulroney era, few organizational changes occurred and the organizational cultures within the three ports groups remained virtually unchanged. As noted in the previous analysis, employee morale had been low in ports administration since the late 1970s, and a lack of organizational reforms likely contributed to continued employee frustration with the many layers of bureaucratic red tape amongst the three port groups. The former CEO of Ports Canada, Don Morrison, commented that most of the ports employees of this period recognized that no changes would be forthcoming and attempted to make the best of the organizational ports structure (2014):

I think that the ports were running well, and the infighting among the ports and between them and Ottawa was down to a dull roar. It was also a non-expansion time...In sum, the ports were in good shape; it was not a period of expansion, and I think that people had learned to live with each other.

Despite the appetite for transportation deregulation during this era, there was a noticeable absence of a desire for change amongst senior ports leadership. From a meso perspective, it would appear that a government in favour of devolution during a period of fiscal constraint would present an opportunity for a visionary ports leadership strategy. Instead, the ports leadership cadre chose inaction over reforms and in turn advocated for the status quo. According to Morrison, such behaviour was motivated by political cronyism and the opportunity for board members at the national and local levels to retain their executive positions (2014): 
The port boards of directors were all made-up of political appointees. Some of it could have been selfish in that some politicos didn't want to give up their spots on the boards. These people on the boards were pretty friendly with their MPs and the ministers in Ottawa. I think that they knew what they were doing and it was running well. That may run back to why there wasn't a lot of pressure for change from the late ' 80 s to the mid ' 90 s.

\section{3-2000: The Creation of Canadian Port Authorities}

In 1995, the House of Commons SCOT conducted an analysis of the port governance structure and warned of several major deficiencies in its overall organizational performance. In particular, it noted that local port corporations were not granted the original level of autonomy as intended in the 1982 legislation, leading to tensions and disputes within and amongst its member ports. Interestingly, this outcome was previously noted in Dosman's (1978) prediction that such a quasi-autonomous structure would lead to low employee morale and a toxic employee culture. The SCOT report also agreed with Ports Canada's acknowledgement during its testimony to SCOT that its governance framework was "arguably the most archaic, complex and confusing system of regulation of any federal Crown corporation (House of Commons, 1995, p. 5).

The preference of local port corporations, harbour commissions and public harbours to maintain the status quo continued to impact the overall ports organizational culture during the 1990s. The SCOT report discovered that despite legislative and administrative differences amongst the three port structures, there was unanimous agreement on three key reform proposals (House of Commons, 1995). First, all ports agreed to maintain the Ports Canada operational objectives of efficiency and local autonomy while making valuable contributions to Canada's international trade objectives. Second, ports agreed to maintain or enhance accountability provisions to the Minister of 
Transport. Last, ports supported reforms that would increase local port autonomy and operational efficiencies.

Despite many operational differences amongst the major ports, the unanimous agreement of these reform objectives provides evidence of Schneider's (1987) claim that coordinated organizational behaviour, and not macro factors, is a potential determinant of organizational culture. When port behaviour is viewed in its aggregate form, it is clear that all major ports advocated for continued government dependence in some areas with increased local autonomy over operational issues. The SCOT report echoed Ircha's abovementioned claim of the ports sector's long-standing preference for government protection, claiming (House of Commons, 1995, p. 6):

One of the major reasons for this is the marketing advantage of the Canadian flag on their business cards. In many countries being a federal agency provides enhanced stature and prestige when promoting the port. Another marked advantage of the Crown status is lower interest rates on any debt as the federal government is the guarantor.

A further contributor to the successful implementation of port reforms in this era was strong bureaucratic and political leadership. As part of bureaucratic transition planning for the 1993 election, Transport Canada Deputy Minister Jocelyne Bourgon instructed her senior managers to conduct a review of all major federal transportation initiatives. The Policy Group review was led by the Assistant Deputy Minister, Moya Greene, who described the process as follows (2014):

[W] looked at the state of each one of those sectors...how many ports we had, what need did we have in the future, how much infrastructure should we have, what was the capital demands that were likely to arise, how might those demands be satisfied by just the revenues that each one of the segments would be able to generate, what sort of a regulatory approach would have to be put in place to allow each sector to operate in a more commercial way, what sort of amendments 
to various pieces of transportation legislation would be required to support a more commercial approach to the operation of each segment, and then finally, what were the various ways that outside capital might be attracted to each segment.

It is also worth noting that ports policy issues were not a major political factor during this period and there was little to no public demand for change originating from the ports sector. In light of this, senior bureaucratic managers acted in the transformational character outlined by Denis, Langley and Rouleau (2007), in that they demonstrated a concrete vision of a future ports organization, including the specifics of regulatory, legislative and financial issues.

Strong leadership qualities continued amongst the senior bureaucratic cadre following the implementation of major commercialization reforms between 1994 and 1996. From the time that Minister Young delivered his Thunder Bay speech to his introduction of the National Marine Policy in the House of Commons, Transport Canada had implemented eight major regulatory, legislative and commercialization reforms (Transport Canada, 1995c). ${ }^{52}$ Keeping port reforms on the agenda within the department and the minister's office required a forward-looking strategy to ensure milestones were met and reforms continued to occur. In other words, skilled leadership in policy making requires an ability to not only balance current files, but also ensure the department's mandate is fulfilled.

\footnotetext{
${ }^{52}$ The eight major reforms were domestic airline liberalization, the National Airports Policy, the commercialization of NAV Canada, the development of the International Air Transportation Policy, the "Open Skies Agreement" with the United States, the commercialization of CN Rail, the introduction of the Canada Transportation Act, and the reduction of subsidies under the Western Grain Transportation Act and the Atlantic Region Freight Assistance Program.
} 
Skilled political leadership was also a major requirement for success during this era. As demonstrated in the analysis of the privatization of $\mathrm{CN}$ Rail and the divestiture of major airports, Minister Young was instrumental in garnering support for reforms within cabinet and amongst major stakeholders. It must also be remembered that many of Canada's major ports, such as local ports corporations and harbour commissions, were quasi-independent Crown agencies and did not follow the traditional bureaucratic hierarchy. Given the political nature of ports, Minister Young was well aware of the risks involved in reforming these historic and locally controlled institutions. He nevertheless revealed his transformative leadership nature and pursued the necessary reforms. In his view (Young, 2014):

We had to be careful with the ports....Much of what we did, between this and Employment Insurance, cost 21 seats in the 1997 election because it was hard pills to swallow. We took Transport Canada, not including CN, from over 20,000 to 7,000 in two years. And hardly anybody [within the implicated sectors] was upset, because the transition was done carefully.

From a strategic management perspective, the decision to implement port reforms followed similar reasoning and circumstances as the governance reforms of CN Rail and federal airports. The major difference, however, in the ports model was the unique and unintended final structure for Canada Port Authorities. Mintzberg and Jorgensen (1987) classified emergent strategies as policy outcomes that were not deliberately planned within an organization but nonetheless occurred. As mentioned above, the initial plan for port governance reforms was to follow the recently implemented and well received model for Canadian Airport Authorities. In the words of the department's ministerial liaison and senior bureaucrat, Gerard McDonald (2014): 
I think it was a matter of timing and readiness. The airport model was there....[and Minister Young] very much drove the idea of the National Airports Policy. It was seen as a great success when it was released, and....[t]he logical next step was, 'why don't we do it for the ports as well?' And that was the genesis of what happened.

For reasons that will be further analysed below in the macro subsection, political influences in the form of lobbying by major port authorities convinced the new Minister of Transport, David Anderson, to adopt a governance model that involved a closer relationship between ports and the federal government when compared to the airports model. As Deputy Minister Mulder described (2014):

We had problems with the Canada Ports Corporation, which was still then in existence. They weren't prepared to make as many changes as we thought it should. And then different ports had different priorities, which took a while to get it together. And then we had a change in ministers, because Doug Young left in the Fall/Summer of '96. And then David Anderson came in.

In this situation, the emergent strategy occurred from within the federal ports family and not from the core Transport Canada bureaucracy. Perhaps the most interesting aspect of this outcome is that port sector's decision to lobby in support of a close relationship to the Crown was of a reactionary, protectionist nature, as opposed to an entrepreneurial response as predicted by Mintzberg and Jorgensen. Moreover, Ircha (1997a, p. 129) surveyed the opinions of many senior port managers toward commercialization during this period and discovered "a case of [them] wanting to be competitive in an integrated continental system of ports but not willing to take on the difficult tasks of ensuring the development of a profitable, efficient and competitive port." In this case, it appears as though the government's planned governance reforms were interpreted by many ports as a threat to the status quo and became an unintended rallying cry to coordinate a unified 
response and ensure an outcome more amenable to their long standing organizational culture.

\subsubsection{Macro Analysis}

The 1970s: Failed Attempts at Port Reform

Despite rising government deficits, public finance considerations were not a substantial factor of influence behind port reforms in the 1970s. However, a major environmental factor during this period was the advent of containerization along with the development of increasingly large cargo ships and new global shipping patterns (Lang, 1976; Transport Canada, 1977b). With the advent of the global seaborne trade, many Canadian ports began demanding greater influence in making local port related decisions. Transport Canada was therefore faced with a choice of accommodating local port interests or witnessing the loss of significant Canadian export business to nearby (and highly competitive) American ports (Dosman, 1978).

This decade also featured several attempts by the government to reclaim what it perceived as a diminishing federal role in ports administration. As previously mentioned, Transport Canada was responsible for a myriad of port structures, including harbour commissions, NHB ports, local ports and public harbours, as well as government wharves. Dosman (1978) noted that the department experienced difficulty in managing financial accountability measures across the many governance structures and maintaining effective communication strategies with all Transport Canada ports. The desire for greater local port autonomy and provincial demands for increasing influence over port decisions also motivated the government in favour of reform. By the late 1970s, Dosman 
had commented, "the Ministry's ability to influence, let alone control, the development of the fragmented ports system is strained" $(1978$, p. 9). The need for greater port uniformity therefore served as the official reason behind the government's desire to retain federal ports under one centralized organizational framework.

It is also noteworthy to next consider the ideological underpinnings of port reforms during this period. Some of the main objectives of Bill C-6, the Canada Ports Act, included (Dosman, p. 5):

[T] hat the objective of the national ports policy for Canada is to achieve a port system that (a) is an effective instrument of support for the achievement of Canadian international trade objectives; (b) is efficient; ... [and] (d) provides local port commissions with a high degree of autonomy to manage and operate the ports, consistent with...the efficiency of the national ports system and the optimum deployment of resources.

At first glance, such a legislative commitment to international trade, efficiency and local autonomy appears to follow the fundamental tenets of neoliberalism. A useful tool to examine the neoliberal influence of this period is to employ Clarke's (2008) method to determine the degree of neoliberal dominance in influencing the environmental context surrounding reforms. In particular, Clarke's theory states that an organizational culture's neoliberal principles must be present in order to confirm the ideology's influence. However, as discussed above, the organizational culture of the ports administration group was one of a low morale, short-staffed workforce with little subject matter knowledge. Such a workforce hardly appears capable of adhering to the neoliberal principles of bureaucratic autonomy, efficient service delivery, and bottom-line financial accounting.

Indeed, further research has demonstrated that these neoliberal-themed portrelated reform proposals existed in Canada for 45 years before the introduction of Bill C- 
6. The 1975 Scott Committee Report noted that the Sir Alexander Gibb Report of 1932 "concerned itself with the questions of efficiency of existing port facilities, additional facilities required for future growth and finally, the best method for administration" (Canada, 1975, p. 1). The Gibb Report principles were written at a time before the introduction of Keynesianism, not to mention the neoliberalism that spread through Western industrialized nations in the early 1980s. In addition, the need for port reforms was even mentioned in the final report of the abovementioned Glassco Commission in 1964, which noted that the federal government possessed "a somewhat chaotic pattern" of port governance in Canada (quoted in Gratwick and Elliott, 1992, p. 240a).

A major contributor to the introduction of the new ports legislation, as well as its eventual demise, was the role of politics in ports policy development. As explained earlier by Stone (1988), policy decisions periodically feature paradoxes not readily explained by traditional rationalist theory. An excellent example of such a paradox was the department's decision to promote increased local autonomy in ports governance while also perusing greater centralization of ports management within national headquarters. Invoking Stone's model of policy making, the most relevant characteristics of this policy community are exerting influence and controlling information. In other words, the desire for centralization was rooted in both bureaucratic and cabinet politics of this period.

The most dramatic example of political influence during this period occurred following the recommendations of a committee of port authority chairmen in December 1973. Their report "recommended the retention of a national ports system, but...along the lines of Canadian National... which would permit subsidiary corporations and would decisively shift operating responsibilities to the port level and away from a headquarters 
overburdened with detail" (Dosman, 1978, p. 13). This proposal was swiftly rejected by the federal Cabinet in early 1974, only to be replaced by a centralized in-house bureaucratic framework for the February Throne Speech. In Dosman's view, “a crown corporation model of any kind was politically impossible to recommend with any hope of assurance" (Ibid).

The bureaucratic desire to control the flow of information through a centralized public service hierarchy resulted in negative consequences for ports administration. First, Dosman claimed that the absence of a "buffer" between the ports administration and political superiors implies that decisions will be made based on political and not economic motives, leading to an inefficient and unequitable national ports system. This outcome would therefore imply that special interest groups that lobby the minister or senior bureaucrats would obtain special treatment that would jeopardize Canadian port competitiveness in global markets. Hence, in Dosman's view, “[o]nly a [sic] central ports agency with statutory independence, though subject to Ministerial direction, can prevent the total politicization of ports policy, where the political needs of the day will be serviced" (p. 23).

\section{The Early 1980s: Incremental Progress}

As observed in analysis of the late 1970s reforms, the government's fiscal situation and surrounding economic environment were not the prime determinants of port planning and development during the early 1980s. In fact, the lone mention of fiscal responsibility was in the concluding section of the 1981 White Paper, which stated that local port autonomy under the new Act "will also allow each port to evolve in a manner 
that best suits its own developmental needs without at the outset having to be independent of government financial contributions" (Transport Canada, 1981, p. 12). The absence of such a fiscal policy context during this era is notable given the rising inflation and national debt and deficit issues mentioned in Chapter Two. However, given the repeated delays in implementing port reforms over the previous decade, it is likely that deficit issues ranked behind the government's desire to successfully pass port governance legislation, regardless of the strength of reforms or financial relief to federal coffers.

The government also continued its attempt to redefine and assert the federal role in national ports policy in the early 1980s. Although the White Paper and subsequent legislation omitted previous plans to consolidate all transportation related ports under the Transport Canada bureaucracy, there still remained a deliberate effort to exert federal influence over national port policies. For example, the newly renamed local port corporations were granted the ability to appoint up to seven members of a board of directors and one chairperson. On the surface such a framework appears to grant greater autonomy to ports that would encourage local decision making and representation.

The major caveat of reforms, however, was that many port policy and planning decisions were subject to approval by the national board of directors at Ports Canada's Ottawa headquarters. The White Paper even took a paternalistic approach to describing the governance format by frequently referring to the national body as the "parent Board" in order to reiterate its dominance in the administrative hierarchy. Ken Krauter, a former CEO of two local port corporations during this period, described the outcome from the local ports' perspective as follows (2014): 
While the establishment of local port corporations in the early 1980s was a very important step, I would say that within the ports, many of us felt that it didn't really go far enough and that there were still many constraints within that legislation....The CPC Act greatly improved what the situation had been under the NHB, and we appreciated the changes, but we felt that it didn't go far enough in bringing reforms.

Furthermore, despite the opportunity for local interests to be represented on port boards of directors, the federal government retained most of the financial and senior port appointment powers. Brooks concluded that " $[\mathrm{t}]$ he control ... was in line with the vision of the government of the day and not with that of the port's managers or its LPC board" (2007a, p. 241).

There is also little evidence to link any substantial neoliberal influence upon the passing of the Canada Ports Corporation Act. On the surface, the objectives of the Act were very similar to those of the failed Canada Ports Act, namely effectiveness, efficiency, and a contribution to Canada's international trade objectives. A closer examination, however, using Clarke's (2008) test of neoliberalism reveals no significant neoliberal themed organizational principles during this period. As explained above, the organizational culture continued to suffer from low employee morale and an absence of motivation to encourage emergent strategies of a neoliberal nature. Furthermore, the new legislation provided no reform options (neoliberal or otherwise) for non-Ports Canada entities, such as federal Harbour Commissions, Transport Canada ports, and privately run ports (Ircha, 1996). Contrary to neoliberal principles, bureaucratic red tape also resulted in substantial time lags in financial approvals among Ports Canada ports, placing these facilities at a competitive disadvantage compared to their American rivals (Ircha, 1999). Given these issues, Ircha argued, "the lack of any action in developing a national ports policy makes a mockery of this portion of the [1982] legislation" (1996, p. 2). Brooks 
added, "the model did not make significant progress along the devolution continuum" (2007a, p. 241).

Although the 1982 ports legislation implemented fewer governance reforms than its failed predecessor, it nonetheless featured significant political influence. Applying Stone's (1988) theory of political behaviour, the key political goals of this period were the desire to exert control and influence over all aspects of port reforms. First, the boards of directors of local port corporations and the "parent Board" were appointed by Cabinet on the recommendation of the Minister of Transport. ${ }^{53}$ Second, the Minister of Transport was solely responsible for the appointment of external policy advisors to serve on the policy council to the national board. Perhaps the most glaring paradox from this legislation was the federal government's assertion that "the federal presence at the local and regional levels will be enhanced by coordinating national policy directions, while encouraging local initiatives" (Transport Canada, 1981, p. 12). The degree of freedom of individual port corporations to act according to local demands and pressures is questionable in light of the federal government's decision to appoint all board members and regional policy advisors. It is doubtful that many ports in fact received decentralization decision making authority but were instead faced with de facto federal control operating under the guise of local autonomy.

1984-1993: Staying the Course

\footnotetext{
${ }^{53}$ This form of ministerial appointment was subsequently carried over to the Canada Marine Act for CPA boards with the modification that designated local user groups provide lists of potential nominees to the Minister of Transport for consideration. However, the Act is absent on a requirement to compel the Minister to use the submitted lists for board appointments.
} 
Despite the federal government's inaction on port reform during this era, the macro ports environment continued to evolve with the advent of international trade and globalization. Following the previously mentioned growth of containerization, Christopher (1993) stated that the ports industry had now matured and was shifting in response to growing international trade flows. In addition, he noted that increased public and private investments in American ports had significantly increased competition for Canadian ports. Gratwick and Elliott (1992) further emphasized that the implementation of the Canada-U.S. Free Trade Agreement in 1989, followed by the newly established European Community internal trade zone, greatly increased trade and shipping flows among North American ports. Gillen and Cooper (1995, p. 18) therefore concluded, "[f]or all practical purposes, North America is now one transportation market."

These resulting macro environmental changes further highlighted the missed opportunity for political and bureaucratic port leaders to reform the efficiency of ports to take advantage of new market opportunities. Ken Krauter, for example, lamented the lack of public and political interest in ports policy during this period (2014):

I've always felt that ports are a forgotten mode of transport. The majority of Canadians have never seen a deep sea ship, never been to a sea port, and there's a minimal understanding of the importance and significance of ports, and the industry and what it means to the Canadian economy.

As a result of these shifting market conditions, the culture of Canada's major shippers also changed. Interestingly, however, Gratwick and Elliott (1992) noted that the National Transportation Act, 1987 encouraged Canadian shippers to remain loyal to Canadian ports for maritime shipping needs, even if more efficient or less costly alternatives exist in American ports. Such a statement is ironic given the Progressive Conservative 
government's commitment to international trade, individual choice and free market principles. Gratwick and Elliott (p. 258) claimed that Canada's major shippers became "port blind" to Canadian ports and that it is unreasonable in such a competitive port setting to expect shippers to be "good corporate citizens" and remain loyal to domestic ports when pricing signals dictated otherwise. It was therefore evident that the market was evolving at a faster rate than Canadian ports and the federal government were prepared to recognize.

\section{3-2000: Creation of Canadian Port Authorities}

Following two federal budgets in which transportation commercialization had played a major role, government priorities began to shift away from primarily fiscal issues by late 1995. As Moya Greene noted (2014):

I think the drive to create more fiscal capacity for the government just wasn't as imperative at that time, as we already delivered a lot of savings in getting rid of the subsidies and making sure that we had other avenues to finance the railway and other avenues to finance the airports. By the time we got to the ports, the financial requirements were lesser than they were a year-and-half or two years before.

Such a shift became evident in government documents describing port reforms. As part of the government's official response to the SCOT's marine strategy, Ministers Young and Tobin outlined their planned approach to reform (Canada, 1995):

In the more detailed marine strategy the government's commitment to maintaining the competitiveness of the Canadian marine transportation system will be paramount. Canada, as a trading nation, cannot allow its marine sector to operate in isolation from international competitive pressures. It is essential to reduce costs and improve productivity, but it is equally important to remove economic distortions and create a competitive environment. 
Perhaps most interesting in this official response is the absence of any direct mention of the need to reduce the government's fiscal burden through port reform. In addition, it appears that neoliberal influences contributed somewhat to the government's decision to remove itself from direct operations of major ports. However, this form of the ideology exhibits Clarke's (2008) classification of neoliberalism as a form of cultural dominance in the form of globalization. As Clarke described, neoliberalism adapts itself to the local context and environment, which in this case is the need for marine (and hence port) reforms to ensure the industry remains responsive to international competitive pressures.

Although the presence of globalization related neoliberalism was an influence during this period, a lack of previous governance reforms also contributed to the government's quest to increase the competitiveness of Canada's largest ports. As previously mentioned, efficiency and the requirement for ports to contribute to Canada's international trade objectives were first cited as core port objectives in the late 1970s. Despite an increase in seaborne trade, containerization, and the expansion of nearby American ports, the government adopted a relatively lax approach to port reforms. When the political will for reform finally occurred in the mid-1990s, the government was forced to take urgent action to address the national ports system.

The next step in the macro analysis is to analyse the sequencing of reforms using the historical institutionalism framework. As Sanders (2006) noted, such an analysis requires careful consideration of the historical aspects of the institution and political players and their contribution to path dependence. As previously mentioned, the Canadian port industry prior to reform was composed of a myriad of port governance structures that included major commercial ports within Ports Canada, many local and 
regional ports operated directly by Transport Canada, various harbour commissions, as well as private ports. It is worth noting that such a close relationship between ports and the federal government had occurred since Confederation, and was also based largely on historical reliance on federal funding (Ircha, 2001). In the context of the historical institutional framework, this close financially dependent relationship between Canada's major ports and the federal government would require a significant exogenous shock to shift the system onto a new reform path.

Research has revealed that there were several relatively smaller exogenous shocks that contributed to the development of port reforms during this period. The first initiative was Minister Young's Thunder Bay Speech in 1994 that signalled the government's commitment to adopt commercialization of many federally run transportation operations, including ports. The second action that triggered reforms was Minister Young's request to the House of Commons SCOT to conduct consultations and prepare a set of formal recommendations for marine reforms in 1995. As previously mentioned, both these shocks triggered a reactionary response for local ports, which yielded a coordinated strategy to oppose airport-style reforms in favour of a closer relationship with the federal government. This coordinated strategy was noted by the SCOT in the consistent proposals submitted by LPCs at cross-country consultation sessions. Although the probability of port reform increased as time passed and the government made new port announcements, the outcomes were not as the government predicted. This finding is interesting, as it modifies Pierson's (2000a) theory of increasing returns to include the possibility of how some government actions may lead to unintended path dependent outcomes. 
The relationships of territorial political interests are also useful to examine in the context of Falleti's theory of decentralization. Of all three cases studied, the port sector was the most politically active seeking to ensure that any new governance framework would respect a desire for greater local involvement while still remaining within close proximity to federal resources. In Falleti's terms, the federal government and the ports sector both agreed to unfunded administrative decentralization, however a consensus was not initially reached as to the specifics of the framework. Following extensive negotiations, the end result was a form of administrative decentralization that included guarantees of political support via the appointment of board members and the retention of Crown corporation status. Falleti's framework was correct in predicting that national (federal) interests would be most dominant in the first round of reforms, as witnessed by Minister Young's determined and specific instructions to Transport Canada and the House of Commons SCOT to initiate reforms. An exception to her theory, however, was that the subnational (ports) sector responded to the national call for reforms in the second round with an appeal for a lighter form of decentralization than originally proposed. This outcome is a unique application of this model and decentralization in general, as most governance reforms during the 1990s featured aggressive reforms that were well received by nearly all stakeholders.

Stone's (1988) theory of political behaviour is a valuable framework from which to describe the divergent intended and realized outcomes to port reforms. The two major outcomes of port reforms to this analysis are the roles of both influence and policy communities in decision making. The major actors to exert influence during this reform period were the large number of port corporations and commissions that jointly argued 
against airport-style reforms to the SCOT, local MPs and the Minister of Transport. In effect, these ports became an ad hoc committee that successfully exerted policy pressure to achieve their desired goals. For example, during the required legislative process to create the 1995 National Marine Policy (NMP), there was political resistance to revise the national ports system from the SCOT, as well as a lack of interest in ports expressed by the new junior minister, David Anderson, assigned to the federal ports file (Brooks, Prentice and Flood, 2000). Hesitation towards reforms was also expressed by individual port managers who were opposed to a ports system with little federal presence, which would have meant significant changes to their organizational culture (Brooks, 2007a).

\subsubsection{Meso Analysis}

The myriad of port governance structures over the period studied rendered effective policy reforms inherently difficult to achieve. Between 1975 and 1995, ports were administered by local corporations that reported to a "parent" corporation, harbour commissions that reported exclusively to the Minister of Transport, and public harbours contained within the Transport Canada bureaucracy. As predicted by Downs (1967) and later Maor (1999) this governance smorgasbord presented a disincentive to senior bureaucratic managers to initiate reforms, as the likelihood of success remained low due to ardent task of negotiating with many personalities and dealing with numerous pieces of legislation.

Such a complex web of bureaucratic, political and environmental circumstances is best examined with the use of Kingdon's (1984) theory of policy windows. Perhaps the most interesting observation in applying Kingdon's framework to this analysis is the 
relatively constant problem window throughout from the mid-1970s to the mid-1990s. Specifically, every major port reform attempt cited the macro conditions of rising international competitive pressures in seaborne trade as a result of containerization and globalization as a prime rationale for governance reform. In the first round of reforms, Transport Canada and its associated task forces developed policy recommendations to amalgamate all major federal ports under one bureaucratic umbrella. With the problem and political windows now open, final step was for political acceptance. According to Don Morrison (2014):

[Transport Canada] set up a task force and we looked at all facets of port administration in Canada, from the administration, operations, layout, planning, policy and we made recommendations as to what should happen in about 197879. When we made those recommendations, the Clark government had been elected and then fell. That bump was when we thought we had the Conservatives convinced that it was good to continue the efforts that the Liberals had made. At that point, ports weren't a priority, as the Liberals were trying to get elected, which they did. Then once they were re-elected, it lost its priority status.

In this situation, port reforms failed due to the closing of the political window, as both Liberal and Conservative politicians were more focussed on re-election than port policy. Regardless of individual opinions on whether the proposed new port structure during this era was considered too bureaucratic, it marked the only time there was near-universal agreement among the many major port organizations on an approach to reform.

With the problem window still open, there was a brief period of unison between the opening of the political and policy windows in the early 1980s. The 1981 White Paper on port reform introduced changes to convert National Harbours Board ports into local port corporations but avoided reforms to harbour commissions and Transport Canada ports. As previously mentioned, the report was prepared by Transport Canada, as 
opposed to a task force, and included an opening message by the Minister that implied the department had conceded defeat on ports-wide reforms and had chosen the next-best scenario. In this period the political and policy windows had opened, but lacked a policy entrepreneur to pursue sector wide reforms and implement a more wide-ranging ports policy.

Despite the emergence of neoliberal principles and the growing opposition to Ports Canada in the Mulroney era, there were no substantial port governance reforms for the remainder of the 1980s and early 1990s. With the economic rise of Asia and the emergence of several Canadian free trade agreements, ports continued to face greater challenges attracting shippers to their sites. The Transport Canada policy cadre was aware of the many infrastructure related issues and proceeded to prepare potential solutions as part of transition planning for the 1993 general election. The political leadership, however, displayed no intention of entertaining port reform and ensured the political window remained firmly closed. Former Progressive Conservative Minister of Transport, Benoit Bouchard, commented, for example (2014):

It's a different industry, and quite frankly, I don't believe that we would have been able to sell the ports. We never considered, to my memory, such a plan....And Canadians, in my view, would be very reluctant....I don't remember ever having the same discussion about that, and if I had, I certainly would have been opposed....I believe it's very sensitive in terms of management.

It was not until the return of the Liberals to government in late 1993 that the next coupling of the problem, political, and policy windows occurred. Although globalization continued to challenge the port industry, the most significant problem window at the beginning of this period was the federal deficit and national debt. Given that the Liberals 
had just been elected, the political window opened and Minister Young set the stage for the National Marine Policy. As a result of the House of Commons SCOT report and extensive Canada-wide consultations, the Transport Canada bureaucracy proposed an airports-style reform package for ports. In this case, however, the department's bureaucrats received significant opposition from ports and their representative pressure group, the newly formed Canadian Ports and Harbours Association (CPHA), who both argued in favour of more tepid reforms. Consequently, the policy window closed somewhat, as the degree of reforms was now less comprehensive as originally intended. During this time, Minister Young was replaced by David Anderson, and the Liberals were within one year of an eventual general election call. The political window therefore closed, and the result was another second-best scenario of port reforms. It remains for the imagination to consider what would have happened had the Prime Minister retained Doug Young as Minister of Transport, given his determination to achieve transportation commercialization.

\subsection{Conclusions}

Relationship between Bureaucratic Leadership and Political Responsiveness

Contrary to the commercialization experiences of $\mathrm{CN}$ Rail and federal airports, the evolutionary transition to Canada Port Authorities included a positive, professional working relationship between the political leadership and senior Transport Canada bureaucrats. The primary political-bureaucratic issue during this period, however, was the ability of local port authorities and their national port association (the CPHA) to 
circumvent senior bureaucrats and successfully lobby political leaders for change. As Moya Greene described (2014), "ports have always been more political. From time immemorial, the ports have had a huge amount of regional politics attached to them."

The myriad of ports governance structures was a major contributor to a complicated and at times contradictory policy landscape during this era. Although Transport Canada was traditionally responsible for an assortment of public harbours and ports, these ports were much smaller and had less regional influence compared to the larger ports. As a result, departmental bureaucrats often had little influence on ministerial port decisions and were forced to negotiate with harbour commissions and Ports Canada on national ports issues. Former Deputy Minister, Louis Ranger, recalled the relationship as follows (2014):

I think there was more of an...established political influence in terms of attracting investments of ports than anywhere else. And that's probably just by the nature of ports and established tradition.....And it did create discrepancies, and some would argue that there was unequal treatments and handling of port investments, depending on success of people being able to make representations to government and explain the economic and social benefits that would flow from these investments. There was a closer link between government and ports than any other mode.

The other point is that ports were not managed directly by Transport Canada, they were managed by a Crown Corporation, so there was more distance. I would argue that there was a perceived higher degree of difficulty with ports and an anticipated amount of push-back from very dramatic changes.

Perhaps most interesting about this political relationship was that larger ports were not only able to influence political decisions impacting individual or regional ports, but the entire national level as well. Louis Ranger, for example, explained how the Port of Vancouver was able to influence the Minister of Transport (and British Columbia MP), David Anderson, to agree to amend the proposed ports legislation (2014): 
By the time Transport Canada moved to ports, there was a new minister....A very active port authority at the time was in Vancouver, with lots of ideas on what to do and not to do. The Minister of Transport, Mr. Anderson, was very committed to commercialization but was also very attentive to what the Port of Vancouver was saying, and they were very persuasive. It didn't take long until all the large ports were singing from the same song sheet and arguing very strongly that ports had to remain government assets and had to be seen as being governed by government.... Whether that's true or not is irrelevant....it did become a different model through lengthy discussions and passing of a very long legislative process. Overall, I think that the model does work, but it's different.

\section{Concluding Remarks}

This chapter has illustrated some of the major pitfalls that may arise when political and policy decisions fail to align. Despite the fact that a degree of port reform received the near-unanimous support of major ports, many stakeholders desired more extensive port reforms in the same spirit as the airport sector. The main proponent of port restructuring was the shipping industry, which argued before the SCOT in 1995 for greater efficiency and market focus, while characterizing the present system as outdated and inefficient (Ircha, 1997b). In addition to shippers, municipalities also lobbied the Committee for greater local airport-style representation within boards of directors of port corporations, claiming that ports are seldom in tune with the needs of their communities and are rarely required to pay municipal property taxes (Ircha, 1997b). Arguing that their role was to represent the view of the majority of witnesses before the Committee, Ircha (1997) noted that the SCOT recommended relatively minor changes to the port governance framework, much to the chagrin of stakeholders wanting a more businessfocussed, financially accountable system.

A healthy bureaucratic-political relationship is essential for sound policy making in any Western democracy. In its most optimal form, senior bureaucrats and politicians 
act as a healthy check and balance on major policy decisions. Stone (1988) demonstrated, for example, that irrational decisions may occur if one or both policy players routinely allow political incentives to jeopardize policy making and implementation. In the case of national ports policy, fiscal considerations and competitive pressures did not garner the same political motivations. This rendered a political compromise that fell short of policy recommendations. Whether or not the resulting governance framework was the "right" or "wrong" decision is a moral judgement beyond the role of senior bureaucrats. Rather, they are required to use judgement in achieving the best-case results from such decisions. In any organization, however, repeated ignorance of senior bureaucratic advice leads to a potentially toxic slope of low morale, poor retention, and a negative organizational reputation. As Dosman foreshadowed in 1978, such behaviour has the potential to generate lower quality policy advice and produce ineffective policy outcomes.

Although the port reforms brought commercialization practices to a previously scattered and ad hoc governance regime, many criticisms of current port governance practices remain. The 2001 Canada Transportation Act Review (CTAR) Panel identified many recommendations to improve the port governance framework for Canada Port Authorities (CPAs) that was originally outlined in the Canada Marine Act. According to Brooks, the high number of port recommendations "was confirmation that devolution was not perceived to have gone as well as it might have" (2007a, p. 250). From a financial perspective, the ability of CPAs to generate extra revenue streams has been limited, especially when compared to their American competitors (Sherman, 2002; Brooks, 2007a). For example, CPAs are not permitted to engage in external revenue initiatives 
such as establishing bridge and road tolls, and the federal government will not guarantee loans secured from private sector lenders. In addition, the continued appointment of board members by the Minister of Transport has raised accountability concerns in recent years, leaving Brooks to conclude "[t]he current system lacks transparency and is not well managed from a system performance and customer service perspective" (2007b, p. $8)$. 


\section{Chapter Six: Conclusion}

What the experience of the past illustrates...is that success is a very relative concept. The perfect decision-making system is a chimera. What every government has to undertake in its time is to seek such balance as may be possible among the complicated and diverse factors that bear upon decision-making, with due regard for the lessons of the past. ${ }^{54}$

\subsection{Theoretical Analysis}

Policy making is complex phenomenon involving the interaction of micro and macro factors operating within a dynamic meso framework. Based upon the research and analysis, there is ample evidence to conclude that Transport Canada followed House's (1991) prediction of a mechanistic organizational form, whereby power and authority was concentrated at the apex of the organization. As with any governance structure, however, the strategic decisions and authorities were not always executed in a linear or mechanistic fashion. The meso organizational framework therefore proved highly effective in this analysis by examining individual components of major commercialization decisions within the context of surrounding environmental pressures.

From a micro organizational perspective, research has revealed that emotional, behavioural and motivational processes were a major factor in influencing reforms, as theorized by House, Rousseau and Thomas-Hunt (1995). Further complicating the analysis was a variety of organizational sub-cultures that varied by modal group and governance structure, such as CN Rail and two of three port systems that operated under the management of quasi-independent, Crown Corporations. In these situations, Dwivedi

\footnotetext{
${ }^{54}$ Arthur Kroeger, quoted in Kroeger, 1996, p. 468.
} 
and Gow's (1999) hierarchy of cultures could be improved by further subdividing to account for behavioural cultures within sub-agencies like Crown Corporations. Such a revision would permit further benchmarking from which to gauge the performance and retention of employees. It would also enable frameworks such as Schneider's (1987) attention-selection-attrition framework to become more powerful in determining employee motivation within public sector organizations.

One of the most effective micro level theories in this thesis was the framework to describe the ability of senior managers to influence organizational change through strong leadership. Providing a plausible and attractive vision for the future, from which Denis, Langley and Rouleau (2007) coined the term transformational leader, proved to be a critical element in the commercialization process across all three decades and three modes. Open communication, as predicted by Magee and Frasier (2014), was most relevant in contributing to the respect earned by senior Transport Canada bureaucrats by regularly communicating with line departmental employees during the fast pace of reforms during the 1990s. Such respect was successfully leveraged as a form of status, which in turn contributed to a healthy organizational culture. With this organizational support, senior bureaucrats inferred the confidence to invoke their authority, or what the authors termed power, to convince the political ranks and central agencies of the need to ensure fair and consistent compensation for employees affected by the transition to commercialized operations.

Despite the explanatory strength of the leadership literature, a potential area of improvement is the consideration of executive motivation in promoting reforms. Comparing the 1980s and 1990s, for example, revealed varying leadership decisions in 
the face of political pressures for reforms. As a Progressive Conservative, Don Mazankowski was motivated to achieve neoliberal-type reforms for the transportation sector, but favoured deregulation in areas of political interest to his electoral base in Western Canada. The privatization experiences that occurred during his tenure as Minister of Transport did not achieve sufficient political success to encourage him engage in political risk by privatizing other Crown Corporations, such as $\mathrm{CN}$. As the new Liberal Minister of Transport, Doug Young exhibited a rare political quality of a determination to reform the transportation system for the benefit of all Canadians. Contrary to Mazankowski, Young faced political opposition to CN's privatization from his caucus and cabinet, not to mention the general public. Although political leadership was predominantly reactionary during the three decades under review, these examples demonstrated how some political decisions originated from the motivation to accept risks and defy the odds for reform.

As a result of the strong leadership qualities displayed in all three cases, strategic decision making did not always follow Mintzberg and Jorgensen's (1987) public sector framework. Emergent strategies were in fact quite rare, as most commercialization decisions were made at either senior bureaucratic or political levels, which in all cases involved top-down umbrella strategies. In addition, a potential weakness in Mintzberg and Jorgensen's theories was a failure to consider the strict hierarchical bureaucratic structure that is designed to channel authority to its apex, leaving major decisions to be made far removed the operational cadres. In addition, the authors claimed that strategies become "collective" from a willingness to learn across an organization, which in turn allows the new structure be adopted as part of an organizational culture. This statement 
is incomplete, however, as it neglects to consider the impact of organizational leadership, and not necessarily emergent strategies, as a major contributor to conditions that encourage widespread acceptance of an idea or process across an organization.

Turning next to the macro perspective, neoliberal theory provided an informative but incomplete framework from which to study the rationale for transportation commercialization. In its broadest form, Harvey's (2005) classification of the neoliberal role of the state as creating and preserving market conditions was at first blush a relevant and descriptive framework to apply to all three cases. As Clarke (2008) predicted for many applications, however, the neoliberal framework proved "promiscuous" but ineffective in determining its degree of contribution to each modal change. In addition, neoliberal themed principles were observed to varying degrees in national transportation policy as early as the abovementioned 1932 Gibb Report, long before the emergence of Thatcherism and Reaganism in the developed world. Furthermore, the lack of dedication to the theoretical principles of neoliberalism amongst Progressive Conservative and Liberal governments rendered cause and effect comparisons of major reforms difficult. A relevant example is Doug Young's efforts to secure an agreement on the privatization of CN Rail, where it was shown that his motivation originated from a primary need to address the fiscal deficit and not to satisfy demands of a neoliberal environment.

A somewhat related theory to neoliberalism was the prevalence and effectiveness of the New Public Management (NPM) in explaining the many governance reforms of the mid-1990s. NPM theory contained two related flaws that inhibited its useful application to this thesis. First, the vagueness of its theoretical foundations prevents any decisive distinction between NPM and neoliberalism when investigating the causes of 
reforms. For example, NPM describes commercialization and managerialism as some of its many components, which are also indirectly addressed by the pro-market foundations of neoliberal theory. Second, if it is assumed that neoliberalism and NPM are independent, or at the minimum, complementary theories, the literature does not convincingly determine when one theory ends and when the other begins. Many of the authors cited in Chapter Two claimed an attribution of NPM principles to the many federal commercialization reforms of the 1990s, while few if any attributed the origins to neoliberal ideas that are in turn based upon thinly supported arguments.

Contrary to neoliberal and NPM theories, historical institutionalism (HI) provided a solid foundation from which to begin an analysis of the sequencing of macro organizational reforms. The most relevant component of the HI framework is Sander's (2006) recommendation to consider the political factors through an analysis of the historical circumstances and organizational culture before and after the reforms. Given the strength of the abovementioned micro theories to describe the organizational culture and leadership aspects of the three case reforms, the predominant historical path dependent track was readily traceable to each major critical juncture. Due to the weakness of neoliberalism as a primary determinant of reforms, HI was required to determine the significant environmental factor, or what Thelen (1999) termed the exogenous shock to signal the transition to the next period.

As one of the major exogenous shocks in all three cases, the urgent need to address the burgeoning national debt and deficit served as a major turning point in the analysis. From this occurrence, however, emerged the lone flaw of $\mathrm{HI}$ within this thesis. In particular, the notion of critical junctures and exogenous shocks fail to account for 
various weights assigned to environmental shocks when compared across the three modal cases during the three decades of analysis. For example, fiscal concerns were a major component behind the Liberal government's decision to strike an airports task force in 1979, however full reforms were not implemented until the creation of the first Local Airport Authorities in 1987. Various other factors of a political and organizational nature contributed to the delay and subsequent amendments to airport divestiture framework, which are all not readily considered by HI principles. A potential solution to this situation would be an extension of Falleti and Lynch's (2009) framework of sequential layering of policy changes in order to incorporate the dynamic impact of policy shocks.

Similar to neoliberalism, Falleti's $(2005,2010)$ theory of sequential decentralization did not achieve its fully anticipated benefits in this thesis. Initially, Mintzberg (1977) promoted the use of decentralization in public organizations as a method of encouraging more emergent policy strategies and hence more innovative public services. Similar to the practical fate of emergent micro strategies, however, Falleti's hypothesized approach to decentralization was not fully applicable to the macro organizational context of this thesis. In particular, her framework displayed an overreliance on the power relationships between two entities, which in her cases involved the behavioural interactions between national and subnational (state, municipal, etc.) levels of government.

One of the major requirements of Falleti's decentralization model was the determination of territorial interests within each sequence of reform. Falleti assumed that territorial interests would conflict as part of the negotiation for greater political, fiscal and administrative powers between the national and subnational governments. In this thesis, 
however, there was a significant lack of conflict over jurisdictional issues across the three modes. The privatization of $\mathrm{CN}$ Rail was negotiated within the confines of the federal government as a Crown Corporation, while the majority of large federal ports sought a smaller transfer of powers than the federal government had initially proposed. Such behaviours were essentially illogical to Falleti's model and therefore resulted in significantly different results than her model predicted.

Stone's (1988) theory of political behaviours was instrumental in the discovery of political-bureaucratic relationships and their resulting impact on policy outcomes. The strength of the theory was its ability to address both micro and macro aspects in the context of the policy community. For example, characteristics such as loyalty and coercion were helpful in describing the leadership qualities of senior bureaucrats and their ability to positively influence line departmental employees in favour of reforms. Macro factors such as cooperation in the pursuit of political influence were also relevant to describe the coordinating effects of coalitions, such as major port authorities, who were able to yield persuasive political influence in convincing the Minister of Transport to approve a revised port governance with greater federal dependence than federal airport authorities.

Combining the simultaneous impact of micro and macro factors in this thesis required a comprehensive meso organizational structure. Kingdon's (1984) theory of policy windows approached commercialization reforms in terms of problem, political and policy streams and considered the actions of individual policy entrepreneurs in promoting policy ideas. One of the core strengths of Kingdon's approach was its dynamic nature that considered policies in multiple combinations that frequently changed over time in 
reaction to new socio-economic realities. This characteristic permitted the deconstruction of major policies into layers with each major policy window. Another strength of Kingdon's model is its portability over multiple time periods and across all three modal cases, which permitted effective comparisons and contributed to sound conclusions.

A potential area of improvement for Kingdon's model would be a widening of the assumptions surrounding the characteristics of a policy entrepreneur. Although Kingdon predicted that policy entrepreneurs may originate from outside the public service, he did not assume that they may occur within the political ranks. The analysis has demonstrated in this thesis that Doug Young was not only successful in convincing many political allies of the need for commercialization, but was also a key player in the development of policy direction at Transport Canada, which was most famously demonstrated in his “Thunder Bay Speech" of 1994. Due to Kingdon's omission of this potentially useful extension to this theory, micro characteristics of leadership and status were applied to explain Doug Young's policy efforts during the mid-1990s.

\subsection{Reassessing the Policy Hypotheses}

The next stage of the cumulative analysis is to consider the policy outcomes in the context of the original thesis hypothesis, which is repeated below:

That the commercialization of federal airport and port assets between 1975 and 2000 occurred primarily due to: (i) federal government concerns over the growing size of the national debt and deficit; and (ii) the emergence of the neoliberal ideology in Canada and its growing influence throughout federal policy making, as witnessed by the swift 1995 privatization of CN Railways. 


\section{The Growing Debt and Deficit}

The federal government's desire for debt and deficit reduction was a common theme among all three modal cases and across all three decades. From a public relations perspective, governments of both Liberal and Progressive Conservative stripes strove to portray deficit control as evidence of a sound economic and fiscal management record. The political rationale offered for resolving the crisis, however, differed significantly across each political era. During the Trudeau era of the 1970s, the official rationale for

deficit reduction was to ensure the federal government focussed on what it determined to be the core Canadian values of health and social policy. A more likely rationale for debt and deficit politics was the government's attempt to address public accountability issues originating from the Auditor General's 1975 statements that federal spending was out of control. The federal public service had also significantly expanded during the era, and the government most likely determined that one of the expedient solutions to curb a growing bureaucracy is to create smaller, sub-bureaucracies at arm's-length from the government. Three key examples of such a strategy were the government's approval of proposed new port and airport frameworks, as well as CN's choice to divest all non-core railway aspects from its corporate governance structure.

Following the Liberal government's shift to curbing inflation between 1980 and 1984, the newly elected Progressive Conservative government returned debt and deficit politics to the forefront of fiscal policy. The government's first budget featured measures to lower government spending and withdraw from provision of many public services, such as the operation of Canada's major airports. Citing the need to control the debt and deficit also provided the government with politically acceptable avenues that would 
generate revenues for urgently needed capital renovations and expansions. At this point, however, debt and deficit politics remained a relatively new phenomenon in policy circles and had yet to feature prominently in policy discussions. This most likely contributes to an explanation of why the Minister of Transport's Office issued a directive to the bureaucracy through the release of the eight fundamental principles of airport management in 1987.

By the early 1990s the first airport authorities were established and well received by politicians, major stakeholders, and the general public. Moving forward, many senior Transport Canada bureaucrats, such as Jocelyne Bourgon and Moya Greene, determined that deficit reduction had become an integral component of policy considerations. Furthermore, the ageing condition of the department's many assets convinced senior managers that future policies urgently needed to consider non-federal sources of revenue in a similar vein as local airport authorities. Deficit reduction henceforth emerged as a major consideration in policy documents where federal funding could be required. At Transport Canada, senior management began planning for the eventual divestiture of major transportation assets when the political will returned following the upcoming general election.

The return of the federal Liberals to power in late 1993 soon signalled a reemergence of debt and deficit politics in major policy discussions. Rising interest rates on federal debt, a declining value of the Canadian dollar, and warnings from major credit agencies and the International Monetary Fund forced the federal government to adopt strict expenditure reductions as part of its second budget in 1995. The day before the budget was delivered, Doug Young made public statements echoing the Liberal 
government of the late 1970s, claiming that significant cuts were necessary to preserve core social programs such as Medicare. With much policy planning already complete, Transport Canada was ready to embrace the new political reality and immediately begin reforms that eventually led to the privatization of $\mathrm{CN}$ and the creation of Canadian Airport Authorities.

The impact of debt and deficit politics upon policy making was also revealed in during the commercialization process of major port authorities between 1995 and 1997. During this period, however, the improving state of federal finances acted as a disincentive for reforms. For the first time in the era of debt and deficit politics, the federal government achieved smaller public deficits and publicly declared itself a sound fiscal manager. This in turn encouraged the Liberal government to scale back expenditure cuts and prepare for the potential of an early election call in 1996. From a policy perspective, deficit politics is its own worst enemy; when deficits are large, political leaders take notice and agree to implement recommended bureaucratic expenditure reforms; whereas when deficits shrink, politicians avoid contentious issues and usually prefer less ambitious (and contentious) options. Despite the recommended airport-style reforms for ports, the newly appointed Minister of Transport, David Anderson, chose the more politically palatable option of port reforms within a closer relationship to the federal government. 


\section{The Emergence of Neoliberalism}

Contrary to the national debt and deficit, neoliberalism did not exert as substantial an impact upon commercialization reforms as originally hypothesized. First, for reasons described above, the neoliberal ideology is an oft-cited but paltry framework from which to analyse complex governance reforms such as transportation commercialization. Second, neoliberalism was never accepted by Liberal or Progressive Conservative governments as what Larner (2000) described as a sociological aspect of reforms similar to Thatcherism in the United Kingdom. For example, upon embarking on its quest to reduce the national debt and deficit, the Progressive Conservative government attempted to frame its initial rationale for budget cuts as a neoliberal-influenced, pro-market approach to public administration. In other words, the government championed the belief that the public sector should recede from the provision of many services in favour of more efficient private sector alternatives.

Despite initial overtures in favour of neoliberalism in Canada, political considerations trumped a dedication to neoliberal during this period during the Mulroney era. For example, as an MP from Western Canada, the Minister of Transport, Don Mazankowski was politically focussed on statutory and regulatory reforms to the transportation sector that favoured his predominantly agricultural based constituents, such as farmers and shippers. As a result, commercialization reforms focussed on deregulation and the elimination of many subsidies perceived as a hindrance to a competitive transportation system. Governance reforms, such as the privatization of Air Canada in 1988 received lukewarm reviews at the time and was most likely a prime reason for Minister Mazankowski's twice refusal of CN President, Ronald Lawless' request to 
privatize CN. Such behaviour is clearly not of the pure neoliberal flavour observed in the United Kingdom and the United States during this period.

By the time of the Liberal government's return to power in 1993, the neoliberal ideology had somewhat transitioned into the dogma of the New Public Management. As illustrated above, however, NPM theories suffered from similar criticisms of a lack of theoretical rigour as its neoliberal relative. In addition, heated discussions and policy disputes occurred between $\mathrm{CN}$ privatization proponents such as Doug Young, and opponents such as David Collenette during cabinet meetings illustrated the lack of universal acceptance of core neoliberal principles amongst the Liberal caucus and cabinet during this period. Moreover, the strongest policy and political rationale for reforms in 1994 and 1995 was the urgent need to address the escalating federal deficit. Regardless of his personal view toward the neoliberal ideal, Doug Young framed arguments in favour of commercialization reforms as an approach to develop a competitive and safe transportation sector through divestitures that would obtain fair market value for previous taxpayer investments in transportation assets such as CN Rail and major federally operated airports.

In sum, politics was always part of policy making during the period studied, but the converse was not necessarily true. Debt and deficit politics influenced policy decisions for nearly twenty years before terms such as balanced budgets and fiscal surpluses became part of everyday policy discussions. However, debt and deficit issues needed time to spread their influence and emerge as part of the bureaucratic lexicon before it became widely adopted as standard policy considerations. Given its high costs of service 
provision, transportation became an excellent target for reform when examined through this debt and deficit lens.

\section{Role of the CN Policy Miracle}

In light of neoliberalism's subdued influence on commercialization reforms, it is next appropriate to reassess the classification of CN Rail reforms as a "policy miracle." The intent of establishing the "policy miracle" benchmark was to provide a context within which the bridging propositions of the meso analysis could be analysed as per the structure outlined by House, Rousseau and Thomas-Hunt (1995). In particular, one of the goals of this analysis was to examine the meso sub-hypothesis that large and mature organizations foster an environment where macro forces will trump micro variables over time.

As discussed in Chapter Three, the research revealed that the swift privatization of $\mathrm{CN}$ occurred due to several policy factors, notably: strong executive leadership at $\mathrm{CN}$; strong political support from the Ministers of Transport and Finance; a warm reception to reforms from senior transportation bureaucrats; a politically opportune time for reform; as well as a lack of public opposition to privatization. Noticeably absent from these factors is mention of an influential link to neoliberal beliefs. For reasons previously discussed, neoliberalism (as well as its derivative, the New Public Management) was present during the $\mathrm{CN}$ privatization era but failed to exert a significant influence over major political and bureaucratic decisions.

\footnotetext{
${ }^{55}$ The term "policy miracle" was also used during the author's interview with Mr. Torrance Wiley, former Vice President of Government Relations at $\mathrm{CN}$, to describe the swiftness of the privatization reforms. The author has been using the term in this context throughout previous thesis draft since June 2011.
} 
The $\mathrm{CN}$ privatization benchmark also provided a useful lens through which to test the hypothesis against airport and port commercialization. A similar approach was implemented for the analysis of airport and port reforms, which included considerations of the interactions of the major micro and macro forces behind each outcome. Significant organizational reforms occurred for major airports and ports, however not to the extent or pace of changes observed with the privatization of $\mathrm{CN}$. In the case of airports and ports, various political and bureaucratic hesitations resulted in delayed decision making and implementation strategies, which ultimately prevented reforms to the extent demonstrated at $\mathrm{CN}$.

In light of these findings, the original hypothesis may now be revised to reflect the analysis as follows:

That the commercialization of federal airport and port assets between 1975 and 2000 occurred primarily due to: (i) federal government concerns over the growing size of the national debt and deficit; and (ii) the strong leadership and determination of senior political and bureaucratic managers at Transport Canada, as witnessed by the swift 1995 privatization of CN Railways.

The case of $\mathrm{CN}$ privatization provided a rare but comprehensive example of the complex alignment of meso factors that are required to achieve significant policy reforms. As mentioned previously, Kingdon's theory of policy windows described the impact of debt and deficit politics and strong leadership in the transition of an organization that was on the verge of requesting a third recapitalization from a government that could not afford it to a fully private enterprise in less than two fiscal years. Senior officials within all three organizational branches of CN, Transport Canada, and the Minister of Transport's Office successfully created the necessary conditions for 
reform in a relatively short period of time. The cases of airport and port reforms displayed short periods of coordination to achieve governance reforms but at a much slower, more incremental pace than reforms at CN. The term "policy miracle" is therefore an appropriate description to describe this unique and fascinating case of transportation policy reform.

\subsection{Lessons from Primary Data Collection}

An attempt at analysing historical policy decisions requires an ability to decipher many empirical puzzles in order to examine complex cause and effect relationships. In response to such a challenge, this thesis made significant use of primary sources of evidence in the form of government documents and personal interviews with 24 major policy actors over the period studied. Government documents included Royal Commissions, task force reports, departmental strategy documents, transcripts of proceedings from House of Commons and Senate Committee hearings, budget documents, ministerial correspondence, and declassified internal departmental memos. These documents contained a wealth of technical information and greatly assisted setting the context for the analysis of the three major modal commercializations. The author obtained the majority of official government documentation from the (now-defunct) Transport Canada Library and the Government Information Centre of the Carleton University Library. The majority of ministerial correspondence and internal Transport Canada documentation was obtained from the Archive of Administrative Records of the Government of Canada, located at Library and Archives Canada in Ottawa. 
Despite their assistance in providing technical and sometimes political rationales for policy reforms, government documents seldom provide "the full picture" behind major reforms. As a result, first hand interviews were used extensively throughout this thesis to assist in analysing the three modal cases. First hand interviews are usually one of the most reliable forms of primary sources, as they contain direct and usually candid recollections of major policy events from key players. They provide additional context rarely obtained from other primary sources, such as the influence of personalities, political motivations (e.g., from cabinet discussions), as well as the identification and description of key stakeholder actions operating behind the scenes (e.g., Kingdon's policy entrepreneurs).

Several interesting observations occurred when comparing the results from the first-hand interviews. First, there was strong positive reaction to the author's request to interview key stakeholders. All stakeholders, with the exception of three individuals who declined to participate in the interview process responded, representing a response rate of nearly 90 percent. Second, and likely related to the first observation, most interviewees described themselves as having a major and influential role in the commercialization reforms. When viewed in retrospect, many interviewees implied that their contributions to reforms were part of the legacy of commercialization and a major career highlight. Third, nearly all respondents provided the expected background context through which a more extensive and prudent analysis of commercialization occurred.

Several potential risks were also taken into close consideration when analysing the first hand interview results. First, as with any historical analysis, some respondents had difficulty recalling specific dates of reform timelines and line relationships among 
former colleagues. This risk was addressed through examining other primary data sources, such as government documents and internal departmental memos to confirm historical details and relationships. Second, although all interviews greatly assisted in the analysis, care was taken to verify the authenticity of claims from all individuals. An empirical risk existed in the analysis whereby an individual may have incorrectly portrayed an event or individual's role in an event, despite an assured confidence that such views were accurate. Government documents and ministerial correspondence again played a major role in verifying facts and ensuring subsequent analysis was based on sound evidence.

\subsection{Areas for Future Research}

The Dynamics of Public Policy Decision Making

A major potential field for future research uncovered during this thesis was the relationship between political leadership and bureaucratic responsiveness. As mentioned in Chapter Two, federal policy making in Canada has witnessed an increasingly public struggle between ministers and bureaucrats for control over policy making. Beginning with the Glassco and Lambert Commissions, political masters have resorted to developing policies and procedures that restrict the scope and authority of bureaucratic activity. These actions have led academics such as Dwivedi, et al. $(2009$, p. 8$)$ to consider:

[t]he burning question in public administration is whether officials have too much power; whether too much or too little leeway is given to experts; whether it is possible for the public to be well-served and at the same time to control its public servants. 
It necessarily follows that there remain many potential avenues of research to further investigate a federal policy environment surrounded by political-bureaucratic tensions. For example, Rose and Cray (2010) conducted an initial analysis of the possible policy consequences that occur when the priorities of the public service do not align with those of the political leadership and are met with mistrust. They postulated that bureaucrats must therefore invest time to consider the political priorities of special interest groups close to the government in order to compensate for an increasingly distant professional relationship with political masters.

Hayes (2007) initiated research into another avenue of this complex relationship when he hypothesized that bureaucrats are less likely to implement the most technically sound policies due to increasing political pressure to proceed with politically favourable choices. Furthermore, he noted that increasing tensions have emerged across the public services, as limited financial resources has increased the competitive nature of fund seeking for departmental policies. In addition, Aucoin (1986) noted that the responsibilities of ministers and senior bureaucrats have become increasingly blurred since the Trudeau era due to changes in the executive governance structures by incoming prime ministers, which have the potential to complicate and even sour the politicalbureaucratic relationship.

With respect to transportation policy and governance, Ranger (2014) noted the increasing bureaucratic struggle to resist political interference during his tenure as Deputy Minister. In particular, he explained how the political-bureaucratic relationship changed when the Conservatives assumed power in early 2006 : 
Ministers would come with their own perspective and tell us that they want to make changes. They don't necessarily want to make speeches across the country defending what the Liberals did...For a long period, we had three minority governments, and we had much more local pressure to change things. You then have so called unintended consequences of commercialization.... and then you have the 2008-09 economic crisis with the government wanting to spend considerable amounts of money on infrastructure. Where else could you put it but ports, airports, rail, and this would fly in the face of every principle that we fought for in the mid-' 90 s.

The challenge is to reinvent the model to emphasize the benefits of commercialization when the transport sector is the most productive sector in government, in terms of where it was to where it is now. It's a hard sell for a minister who has to deal with the issues of the day. Slowly, I think there's been an erosion of the model.

\section{Transportation Commercialization}

Given the myriad of governance reforms and policy outcomes over the period studied, there remain other significant research opportunities to further study federal transportation commercialization. ${ }^{56}$ One possible avenue of research is the consideration of a coordinated national governance strategy for all major transportation modes. Such an approach would permit a centralization of expertise within Transport Canada and could potentially assist in reducing decision making externalities arising from independently administering individual port and airport sites. On the other hand, a

\footnotetext{
${ }^{56}$ The author received suggestions to also consider Transport Canada's commercialization of air navigation services and the formation of Nav Canada in 1995/96 as part of this dissertation. Despite its unique governance structure as a not-for-profit, non-share capital private corporation formally owned by employees, unions, pilots and the airlines, the author decided not to include this commercialization approach for two key reasons. First, the time and scope constraints of any research project, most especially this doctoral dissertation, restricted the reasonable number of case analyses to three. Second, the commercialization of air navigation services did not experience a similar policy path to the other three commercialization cases, as air navigation was an indirect service that dealt mainly with airports and airlines. Furthermore, this issue received little public attention before the Doug Young era of commercialization reforms of the mid-1990s, rendering a fulsome policy analysis of the modal outcomes difficult due to a lack of empirical data over the entire period studied. For further information on the major differences between airport and air navigation reforms, see ICAO (2013).
} 
coordinated model may not sufficiently address the unique challenges and opportunities facing regional and local ports and airports across Canada. That said, research may discover potential policy options that find a medium between two strategic poles, such as a revised airport or port authority concept that amalgamates authorities upwards into regional or local blocs to encourage economies of scale but still remain attuned to local issues.

Another potential area of governance research is to examine the divestiture experience of medium-sized ports and airports. The analysis in Chapters Four and Five focussed on the commercialization of Canada's largest ports and airports and may have examined elements that were not easily transferrable to other sites. For example, Peacock and MacKinnon (2013) explained that airports in Fredericton, Saint John and Moncton were classified as participating sites under the National Airport System and were subject to divestiture negotiations in the late 1990s. In some situations, such as Transport Canada's negotiations with the Greater Fredericton Airport Authority (GFAA), the department's approach to a template lease and negotiation process was ill suited to the airport's capital requirements and financial resources. The airport authority was forced to secure capital upgrades from other sources, such as the provincial government, as it was unnecessarily and perhaps blindly treated as a large national airport by Transport Canada negotiators.

An additional area for research is to examine present day airport and port governance issues in the context of the original commercialization reforms. For example, many former Transport Canada senior managers involved in past airport reforms expressed frustration and disappointment over calls by some airport authorities and other 
stakeholders for the complete privatization of airports. In addition, other airport experts, such as Dr. David Gillen (2014), have long criticized the current airport governance model, arguing that it prevents the efficient provision of airport services, especially with respect to the government's charging of airport rents. Examining current issues using historical policy rationales would provide an interesting and thorough examination of the current state of airport and port governance in Canada.

\subsection{Concluding Remarks}

Context is a necessary component of public policy development. This thesis has demonstrated that a thorough analysis of the policy environment is required before formulating policy recommendations and proceeding to implementation. An excellent example from this thesis was the surprisingly minor contribution of neoliberalism and the New Public Management to transportation commercialization reforms. Although federal political and bureaucratic actors were aware of the tenets of neoliberalism and its experiences in the United Kingdom and United States during the 1980s and 1990s, the reality of huge fiscal deficits emerged as the single most important macro variable. From a micro viewpoint, strong bureaucratic leadership must also be supported by an independent thinking and motivated minister with the determination to advance reforms at the caucus and cabinet levels. Putting these factors together, the meso implication emphasizes that timing remains one of the most crucial requirements for policy reform success. In sum, advanced planning, strong leadership and an ability to act swiftly when circumstances require are thus the most important lessons for public policy to be taken from this thesis. 
Despite the past desire of federal governments to achieve substantial savings from an across-the-board review of spending, it does not necessarily follow that history will repeat itself and further transportation divestitures will occur. For example, contrary to the federal financial situation of the mid-1990s, Canada's current credit rating stands at the highest designation of triple- $\mathrm{A}$, and the country has been held as a financial example for other developed countries to follow (Torobin, 2011). In addition, doubt has been expressed as to the willingness of the general public to tolerate significant program cuts, which is in sharp contrast to the public perception in 1995 that urgent fiscal reforms were needed (Harper, 2011). Consequently, at this point it remains to be seen whether a similar alignment of micro, macro and meso institutional factors will occur, and whether public scrutiny around debt and deficit politics will be enough of an exogenous shock to force policy direction on an alternate path of further devolution, such as corporatisation of national port governance frameworks and outright privatization of Canadian Airport Authorities (CAAs). 


\section{Bibliography}

Abma, D. (2012). “CN has travelled a long way: CEO.” The Windsor Star, Friday, February 17. Retrieved May 24, 2012 from: http://www2.canada.com/windsorstar/news/business/story.html?id=06c4000a542e-432c-8b6a-e3d0504bc939

Aeroports de Montreal. (2011). "Airport Governance in Canada.” Retrieved May 24, 2012 from: $\underline{\text { http://www.admtl.com/Passengers/Home.aspx }}$

Aucoin, P. (1986). "Organizational Change in the Machinery of Canadian Government: From Rational Management to Brokerage Politics.” Canadian Journal of Political Science, 19(1), 3-27.

Aucoin, P. (1988). “Contraction, Managerialism and Decentralization in Canadian Government.” Governance: An International Journal of Policy Administration, $1(2), 144-161$.

Aucoin, P. (1995). The New Public Management: Canada in Comparative Perspective. Montreal: Institute for Research on Public Policy (IRPP).

Auditor General of Canada. (1976). Conspectus of the Report of the Auditor General of Canada to the House of Commons. Ottawa: Office of the Auditor General of Canada.

Bakvis, H. (1998). “Transport Canada and Program Review.” In P. Aucoin and D. Savoie (eds.) (1998), Managing strategic change: Learning from Program Review. Ottawa: Canadian Centre for Management Development. 
Berg, B.L. (2009). Qualitative research methods for the social sciences: seventh edition.

Boston: Allyn \& Bacon.

Bouchard, B. (2014). In-person interview with author, June 24, 2014. Ottawa, Ontario.

Brooks, M.R. (2007a). "Port Devolution and Governance in Canada." In M.R. Brooks and K. Cullinane (eds.) Devolution, Port Governance and Port Performance. Research in Transportation Economics Volume 17. Oxford: Elsevier Ltd.

Brooks, M.R. (2007b). “Gateways and Canada's Ports Policy: Issues and Impediments.” Retrieved May 24, 2012 from: http://www.gatewaycorridor.com/vancouverconference/documents/presentations/Brooks $\% 20$ Session \%20IV.pdf

Brooks, M.R., \& Prentice, B. (2000). Airport Devolution: The Canadian Experience. Centre for International Trade and Transportation, Dalhousie University. Retrieved October 23, 2010 from: http://citt.management.dal.ca/Files/pdf's/DP183.pdf

Brooks, M.R., Prentice, B., \& Flood, T. (2000). Governance and Commercialization: Delivering the Vision. Canadian Transportation Research Forum Annual Conference.

Bruce, H. (1997). The Pig that Flew: The Battle to Privatize Canadian National. Toronto: Douglas \& McIntyre.

Budden, S., \& Ernst, J. (1973). The Movable Airport: The Politics of Government Planning. Toronto: A.M. Hakkert Ltd. 
Canada. (1962). The Royal Commission on Government Organization. Ottawa: Queen's Printer.

Canada. (1973). Report of the Airport Inquiry Commission. Ottawa: Queen's Printer.

Canada. (1975). Summary of the Scott Committee Report on Canadian Port Organization. Ottawa, Queen's Printer.

Canada. (1979). The Royal Commission on Financial Management and Accountability: Final Report. Ottawa: Queen's Printer.

Canada. (1985a). Managing Government More Effectively. Ottawa: Queen's Printer.

Canada. (1985b). Controlling the National Debt. Ottawa: Queen's Printer.

Canada. (1990). White Paper - Public Service 2000 The Renewal of the Public Service of Canada. Ottawa: Minister of Supply and Services Canada.

Canada. (1992). Public Service 2000 : First Annual Report to the Prime Minister on the Public Service of Canada. Ottawa: Minister of Supply and Services Canada.

Canada. (1995). "Response by the Minister of Transport and the Minister of Fisheries and Oceans to the Standing Committee on Transport report entitled, 'A National Marine Strategy". Ottawa; Retrieved from Library and Archives Canada on June 9, 2014.

CanLII, (2015). “The Constitution Act, 1867.” Retrieved September 29, 2015 from: http://www.canlii.org/en/ca/laws/stat/30---31-vict-c-3/latest/30---31-vict-c3.html?autocompleteStr=constitution\&autocompletePos=2 
Charih, M., \& Rouillard, L. (1997). “The New Public Management.” In M. Charih and A. Daniels (eds.) New Public Management and Public Administration in Canada. Toronto: Institute of Public Administration of Canada.

Cheung, A.B.L. (1997). "Understanding Public Sector Reforms: Global Trends and Diverse Agendas.” International Review of Administrative Sciences, 63, 435-457.

Christopher, J. (1993). "Ports in Canada: Future Competitiveness." Background Paper - Library of Parliament Research Branch. Ottawa: Library of Parliament.

Clarke, J. (2008). "Living With/In and Without Neo-Liberalism.” Focaal-European Journal of Anthropology, 51, 135-147.

Cloutier, J. (2014). In-person interview with author, June 4, 2014. Ottawa, Ontario

Collenette, D. (2014). In-person interview with author, July 18, 2014. Ottawa, Ontario.

Collyer, F.M. (2003). "Theorising Privatisation: Policy, Network Analysis, and Class." Electronic Journal of Sociology.

Crosbie, J.C. (2007). "Governing from the Centre: Reflections on the Mulroney Cabinet.” In R.B. Blake (ed.) Transforming the Nation: Canada and Brian Mulroney. Montreal \& Kingston: McGill-Queen's University Press.

Denis, J.L., Langley, A., \& Rouleau, L. (2007). "Rethinking Leadership in Public Organizations.” In E. Ferlie, L.E. Lynn Jr., \& C. Pollitt (eds.) The Oxford Handbook of Public Management. New York: Oxford University Press Inc.

Doern, G.B. (1987). "Politics of Trivial Pursuit.” Policy Options. 8(2), 3-6. 
Dosman, E.J. (1978). “Canadian Ports Policy: The Canada Ports Act (Bill C-6) Background and Prospects." Canadian Transport Commission Research Seminar Series. Ottawa: Supply and Service Canada.

Downs, A. (1967). Inside Bureaucracy. Boston: Little, Brown.

Dion, J.P. (2002). Airports in Transition. Ottawa: Library of Parliament.

Dwivedi, O.P., Mau, T.A., \& Sheldrick, B. (2009). “Canadian Public Administration in Transition: An Introduction.” In O.P. Dwivedi, T.A. Mau, \& B. Sheldrick (eds.) The Evolving Physiology of Government: Canadian Public Administration in Transition. Ottawa: University of Ottawa Press.

Dwivedi, O.P. \& Gow, J.I. (1999). From Bureaucracy to Public Management: The Administrative Culture of the Government of Canada. Peterborough: Broadview Press.

Eisenschitz, A. and Gough, J. (1998). "Theorizing the State in Local Economic Governance.” Regional Studies, 32(8), 759-768.

Falleti, T.G. (2005). “A Sequential Theory of Decentralization: Latin American Cases in Comparative Perspective.” American Political Science Review, 99(3), 327-346.

Falleti, T.G., \& Lynch, J.F. (2009). “Context and Causal Mechanisms in Political Analysis.” Comparative Political Studies, 42, 1143-1166.

Falleti, T.G. (2010). Decentralization and Subnational Politics in Latin America. Cambride: Cambridge University Press. 
Farquhar, M. (1989a). Airport Transfers - The Canadian Approach. Speech to the American Transportation Research Board, Washington, D.C., January 23, 1989.

Farquhar, M. (1989b). Airport Transfers in Canada - A Progress Report. Speech to the Airport Operations Council International, Houston, Texas, October 3, 1989.

Farquhar, M. (2014). In-person interview with author, June 4, 2014. Ottawa, Ontario.

Feldman, E.J., \& Milch, J. (1983). The Politics of Canadian Airport Development: Lessons for Federalism. Durham: Duke Press Policy Studies.

Finance Canada (1985). Securing Economic Renewal: Budget Papers - Tabled in the House of Commons by the Honourable Michael H. Wilson Minister of Finance May 23, 1985. Ottawa: Queen's Printer.

Finance Canada (1994a). The Budget Speech: February 22, 1994. Ottawa: Queen's Printer.

Finance Canada (1994b). The Budget Plan: February 1994. Ottawa: Queen's Printer.

Finance Canada. (2009). Archived: Fiscal Reference Tables - October 2009. Retrieved December 6, 2014 from: http://www.fin.gc.ca/frt-trf/2009/frt09_e.pdf

George, A.L., \& Bennett, A. (2005). Case Studies and Theory Development in the Social Sciences. Cambridge: MIT Press.

Gillen, D. (2014). Telephone interview with author, September 16, 2014. 
Gillen, D. \& Cooper, D. (1995). "Public Versus Private Ownership and Operation of Airports and Seaports in Canada.” In F. Palda (ed.) Essays in Canadian Surface Transportation. Vancouver: The Fraser Institute.

Government Parliamentary Task Force. (1994). Working Together: Possibilities for the Commercialization of Canadian National Railways. Ottawa: House of Commons.

Goss, R. (1983). "Policies for Canadian Seaports.” Cardiff and Ottawa-Hull: University of Wales Institute of Science and Technology.

Gow, I. (2009). "Evolution of Disciplinary Approaches and Paradigms in the Study of Public Administration in Canada.” In O.P. Dwivedi, T.A. Mau, \& B. Sheldrick (eds.) The Evolving Physiology of Government: Canadian Public Administration in Transition. Ottawa: University of Ottawa Press.

Gratwick, J. (2001). "The Evolution of Canadian Transportation Policy: A paper prepared for the Canada Transportation Act Review Panel." Canada Transportation Act Review Panel. Ottawa: Queen's Printer.

Gratwick, J. \& Elliott, W. (1992). “Canadian Ports: Evolving Policy and Practice.” In D. VanderZwaag (ed.) Canadian Ocean Law and Policy. Toronto and Vancouver: Butterworths.

Greene, M. (2014). In-person interview with author, August 11, 2014. Via telephone.

Greenspon, E. \& Wilson-Smith, A. (1997). Double Vision: The Inside Story of the Liberals in Power. Toronto: Doubleday Canada Ltd. 
Harper, T. (2011, June 6). "The axe will fall, but where will it land?" The Toronto Star. Retrieved June 6, 2011 from: http://www.thestar.com/news/canada/politics/article/1003653--tim-harper-the$\underline{\text { axe-will-fall-but-where-will-it-land }}$

Harvey, D. (2005). A Brief History of Neoliberalism. Oxford: Oxford University Press.

Hayes, M. (2007). "Policy Making Through Disjointed Incrementalism.” In G. Morcol (ed.) Handbook of Decision Making. Boca Raton: Taylor \& Francis Group.

Heaver, T.D., \& Waters, W.G. (2005). “Transportation Policy in Canada.” In K.J. Button and D.A. Hensher (eds.) Handbook of Transport Strategy, Policy and Institutions. Oxford: Elsevier Ltd.

Hill, L.B. (1991). "Who Governs the Administrative State? A Bureaucratic-Centred Image of Governance." Journal of Public Administration Research and Theory, 1(3), 261-294.

Historica Canada. (2015). “Crow's Nest Pass Agreement.” Retrieved December 14, 2015 from: http://www.thecanadianencyclopedia.ca/en/article/crows-nest-passagreement/

Hodgetts, J.E.H. (1972). The Canadian Public Service: A Physiology of Government, 1867-1970. Toronto: University of Toronto Press.

House, R.J. (1991). "The Distribution and Exercise of Power in Complex Organizations: A Meso Theory.” Leadership Quarterly, 2(1), 23-58. 
House, R., Rousseau, D.M., \& Thomas-Hunt, M. (1995). “The Meso Paradigm: A Framework for the Integration of Micro and Macro Organizational Behavior.” Research in Organizational Behavior, 17, 71-114.

House of Commons. (1991). Minutes of Proceedings, House of Commons Legislative Committee. Bill C-85, Second Session, $34^{\text {th }}$ Parliament, 1989-91.

House of Commons. (1995). "A National Marine Strategy.” Report of the Standing Committee on Transport. First Session, $35^{\text {th }}$ Parliament, 1994-95.

Huber, E., \& Stephens, J.D. (2001). Development and crisis of the welfare state: Parties and policies in global markets. Chicago: University of Chicago Press.

ICAO. (2013). “Case Study on Commercialization, Privatization and Economic Oversight of Airports and Air Navigation Services Providers: Canada.” Retrieved December 14, 2015 from: http://www.icao.int/sustainability/CaseStudies/Canada.pdf

Intervistas Consulting Inc. (2003). “An Economic and Regulatory Framework for Rail Competitiveness.” Retrieved May 24, 2012 from: http://www.transportation.alberta.ca/Content/docType60/Production/RailEconReg Framework.pdf

Ircha, M.C. (1993). "Institutional Structure of Canadian Ports." Maritime Policy and Management, 20(1), 51-66.

Ircha, M.C. (1995). “U.S. Ports: Evolution and Structure.” Maritime Policy and Management, 22(4), 281-294. 
Ircha, M.C. (1996). Restructuring Canadian Ports: Prospects and Problems. Canadian Transportation Research Forum Annual Conference.

Ircha, M.C. (1997a). "Reforming Canadian Ports." Maritime Policy and Management, 24(2), 123-144.

Ircha, M.C. (1997b). Canadian Port Reform: Commercialisation to Corporatisation (Doctoral Dissertation, University of Wales).

Ircha, M.C. (1999). "Port reform: international perspectives and the Canadian model." Canadian Public Administration, 42(1), 108-132.

Ircha, M.C. (2001). "North American port reform: the Canadian and American experience.” International Journal of Maritime Economics, 3, 198-220.

Ircha, M.C. (2002). "Public Policy for Ports: To Be or Not To Be Corporatised or Privatized?" Retrieved October 1, 2010 from: http://www.unb.ca/transpo/documents/PublicPolicytobeornottobecorporatised..02. pdf

Ircha, M.C. (2008). "Opportunities and Challenges facing Canadian Ports", Proceedings, 43rd Canadian Transportation Research Forum, Fredericton. 612-626

Janigan, M. (1995). “Martin’s Big Plan.” Maclean's, 108 (5), 46.

Keil, R. (2009). “The Urban Politics of Roll-With-It Neoliberalization.” City, 13(2-3), 231-245. 
Kernaghan, K., and Siegel, D. (1995). Public Administration in Canada: A Text. Toronto: Nelson Canada.

Kingdon, J.W. (1984). Agendas, Alternatives, and Public Policies. Boston: Little, Brown.

Krauter, K. (2014). In-person interview with the author, June 27, 2014. Ottawa, Ontario.

Kroeger, A. (1980). "Hard Going: Transportation Development in Lean Times.” Policy Options. 1(2), 13-16.

Kroeger, A. (1992). “On Being a Deputy Minister.” Policy Options. 13(4), 3-6.

Kroeger, A. (1996). "A Retrospective on Policy Development in Ottawa." Canadian Public Administration, 39(4), 457-468.

Kreoger, A. (2009). Retiring the Crow Rate: A Narrative of Political Management. Edmonton: University of Alberta Press.

Larner, W. (2000). "Neo-Liberalism: Policy, Ideology, Governmentality.” Studies in Political Economy, 63, 5-25.

Labelle, H. (2014). Telephone interview with the author. July 9, 2014.

Lacombe, H. (1976). “1976 a Year of Change for Ports.” Transport Canada Jan. - Feb. 1976. Ottawa: Queen's Printer. 
Lang, O. (1976). "A New Ports Policy for Canada: Speech to the Canadian Port and Harbour Association, Charlottetown, P.E.I., September 13, 1976.” Transport Canada: Sept. - Oct. 1976. Ottawa: Queen's Printer.

Lawless, R.E. (2014). In-person interview with the author, May 27, 2014. Beaconsfield, Quebec.

Lemâitre, N. (1987). "La culture d'entreprise: facteur de performance.” In J-F Chanlat \& F. Séguin (eds.) L'analyse des organisations - Tome II: Les composantes de l'organisations. Boucherville: Gaëtan Morin.

Lewis, D. (2014). Telephone interview with the author, July 4, 2014.

Library and Archives Canada (2010). "The Canadian State - Transport (Archived).” Retrieved September 29, 2015 from: https://www.collectionscanada.gc.ca/canadian-state/023012-1608-e.html

Lindquist, E. (2009). "Public Administration Research and Organization Theory: Recovering Alternative Perspectives on Public Service Institutions.” In O.P. Dwivedi, T.A. Mau, \& B. Sheldrick (eds.) The Evolving Physiology of Government: Canadian Public Administration in Transition. Ottawa: University of Ottawa Press.

Linquist, E. \& Paquet, G. (2000). “Government Restructuring and the Federal Public Service: The Search for a New Cosmology.” In E. Lindquist (ed.) Government Restructuring and Career Public Service in Canada. Toronto: The Institute of Public Administration of Canada. 
MacDonald, F. (1980). “The Minister and the Mandarins.” Policy Options. 1(3), 29-31.

MacKay, D. (1992). The People's Railway: A History of Canadian National. Vancouver/Toronto: Douglas \& McIntyre.

Madar, D. (2002). "Rail Mergers, Trade, and Federal Regulation in the United States and Canada." Publius: The Journal of Federalism, 32, 143-159.

Magee, J.C., and Frasier, C.W. (2014). "Status and Power: The Principal Inputs to Influence for Public Managers.” Public Administration Review. 74(3), 307-317.

Manley, J. (2005). "How Canada Slayed the Deficit Dragon and Created the Surplus." Policy Options. October. Retrieved June 2, 2011 from: http://irpp.org/po/archive/oct05/manley.pdf

Maor, M. (1999). “The Paradox of Managerialism.” Public Administration Review. $59(1), 5-18$.

McCalla, R.J. (1982). “Canadian Port Administration: Its Future Structure.” Maritime Policy \& Management. 9(4). 279-293.

McCoomb, L. (2014). In-person interview with author, June 4, 2014. Ottawa, Ontario.

McCurdy, H.E. (1992). “NASA's Organizational Culture.” Public Administration Review. 52(2), 189-192.

McDonald, G. (2014). In-person interview with author, September 2, 2014. Via telephone. 
McLean, D. (2014). A Road Taken: My Journey from a CN Station House to the CN Boardroom. Vancouver: Greystone Books.

Mintzberg, H. (1977). "Strategy formulation as a historical process”, International Studies of Management and Organization, Summer, 28-40.

Mintzberg, H., \& Jorgensen, J. (1987). "Emergent strategy for public policy”, Canadian Public Administration, 30 (2), 214-229.

Mintzberg, H., \& McHugh, A. (1985). "Strategy formation in an adhocracy", Administrative Science Quarterly, 30, 160-197.

Moran, M. (2008). "Economic Institutions." In R.A.W. Rhodes, S.A. Binder, and B.A. Rockman (eds.) The Oxford Handbook of Political Institutions. New York: Oxford University Press Inc.

Mulder, N. (2014). In-person interview with author, May 8, 2014. Ottawa, Ontario.

Nault, R. (2014). Telephone interview with author, July 3, 2014.

O’Connor, L.J. (1991). "Chief of Staff.” Policy Options. 12(3), 23-26.

O’Connor \& Ip. (2012). “Richmond council concerned about airport mega-mall's impact on traffic, neighbours." The Province, July 18. Retrieved July 18, 2012 from: http://www.richmondnews.com $/$ Richmond + council + concerned + about + airport + mega + mall + impact + traf fic+neighbours/6958825/story.html 
OED Online. (2015). “devolution, n.” Oxford University Press. Retrieved September 29, 2015 from:

http://www.oed.com.proxy.library.carleton.ca/view/Entry/51549? redirectedFrom= devolution\#eid

OED Online. (2015). “privatization, n.” Oxford University Press. Retrieved September 29, 2015 from: http://www.oed.com/view/Entry/151617?redirectedFrom=privatization\#eid

O’Neal, Brian. (1994). Reorganizing Government: New Approaches to Public Service Reform. Ottawa: Library of Parliament.

Orum, A. M., Feagin, J.R., \& Sjoberg, G. (1991). The Nature of the Case Study. In J.R. Feagin, A.M. Orum, and G. Sjoberg, (eds.), A Case for the Case Study (pp.1-26). Chapel Hill: The University of North Carolina Press.

Padova, A. (2005). Federal Commercialization in Canada. Ottawa: Library of Parliament.

Padova, A. (2007). Airport Governance Reform in Canada and Abroad. Ottawa: Library of Parliament.

Pal, L.A. (1998). “New Public Management' in Canada: New Whine in Old Battles?" In J. Bickerton and A.G. Gagnon (eds.) Canadian Politics: $4^{\text {th }}$ Edition. Toronto: University of Toronto Press. 
Peacock, K. \& MacKinnon, R. (2013). "Federal Land Transfers in New Brunswick.” In M.C. Ircha and R. Young (eds.) Federal Property Policy in Canadian Municipalities. Montreal \& Kingston: McGill-Queen's University Press.

Peck, J. \& Tickell, A. (2002). "Neoliberalizing Space.” Antipode, 34(3), 380-404.

Pierson, P. (2000a). "Increasing Returns, Path Dependence, and the Study of Politics." American Political Science Review, 94(2), 251-267.

Pierson, P. (2000b). "Not just what, but when: Timing and sequence in political processes." Studies in American Political Development. 14, 72-92.

Pigeon, J. (2014). In-person interview with author, August 19, 2014. Ottawa, Ontario.

Ranger, L. (2014). Telephone interview with author, August 13, 2014.

Roberston, G. (1983). “The Deputies’ Anonymous Duty.” Policy Options. 4(4), 1113.

Rodal, A., \& Mulder, N. (1993). "Partnerships, Devolution and Power-Sharing: Issues and Implications for Management," The Journal of Public Sector Management, 24(3), 27-48.

Roper, M.E. (1992). Railroad Regulation After Staggers. Washington, D.C.: Association of Transportation Practitioners.

Rose, W.R., \& Cray, D. (2010). "Public-sector strategy formulation", Canadian Public Administration, 53 (4), 453-466. 
Rueschemeyer, D. (2003). “Can One or a Few Cases Yield Theoretical Gains?” In J. Mahoney and D. Rueschemeyer (eds.) Comparative Historical Analysis in the Social Sciences. Cambridge: Cambridge University Press.

Sanders, E. (2006). "Historical Institutionalism.” In R.A.W. Rhodes, S.A. Binder and B.A. Rockman (eds.) The Oxford Handbook of Political Institutions. Oxford: Oxford University Press.

Savoie, D.J. (1990). The Politics of Public Spending in Canada. Toronto: University of Toronto Press.

Savoie, D.J. (1995). "What is wrong with the new public management?" Canadian Public Administration. 38(1), 112-121.

Savoie, D.J. (2003). Breaking The Bargain: Public Servants, Ministers, And Parliament. Toronto: University of Toronto Press.

Scheider, B. (1987). “The People Make the Place.” Personnel Psychology. 40, 437453.

Senate of Canada (1991a). Proceedings of the Standing Senate Committee on Transport and Communications. Wednesday, October 23, 1991. Ottawa.

Senate of Canada. (2012). The Future of Canadian Air Travel: Toll Booth or Spark Plug? Report on the Future Growth and Global Competitiveness of Canada's Airports. Ottawa: Queen's Printer.

Sharp, M. (1981). "The Role of the Mandarins." Policy Options. 2(2), 43-44. 
Sherman, R. (2002). "Seaport Governance in the United States and Canada." American Association of Port Authorities. Retrieved May 24, 2012 from: http://www.aapaports.org/pdf/governance_uscan.PDF

Simard, F. (2004). "Self-interest in public administration: Niskanen and the budgetmaximizing bureaucrat." Canadian Public Administration, 47(3), 406-411.

Stewart, W. (1979). Paper Juggernaut: Big Government Gone Mad. Toronto: McClelland and Stewart.

Strain, J.F. (2007). “Debts Paid and Debts Owed: The Legacy of Mulroney's Economic Policies." In R.B. Blake (ed.) Transforming the Nation: Canada and Brian Mulroney. Montreal \& Kingston: McGill-Queen's University Press.

Streeck, W., \& Thelen, K. (2005). Beyond continuity, institutional change in advanced political economies. Oxford: Oxford University Press.

Thelen, K. (1999). "Historical Institutionalism in Comparative Politics." American Review of Political Science, 2, 369-404.

Thompson, L.S. (2003). "Changing railway structure and ownership: is anything working?" Transport Reviews, 23(3), 311-355.

Torobin, J. (2011, July 28). Moody's renews Canada's triple-A credit rating. The Globe and Mail. Retrieved July 28, 2011, from: http://www.theglobeandmail.com/report-on-business/economy/moodys-renewscanadas-triple-a-rating/article2112783/

Transport Canada (1977a). Annual Report 1976/1977. Ottawa: Queen’s Printer. 
Transport Canada. (1977b). A New Ports Policy for Canada. Ottawa: Supply and Services Canada.

Transport Canada (1979a). Annual Report 1978/1979. Ottawa: Queen's Printer.

Transport Canada (1979b). Transport Canada: Its Roles and Objectives. Ottawa: Queen's Printer.

Transport Canada (1979c). Task Force on Airport Management: Volume I Progress Report. Ottawa: Queen's Printer.

Transport Canada (1979d). Task Force on Airport Management: Volume II Progress Report (Appendices). Ottawa: Queen’s Printer.

Transport Canada. (1981). Canadian Ports Policy. Ottawa: Queen's Printer.

Transport Canada. (1985). Freedom to Move: A Framework for Transportation Reform. Ottawa: Queen's Printer.

Transport Canada. (1986). The Future of Canadian Airport Management: Results of the Airports Task Force. Ottawa: Queen's Printer.

Transport Canada. (1994a). Public Accountability Principles for Canadian Airport Authorities. Ottawa: Airports Group.

Transport Canada. (1994b). "National Air Policy - Cabinet Committee Meeting." Memorandum to Minister, May 6, 1994 [declassified]. Retrieved from Library and Archives Canada on June 9, 2014. 
Transport Canada. (1995a). Transport Canada's New Direction and the 1995 Budget:

Towards and Integrated and Affordable National Transportation System. Ottawa: Queen's Printer.

Transport Canada. (1995b). "Transport Minister Announces National Marine Policy." Press Release, December 15, 1995. Retrieved from Library and Archives Canada on June 5, 2014.

Transport Canada. (1995c). "The National Marine Policy: Notes for an Address by Transport Minister Douglas Young to the House of Commons.” December 14, 1995. Retrieved from Library and Archives Canada on June 5, 2014.

Transport Canada. (1997). Supplementary Principles for the Creation and Operation of Local Airport Authorities, May 1989. Retrieved from Library and Archives Canada on June 4, 2014.

Transport Canada. (2010a). “About Transport Canada.” Retrieved October 1, 2010 from: $\underline{\text { http://www.tc.gc.ca/eng/aboutus-menu.htm }}$

Transport Canada (2010b). "National Airports Policy: The National Airports System." Retrieved October 1, 2010 from: http://www.tc.gc.ca/eng/programs/airportspolicy-nas-1129.htm

Transport Canada (2010c). “Marine Policy.” Retrieved October 1, 2010 from: http://www.tc.gc.ca/eng/policy/acf-menu.htm 
Tretheway, M.W. (2006). Airport Policy in Canada: Limitations of the Not-for-Profit Governance Model. Draft Paper: Faculty of Commerce and Business Administration, University of British Columbia.

Truitt, L.J., \& Esler, M. (1996). “Airport Privatization: Full Divestiture and Its Alternatives," Policy Studies Journal, 24(1), 100-110.

Valo, S. (2001) "The continuing evolution in Canadian airports privatization." Annals of Air and Space Law, 26, 225-236.

Veldhuis, N., Clemens, J. \& Palacios, M. (2011). Budget Blueprint: How Lessons from Canada's 1995 Federal Budget Can Be Applied Today. Retrieved March 5, 2011, from: http://www.fraserinstitute.org/uploadedFiles/fraser-ca/Content/researchnews/research/publications/BudgetBlueprint.pdf

Ventura, P. (1995). “The Comprehensive Transport Plan.” In Insight Press (ed.) Commercializing Government Operations: Canadian Examples and Experiences. Toronto: Insight Information Inc.

Wiley, T. (2014). In-person interview with author, September 27, 2014. Ottawa, Ontario.

Young, D. (1994). "The Budget, Government Orders, March 10, 1994, 3:45 pm.” OpenParliament.ca. Retrieved June 14, 2014 from: http://openparliament.ca/debates/1994/3/10/douglas-young-1/

Young, D. (2014). In-person interview with author, June 14, 2014. Ottawa, Ontario. 